\title{
Psychoactive prescription drug use disorders, misuse and abuse

\author{
Pharmacoepidemiological aspects
}

Micaela Tjäderborn

Division of Drug Research

Institution of Medical and Health Sciences

Linköping University

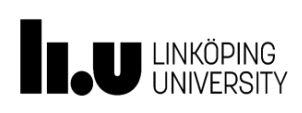

Linköping, Sweden 2016 
Psychoactive prescription drug use disorders, misuse and abuse

(C) Micaela Tjäderborn 2016

Micaela.tjaderborn@liu.se

ISBN: 978-91-7685-770-0

ISSN: 0345-0082

Printed in Linköping, Sweden 2016

Liu-Tryck AB 
All the passionate work I put into this thesis is dedicated to my parents, who always emphasized the importance of knowledge and of caring for the less fortunate. 


\title{
Psychoactive prescription drug use disorders, misuse and abuse
}

\section{Pharmacoepidemiological aspects}

\author{
Micaela Tjäderborn \\ Division of Drug Research \\ Institution of Medical and Health Sciences \\ Linköping University, Linköping, Sweden
}

\begin{abstract}
Background: There is a widespread and increasing use of psychoactive prescription drugs, such as opioid analgesics, anxiolytics, hypnotics and anti-epileptics, but their use is associated with a risk of drug use disorder, misuse and abuse. Today, these are globally recognised and emerging public health concerns.
\end{abstract}

Aim: The aim of this thesis is to estimate the occurrence and prevalence of psychoactive prescription drug use disorders, misuse and abuse, and to investigate the association with some potential risk factors.

Methods: A study using register data from forensic cause of death investigations analysed and described cases of fatal unintentional intoxications with tramadol (Study I). Based on register data on spontaneously reported adverse drug reactions (ADRs) reported cases of tramadol dependence were scrutinized and summarised (Study II). In a study in suspected drug-impaired drivers with a toxicology analysis confirming intake of tramadol, diazepam, flunitrazepam, zolpidem and zopiclone, the prevalence of non-prescribed use was assessed and associated factors were investigated (Study III). From a national cohort of patients initiating prescribed treatment with pregabalin, identified using data on prescription fills, a study investigated longitudinal utilisation patterns during five years with regards to use above the maximum approved daily dose (MAD) of the drug, and factors associated with the utilisation patterns (Study IV).

Results: In the first study, 17 cases of unintentional intoxications were identified, in which tramadol was judged to have caused or contributed to the death. Of the deceased, more were men, the median age was 44 years and the majority used multiple psychoactive substances (prescription drugs, alcohol and/or illicit drugs). In the second study, 104 spontaneously 
reported cases of possible or probable tramadol dependence were identified, of which more concerned women. The median age in these cases was 45 years and in about a third of cases the person had a history of substance abuse and in $40 \%$ of cases there was documented history of psychoactive medication use. Severe addiction was reported. In the third study, more than half of the individuals suspected of drug-impaired driving used the drug without a recent prescription. Non prescribed use was most frequent in users of benzodiazepines and of tramadol compared to users of zolpidem or zopiclone, and was more likely in younger individuals and in multiplesubstance users and less likely in individuals with a recent prescription for another psychoactive medication. In the last paper, five longitudinal utilisation patterns were found in pregabalin users, with two patterns associated with a particularly high risk of use of doses above the maximum approved daily dose. The highest risk of use of daily doses above the MAD over time was associated with male sex, younger age, non-urban residency, and a recent prescribed treatment with an antiepileptic or opioid analgesic drug.

Conclusions: This thesis shows that psychoactive prescription drug use disorders, misuse and abuse occur across groups in the population and may have serious and even fatal consequences. The prevalence varies between different drugs and groups in the population. Abuse and misuse seem to be more common in young people. Fatal intoxications and misuse of prescribed drugs may be more common in men, while drug use disorders following prescribed treatment may be more common in women and non-prescribed use equally distributed between women and men. Individuals with a history of mental illness, past use of other psychoactive medications, or substance use disorder or abuse, are likely important risk groups. The findings suggest a potential for improvements in the utilisation of psychoactive prescription drugs. The results may be useful in the planning of clinical and regulatory preventive interventions to promote the rational, individualised and safe use of such drugs.

Key words: Psychoactive prescription drugs, psychotropic drugs, prescription drug use disorders, prescription drug misuse, abuse, pharmacovigilance, drug utilization, pharmacoepidemiology

ISBN: 978-91-7685-770-0

ISSN: 0345-0082

Linköping University Medical Dissertations No: 1521 


\section{SVENSK SAMMANFATTNING}

I dag finns en utbredd användning av läkemedel med verkan på centrala nervsystemet och som kan orsaka beroende och har potential för missbruk och felaktig användning. Exempel på sådana läkemedel är vissa smärtstillande läkemedel, ångestdämpande medel, sömnmedel och epilepsiläkemedel. Icke-medicinskt motiverad felanvändning av läkemedel kan medföra allvarliga konsekvenser och anses idag vara ett globalt och ökande folkhälsoproblem. Detta avhandlingsprojekt avser att studera förekomsten av beroende, felaktig användning och missbruk av läkemedel med verkan på centrala nervsystemet, och de riskfaktorer som är kopplade till dessa.

I avhandlingen ingår fyra delstudier som använde uppgifter från olika svenska nationella hälsooch sjukvårdsregister, exempelvis uppgifter om rättsmedicinsk och rättstoxikologisk utredning, spontanrapporterade biverkningar, receptförskrivna läkemedel uthämtade på apotek, och sociodemografiska faktorer. I delstudie I identifierades oavsiktliga dödliga förgiftningar med tramadol, ett smärtstillande läkemedel av opioidtyp, i rättsmedicinska register. I delstudie II identifierades spontant inrapporterade biverkningsfall av tramadolberoende i det svenska biverkningsregistret. Delstudie III studerade hur vanligt förekommande användning är av ickeförskrivna läkemedel med verkan på centrala nervsystemet, bland personer som vid utredning för misstänkt drograttfylleri har påvisats använda dessa läkemedel, och vilka faktorer som är kopplade till sådan icke-förskriven användning. I delstudie IV identifierades olika långsiktiga användningsmönster för pregabalin, ett antiepileptiskt läkemedel, med avseende på den högsta godkända dygnsdosen, bland personer som inleder förskriven behandling med läkemedlet, samt faktorer som kan vara kopplade till de olika användningsmönstren.

I den första delstudien redovisas 17 dödsfall som ansågs vara orsakade av en oavsiktlig förgiftning där läkemedlet tramadol haft en central roll. Män, yngre individer, och individer som samtidigt använde andra medel med verkan på centrala nervsystemet (alkohol, illegala droger och läkemedel) föreföll vara vanliga i sådana dödsfall. I den andra delstudien där 104 rapporterade fall av möjligt eller troligt tramadolberoende studerades, drabbades kvinnor oftare. Åldern i dessa fall var i genomsnitt 45 år och i cirka en tredjedel av fallen hade personerna tidigare haft problem med beroende eller missbruk, vanligen av ett annat smärtstillande läkemedel. 
I den tredje delstudien fann man att hälften av personer som misstänktes för drograttfylleri och som hade visats använda något av läkemedlen med verkan på centrala nervsystemet, använde läkemedlet utan en förskriven pågående behandling. Vanligast var detta för bensodiazepiner och tramadol och hos unga individer och användare av många samtidiga substanser. Det var dock mindre vanligt hos individer med en pågående behandling med annat läkemedel med verkan på det centrala nervsystemet.

I den sista delstudien identifierades fem olika användningsmönster för läkemedelet pregabalin. En liten andel av patienterna fanns ha en stor risk för att under loppet av sin behandling använda pregabalin över den godkända dygnsdosen. Högst risk noterades bland yngre, män, personer som inte bor i en storstad och bland personer som inom det senaste året hämtade ut ett antiepileptiskt läkemedel eller smärtstillande läkemedel av opioidtyp.

Sammanfattningsvis visar detta avhandlingsprojekt att beroende, missbruk och felaktig användning av läkemedel som verkar på det centrala nervsystemet förekommer i hela befolkningen och kan ha allvarliga följder. Förekomsten skiljer sig åt mellan olika läkemedel och är särskilt hög i vissa grupper i befolkningen. Oavsett om läkemedlet är förskrivet eller ej verkar missbruk och felaktig användning vara vanligare hos unga. Dödsfall på grund av förgiftning liksom felaktig användning av förskrivna läkemedel kan vara vanligare bland män, medan beroende efter ordinerad behandling kan vara vanligare hos kvinnor och användning av ickeförskrivna läkemedel lika vanligt hos båda könen. Personer med en tidigare psykisk sjukdom och personer med en tidigare eller pågående behandling av läkemedel med verkan på det centrala nervsystemet, samt personer med tidigare beroende- eller missbruksproblematik identifierades som grupper med förhöjd risk. Sammantaget pekar avhandlingsprojektet på att det finns potential för att förhindra missbruk och felaktig användning och resultaten kan vara underlag för individanpassade interventioner för en säkrare användning av denna typ av läkemedel.

ISBN: 978-91-7685-770-0

ISSN: $0345-0082$ 


\section{LIST OF PAPERS}

This thesis is based on the following studies, referred to in the text by their Roman numerals.

The articles have been printed in the thesis with the permission of the publishers.

I. Tjäderborn M, Jönsson AK, Hägg S, Ahlner J. Fatal unintentional intoxications with tramadol during 1995-2005. Forensic Sci Int 2007;173(2-3):107-11.

II. Tjäderborn M, Jönsson AK, Ahlner J, Hägg S. Tramadol dependence: a survey of spontanously reported cases in Sweden. Pharmacoepidemiol Drug Saf 2009;18(12):11928.

III. Tjäderborn M, Jönsson AK, Sandström TZ, Ahlner J, Hägg S. Non-prescribed use of psychoactive prescription drugs among drug-impaired drivers in Sweden. Drug Alcohol Depend 2016;161:77-85.

IV. Tjäderborn M, Bardage C, Schiöler L, Jönsson AK, Hägg S. Longitudinal patterns of pregabalin use above the maximum approved daily dose: a five-year cohort study in Sweden. Submitted manuscript. 


\section{TABLE OF CONTENTS}

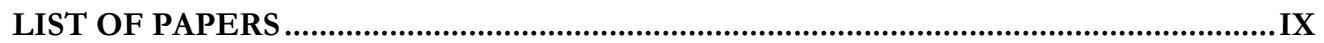

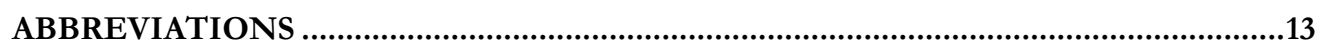

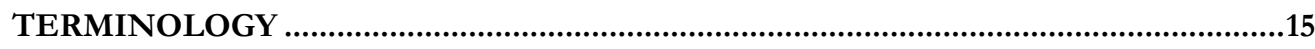

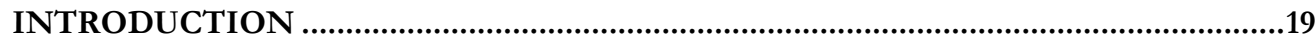

Drug safety, rational drug utilisation and pharmacoepidemiology ……………...................................19

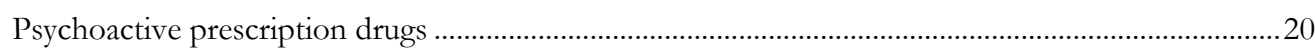

Psychoactive prescription drug use disorders .................................................................................22

Psychoactive prescription drug misuse and abuse .................................................................................2

Methods to study psychoactive prescription drug use disorder, misuse and abuse .............................27

Occurrence and prevalence of psychoactive prescription drug use disorder, misuse and abuse........31

Factors associated with psychoactive prescription drug use disorder, misuse and abuse ....................34

Examples of psychoactive prescription drugs with concerns on drug use disorder, misuse and

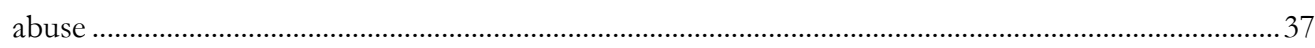

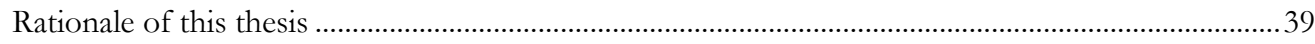

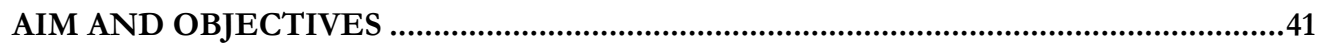

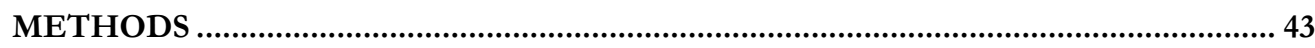

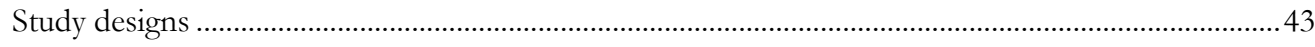

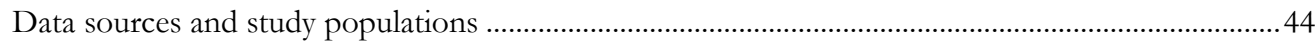

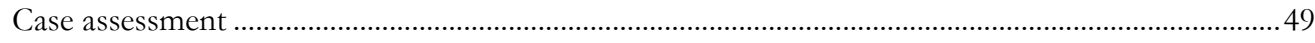

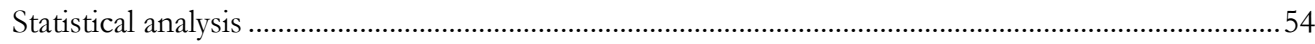

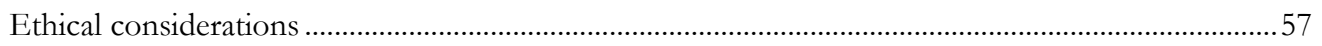

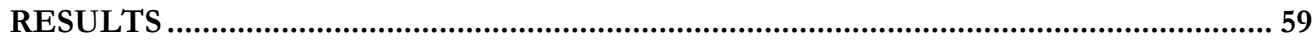

Fatal unintentional intoxications with tramadol (Paper I) ...................................................................59

Spontaneously reported tramadol dependence (Paper II) ......................................................................59

Non-prescribed use of psychoactive prescription drugs among drug-impaired drivers (Paper III) .60

Longitudinal pregabalin utilisation patterns above the maximum approved daily dose (Paper IV)..61 
DISCUSSION

Occurrence and prevalence of psychoactive prescription drug use disorders, misuse and abuse .....65

Factors associated with psychoactive prescription drug use disorders, misuse and abuse .................69

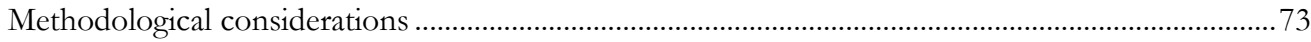

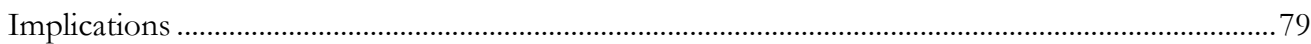

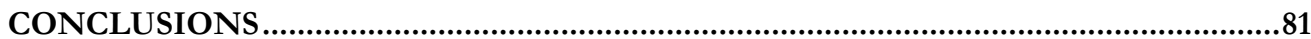

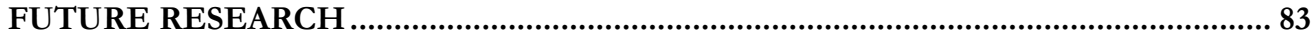

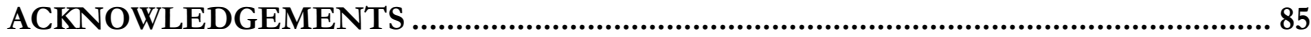

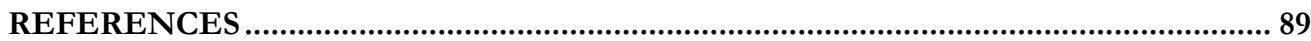

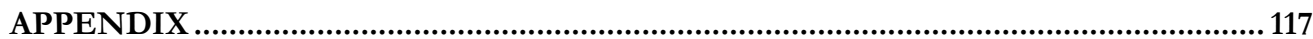




\section{ABBREVIATIONS}

ACTTION the Analgesic, Anesthetic, and Addiction Clinical Trial Translations, Innovations, Opportunities, and Networks

ADR Adverse drug reaction

ATC Anatomical Therapeutic Chemical Classification System

BIC Bayesian information criterion

CI Confidence interval

CNS Central nervous system

DALY Disability-adjusted life year

DDD Defined daily dose

DSM Diagnostic and Statistical Manual of Mental Disorder

DUID Driving under influence of drugs

EMA European Medicines Agency

EMCDDA European Monitoring Centre for Drugs and Drug Addiction

EU European Union

FDA Food and Drug Administration

GABA Gamma-aminobutyric acid

GBTM Group-based trajectory model

GHB $\quad \gamma$-Hydroxybutyric acid

GPP Good pharmacoepidemiological practice

ICD International Classification of Diseases

IEC Independent ethics committee

INCB International Narcotics Control Board

IRB Institutional review board

LISA Longitudinal integration database for health insurance and labour market studies

MAD Maximum approved daily dose

$\mathrm{MeSH} \quad$ Medical subject heading

MPA Medical Product Agency

OR Odds ratio

OTC Over-the-counter

PDC Proportion of days covered

PPD Psychoactive prescription drug

SEK Swedish krona

SPC Summary of product characteristics

SPDR Swedish Prescribed Drug Register

SSRI Selective serotonin reuptake inhibitor

SweDIS Swedish Drug Information System

TCA Tricyclic antidepressants

TIAFT The International Association of Forensic Toxicologists

UN United Nations

UNODC United Nations Office on Drugs and Crime

USA United States of America

WHO World Health Organization

WHO-ART World Health Organization Adverse Reaction Terminology

YLL Years of Lost Life 


\section{TERMINOLOGY}

Addictive properties

Adverse drug reaction

Controlled drug

Craving

Counterfeit drug

Drug abuse

Drug dependence

Drug dispense

Drug diversion

Drug misuse

Drug safety

Doctor shopping
Properties of psychoactive drugs, such as positive psychoactive effects, drug dependence and drug tolerance, that may lead to the development of addiction or predispose to abuse. Also referred to as Abuse potential or Dependence potential.

Any response to a medicinal product which is noxious and unintended (1).

A drug (prescription drug or illicit drug) which is scheduled in an act for controlled substances due to addictive properties of the drug, a regulation aimed at preventing misuse and abuse of the drug. In this thesis the Swedish regulation was used (2), which corresponds to international regulations with some exceptions $(3,4)$. Also referred to as Scheduled or Narcotic drug.

Intense desire or urge for a drug, which leads to substance-seeking behaviour (5).

A false or forged drug which is produced to mimic the effects of an approved medicinal drug product.

The persistent or sporadic, intentional and non-medically intended excessive use of a medicine, for the psychoactive effects that the drug produces, which is accompanied by harmful physical or psychological effects. A type of misuse. Modified from (6).

The normal biological response to an addictive drug, which develops when the neurons in the central nervous system adapt to drug exposure. This leads to a state of relying on or needing a drug in order for normal functioning, to withdrawal symptoms when the drug is not present, and craving (7). For the former DSM-IV diagnostic term Substance dependence, see Drug use disorder.

The dispense of a prescribed drug in a pharmacy. Also referred to as Prescription fill.

The transfer of prescription drugs from legal to illegal distribution and marketing networks $(6,8)$.

The intentional or unintentional, inappropriate use of a medicine not in accordance with the authorised product information, clinical guidelines for use or the prescription for the drug. Modified from (6).

See Pharmacovigilance.

A substance-seeking behaviour involving frequent visits to multiple prescribers (commonly physician's) to obtain large amounts of prescribed drug. The term Pharmacy shopping involves the equivalent behaviour involving multiple pharmacies (9-11). 
Drug use disorder

Drug utilisation

Intoxication

Maximum approved daily dose

Non-prescribed use

Overdose

Pharmacoepidemiology

Pharmacovigilance

Positive psychoactive effects

Prescription drug

Psychoactive drug

Psychoactive prescription
A behavioural disorder with multiple biologic, psychologic, and social components, characterised by a pathological patterns of drug use, including impaired control of drug use, social impairment due to drug use, risky drug use, substance-seeking behaviour and pharmacological criteria (tolerance or withdrawal). Also referred to as Drug addiction (5). Corresponds to the DSM-IV definitions Drug dependence and Drug abuse (12).

The marketing, distribution, prescription, and use of drugs in a society, with special emphasis on the resulting medical, social and economic consequences (13).

An intake (by ingestion, injection or inhalation) of an amount of substance with the significant potential to cause harm to an individual. It may be accidental or intentional, and fatal or non-fatal. Also referred to as poisoning.

The maximum daily dose recommended in the product information (Summary of Product Characteristics) of a drug product approved for marketing authorisation.

The use of a prescription drug without a medical prescription for the drug.

The administration of a quantity of a medicinal product given per administration or cumulatively, which is above the maximum approved dose according to the authorised product information. Clinical judgement should always be applied in this case.

The study of the use, effects and side effects of drugs, and their distribution and determinants, in large numbers of people, to support the rational, cost-effective use of drugs, and safe and efficacious treatments, thereby improving health outcomes in the population $(13,14)$.

The science and activities relating to the detection, assessment, understanding, and prevention of adverse effects or any other drugrelated problem (15). Also referred to as Drug safety.

Symptoms, such as euphoria or sedation, that are linked to the affect of drugs on mental processes.

A medicine that can only be obtained in health care by means of a prescription.

A substance that, when taken in or administered into one's system, affect mental processes, e.g. cognition or affect (16). Also referred to as Psychotropic drug.

Psychoactive medicines that can only be obtained in health care by means of a prescription. In Sweden, all psychoactive medications are 
drugs

Rational drug use

Substance seeking

Tampering

Tolerance development

Withdrawal

symptom/syndrome prescription drugs.

Patients receive medications appropriate to their clinical needs, in doses that meet their own individual requirements, for an adequate period of time, and at the lowest cost to them and their community $(17,18)$. Also referred to as Appropriate drug use.

A behaviour, part of substance addiction, characterised by spending a great deal of time and effort, including seeking alternative sources, to obtain a substance. See Doctor shopping.

Intentional modification of a medicinal drug product, such as crushing tablets to enable intravenous injection or using alternative routes of administration than the intended for enhanced drug effect.

The requirement of markedly increased doses of a drug to achieve a certain effect or markedly reduced effect when the dose is maintained (5).

Symptoms(s) that occur when blood or tissue concentrations of a drug decline. Withdrawal symptoms may be physiological and psychological and are drug class specific (5). 


\section{INTRODUCTION}

\section{Drug safety, rational drug utilisation and pharmacoepidemiology}

Today, drug therapy is the most common intervention in clinical practice (19). Advances in medicine and drug development have resulted in major improvements in the treatment of many diseases (20). If used appropriately, drugs can cure disease, reduce or eliminate symptoms, arrest or slow down a disease progress, prevent diseases or symptoms, and, ultimately, improve a patients' quality of life (21). Although drugs are in general safe, they are associated with a risk of various problems and significant morbidity and mortality $(22,23)$. Among the most recognised drug-related problems are adverse drug reactions (ADRs) and irrational drug utilisation.

An ADR is defined in the European Union (EU) as "any response to a medicinal product which is noxious and unintended" (1). This definition, in contrast to the definition by the World Health Organization (WHO) (24) covers also the use of a drug outside the clinically accepted scope and any reactions related to such use, including medication errors and intoxications. Rational drug utilisation is defined by the WHO as "patients receive medications appropriate to their clinical needs, in doses that meet their own individual requirements, for an adequate period of time, and at the lowest cost to them and their community" $(17,18)$. Irrational use of medicines can occur at any stage of the drug use process, including production, distribution, prescribing, dispensing and administration, and may be unintentional (i.e. a medication error) or intentional (i.e. a violation) $(25,26)$. Inappropriate use of drugs is recognised as a major cause of preventable drug-related harm, including ADRs (27). However, medications that are prescribed and used appropriately are also associated with drug-related problems such as ADRs and other safety risks.

Before a new drug is approved for use in the general population its benefits (i.e. the positive, intended effects) must be shown to outweigh the risks (i.e. the adverse drug reactions and other drug-related problems). The pre-marketing studies form the foundation upon which the initial benefit-risk assessment and, ultimately, the decision on marketing authorization of each drug relies. In these studies, the drug is usually assessed for efficacy and safety in small selected populations (commonly $<6000$ patients), for short treatment durations, in low or normal doses and under more or less strict treatment conditions in randomized controlled phase I-III clinical trials (RCTs) (28-30). Hence, only common ADRs (i.e. those which occur in $>1 / 1000$ treated patients) may be detected, and long-term effects, outcomes of drug use outside the investigated doses or treatment durations, and outcomes in real-life use cannot be determined. As RCTs 
rarely include children or adolescents, or persons with a past or current substance use disorder, mental co-morbidity or multiple concomitant medications (31), little is known about the effect and safety of medications in such populations. Thus, when a new medicine is approved for use in the general population its benefit-risk profile is not completely known and post-marketing surveillance, including pharmacovigilance and drug utilisation research, are important (13-15). Pharmacoepidemiology is crucial in pharmacovigilance as well as in drug utilisation research. It may be defined as "the study of the use, effects and side effects of drugs in large numbers of people with the purpose of supporting the rational and cost-effective use of drugs in the population, thereby improving health outcomes" (13) or as "the study of the distribution and determinants of drug-related events in populations and the application of this study to safe and efficacious treatment'(14). Thus, pharmacoepidemiology applies epidemiological methods to study drug use, drug safety and drug effectiveness in real-life settings across sub-groups in the general population. Today, improving drug safety is a highly prioritized part of national as well as international health policy agendas (32-34).

\section{Psychoactive prescription drugs}

Medications are common interventions in the treatment of pain and mental and neurological disorders. The drugs used may be referred to as psychoactive (or psychotropic) drugs. The WHO defines a psychoactive substance as "a substance that, when taken in or administered into one's system, affect mental processes, e.g. cognition or affect' (16). As this definition includes medicines as well as illicit drugs, in this thesis the term psychoactive prescription drug (PPD) is used. This includes a range of drug classes, such as opioid analgesics, antiepileptics, psycholeptics (including anxiolytics, sedatives and hypnotics) and psychoanaleptics (including antidepressants and stimulants) (35).

\section{Clinical utilisation of psychoactive prescription drugs}

Mental disorders, such as depression, anxiety, insomnia, and schizophrenia account for a considerable proportion of the global burden of disease (36). In Sweden, mental disease is the fastest-growing health problem $(37,34)$ and the most common reason for labour market exclusion $(38,39)$. Women are at higher risk than are men, and incidence rates peak at the ages 30-39 years of age. Due to lost productivity, social benefits and health care, mental disorders account for a substantial societal burden, and the high impact on quality of life, isolation, discrimination and stigma (36) are associated with considerable suffering of affected individuals. 
Chronic pain affects $20 \%$ of the adult global population (40) and low back pain affects nearly everyone at some point in time (41). In Sweden, $10 \%$ of the population is diagnosed with chronic pain, which is the second leading cause of work disability (42). It occurs more often in women, with increasing age and as a co-morbidity to other disorders. Chronic pain contributes to considerable suffering and has a high impact on quality of life.

Epilepsy is one of the most common neurological conditions, affecting worldwide more than 40 million people (43) across age, gender, social, and other groups. The causes of this condition are multiple, as are the consequences. The disease burden of epilepsy is attributable to medical consequences due to seizures or sudden death, and the psychosocial consequences resulting from the unpredictability of seizures, social exclusion due to stigma, and mental co-morbidities, including anxiety and depression (44). In Sweden, around 60000 persons are diagnosed with epilepsy and each year around 3600 are affected each year (45).

Increased morbidity, improved diagnosing, medical and pharmaceutic advancements and increased availability to pharmacological treatments has considerably increased the clinical use of psychoactive medicines in medical treatment $(46,47)$. In 2006, the WHO noted an additional, dramatic increase in the global prescribing of psychoactive prescription drugs, in particular of opioids (opioid analgesics and opioid substitution therapies), sedatives and hypnotics (48). In Sweden, the clinical utilisation of psychoactive medicines has also increased considerably, although not as dramatically as in countries such as the USA (49). In 2015, 78 of 100.000 Swedish inhabitants used an opioid analgesic or sedative drug, 58 used an antiepileptic drug and 23 used an anxiolytic or hypnotic drug (50). Prescription rates for psychoactive medications are higher in women, and due to mental co-morbidity patients commonly use a combination of several psychoactive medicines (51).

The use of psychoactive medications has benefits but also comes with risks of drug-related problems, such as ADRs, sub-therapeutic effects and inappropriate use (52, 53), of which at least $10 \%$ are reported to be preventable $(23,27,54-56)$. Examples of inappropriate use of psychoactive prescription drugs which have received attention include the long-term use of opioid analgesics, use of hypnotics outside approved indications, use of long-acting benzodiazepines in the elderly and polypharmacy (57). In addition, addictive properties, misuse and abuse are an important aspect of the safety profile of some psychoactive prescription drugs. 


\section{Psychoactive prescription drugs and addictive properties}

The mechanism of action in the central nervous system (CNS) and the related effects on mental processes (i.e. positive psychoactive effects) of some psychoactive prescription drugs may lead to addictive properties (i.e. an ability to induce drug addiction). Terms such as "abuse potential", “abuse liability", "dependence-producing" or "dependence potential" can be understood to encompass similar concepts (58-60). Examples of positive psychoactive effects include sedation, euphoria, perceptual and other cognitive distortions, hallucinations, and mood changes $(16,60)$. Several neurotransmitter systems are known to be implicated in producing such effects and to affect the reward system in the CNS (60-62), including the dopamine, norepinephrine, serotonin, gamma-aminobutyric acid (GABA), acetylcholine, opioid (63), N-methyl-D-aspartate (NMDDA) and endocannabinoid neurotransmitter systems. Thus, opioid analgesics, benzodiazepines, benzodiazepine-like hypnotics (also referred to z-drugs) and stimulants are among the prescription drugs known to have addictive properties (60), however, other and novel mechanisms of action may also show important. Notably, the addictive properties differ considerably between drugs as a reflection of their different pharmacokinetic and pharmacodynamic profiles. Drugs such as benzodiazepines and strong opioid agonists are known to possess more addictive properties and to more often be misused compared to some others (3).

\section{Psychoactive prescription drug use disorders}

Addictive properties of psychoactive drugs may cause a range of clinical symptoms, including positive psychoactive effects, tolerance development, physical dependence, and withdrawal symptoms (for definitions, see Terminology), which may lead to a risk of developing a psychoactive prescription drug use disorder. Importantly, while this disorder is an important and serious outcome of inappropriate use of psychoactive prescription drugs, the disorder may also occur following appropriate drug use (such as long-term opioid use in severe chronic pain).

The American Psychiatric Association (APA) defines substance use disorder as an addictive disorder characterised by a cluster of symptoms indicating a pathological pattern of behaviours related to the use of a substance, as described in Table 1 (5). The essential feature of drug addiction is the chronic nature (64), impaired control over drug use, compulsive use and continued use despite harms (65), which leads to significant medical, psychosocial and other adverse consequences. The psychoactive prescription drug use disorder has various 
manifestations and range widely in severity, however, by definition, are most often serious (66). The diagnosis of substance use disorder is drug class-specific and addresses separate use disorders for each drug class, including for some classes of psychoactive medications (such as opioid use disorder, stimulant use disorder, etc.), where the same overarching criteria apply to most substances.

Notably, the terminology within this research area is heterogeneous and there is a lack of internationally accepted, standardised terms. The current APA Diagnostic and Statistical Manual of Mental Disorders (DSM)-5 criteria (5) combine the former criteria in DSM-IV (67) for "substance abuse" and "substance dependence" into a single disorder. The corresponding term "dependence syndrome" defined by the WHO in the International Classification of Disease codes 10 (ICD-10) criteria, is equivalent but not identical $(16,68)$. In this thesis, a substance use disorder concerning a psychoactive prescription drug is referred to as a "psychoactive prescription drug use disorder".

In research, due to lack of sufficient clinical information it is generally difficult to establish a drug use disorder $(69,70)$. In study II of this thesis, the DSM-IV criteria of substance dependence were assessed, which are equal, but not identical, to the current DSM-5 criteria for mild substance use disorder. In the other studies within this thesis, limitations in the register data did not enable assessment of a substance use disorder, but different aspects of substance use disorder were inferred based on various indicators. 
Table 1. Diagnostic criteria for American Psychiatric Association DSM-5 Substance Use Disorder (5)

A problematic pattern of substance use leading to clinically significant impairment or distress, as manifested by at least two of the following symptoms occurring within a 12-month period. Severity of the disorder is assessed as mild (2-3 criteria fulfilled), moderate (4-5 criteria fulfilled), or severe (6 or more criteria fulfilled):

1. The substance is often taken in larger amounts or over a longer period of time than was intended.

2. There is a persistent desire or unsuccessful efforts to cut down or control use of the substance.

3. A great deal of time is spent in activities necessary to obtain the substance, use the substance, or recover from its effects.

4. Craving, or a strong desire or urge to use the substance.

5. Recurrent substance use resulting in a failure to fulfill major role obligations at work, school or home.

6. Continued use of the substance despite having persistent or recurrent social or interpersonal problems caused or exacerbated by the effects of the substance.

7. Important social, occupational or recreational activities are given up or reduced because of substance use.

8. Recurrent opioid use in situations in which it is physically hazardous.

9. Continued use despite knowledge of having a persistent or recurrent physical or psychological problem that is likely to have been caused or exacerbated by the substance.

10. Tolerance ${ }^{\mathrm{a}}$, as defined by either of the following:

a. A need for markedly increased amounts of the substance to achieve intoxication or desired effect.

b. A markedly diminished effect with continued use of the same amount of the substance.

11. Withdrawala ${ }^{\mathrm{a}}$, as manifested by either of the following:

a. The substance characteristic withdrawal syndrome.

b. The substance (or a closely related substance) is taken to relieve or avoid withdrawal symptoms.

${ }^{a}$ This criterion is not considered to be met when taking the substance solely under appropriate medical supervision. 


\section{Psychoactive prescription drug misuse and abuse}

There is a wide variation in the use of psychoactive medications. A consequence of addiction is the irrational use of these drugs, which may occur at several stages of the drug use process. At the level of the individual patient (or drug user) addiction is typified by the use of excessive and gradually increasing doses, overdosing, use of non-prescribed drugs, multiple substance use, substance-seeking behaviour and tampering, the manifestation of which shows large variation between individuals and over time (69-74). This misuse of psychoactive medications also involves diversion and counterfeit production (for definitions, see Terminology).

The terms used to describe this irrational drug use range widely as a result of the various manifestations of the misuse (69-74), discrepancies in the two major diagnostic systems $(5,68)$ and a lack of standard terminology and methodology. In a recent review Blanch et al. identified 46 different terms used to describe the concept of prescription drug misuse and abuse, such as non-medical use, nontherapeutic use, problematic use, high-risk use, deviant use, inappropriate use, excessive use, heavy use, high use, and other terms (69).

The European Medicines Agency (EMA) defines misuse as "situations where the medicinal product is intentionally and inappropriately used not in accordance with the authorised product information "and abuse as "the persistent or sporadic, intentional excessive use of a medicinal product, which is accompanied by harmful physical or psychological effects" (6). In 2010, the Food and Drug Administration (FDA) defined misuse as "the use of a drug outside label directions or in a way other than prescribed or directed by health care practitioner" (75) and abuse as "the nonmedical use of a drug, repeatedly or even sporadically, for the positive psychoactive effects it produces" (76). In 2013, the Analgesic, Anesthetic and Addiction Clinical Trials, Translations Innovations, Opportunities and Networks (ACTTION) expert panel suggested misuse to be defined as "any intentional non-therapeutic use of a drug product in an inappropriate way (excluding events that meet the definition of abuse" (73). The panel further defined abuse as "any intentional, non-therapeutic use of a drug product or substance, even once, for the purpose of achieving a desirable psychological or physiological effect". Also in 2013, the US National library of Medicine introduced the Medical Subjects Heading (MeSH) term "prescription drug misuse", defined as "the improper use of drugs or medications outside the intended purpose, scope, or guidelines for use. This is in contrast to medication adherence, and distinguished from drug abuse, which is a willful action" (8).

Thus, while the ACTTION and MeSH definitions do not recognise abuse as a sub-category of misuse, the EMA and FDA definitions do. Consistent across definitions is the important 
distinction that abuse as opposed to (other forms of) misuse, involves the use of psychoactive medications with deliberate, non-medical intentions of use to achieve positive psychoactive effects. As such, it is an extreme form of non-adherence (77) and a violation to the rationale use of medicines $(17,18)$. Notably, misuse and abuse of psychoactive prescription drugs occur also in the absence of a drug use disorder. The association between the concepts of adverse drug reactions and irrational drug use, and psychoactive prescription drug use disorder, misuse and abuse are illustrated in Figure 1.

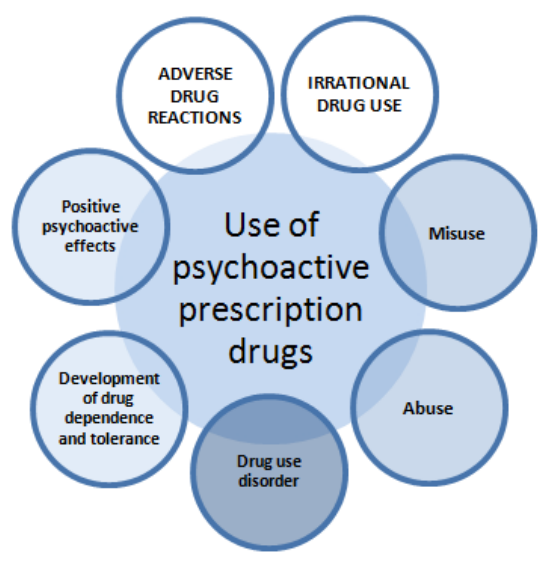

Figure 1. Association between adverse drug reactions and irrational drug use, and psychoactive prescription drug use disorder, misuse and abuse

The lack of international consensus on what actually constitutes misuse and abuse complicates the assessment of prevalence and risk factors, and makes communication, interpretation and comparison of results over time and across countries difficult (73). In research, the intention of drug use is often not known due to a lack of sufficient clinical information in routinely collected data. Thus, the distinction between prescription abuse from other forms of misuse is difficult, and misuse may be assessed to indicate abuse $(78,79)$. Of this reason, the term "prescription drug misuse" is used in this thesis to capture the continuum, ranging from medically intended use outside the clinical recommendations (such as use of daily doses above approved labels), through to non-medically intended abuse $(69,80)$.

The motives for prescription drug misuse and abuse range widely. In drug abuse, psychoactive prescription drugs are taken to achieve the positive psychoactive effects of the drug per se, but also to relieve withdrawal symptoms and to enhance the effect of other prescription drugs, 
alcohol or illicit drugs $(71,81,82)$. Prescription drugs may be perceived as more available, less stigmatising, safer, less subject to legal consequences (83, 84), and more accepted (85) than illicit drugs. In US young adults, self-medication (i.e. "to relieve pain" or "to relieve anxiety") followed by recreational motives (i.e. "to get high") are the most commonly reported motives for prescription drug misuse $(86,87)$. Self-medication, where medicines are used without medical supervision to alleviate symptoms of mental symptoms such as stress and anxiety, may be an important motive of psychoactive prescription drug misuse across groups in the general population of today (88-90).

Recently, research has described the existence of different subtypes of prescription drug misusers. The different subtypes have different motives of their drug use, differ in the severity of any addiction and comorbid health problems, and also differ with respect to the source of diversion. In turn, these factors are suggested to be correlated to the choice of psychoactive substance, how the drug use is onset, the pattern and severity of drug misuse and the outcomes of the use (87, 91-96). As an example, an illicit source of drug and more serious outcomes appear more common in persons with a history of mental co-morbidity, in whom the addiction is more severe, however, the literature is sparse.

Diverse terminology is evident also in the papers within in this thesis. In Study II the term "dependence" was used based on DSM-IV criteria (67), the equivalent to the term "substance use disorder" based on DSM-5 (5) in this thesis. The term "diversion" used in study III is the equivalent to the term "abuse" used in this thesis. In Study IV the term misuse was used, as the study investigated use of a prescription drug above the clinically recommended dose levels, but did not enable establishing any intentions of the use.

\section{Methods to study psychoactive prescription drug use disorder, misuse and}

\section{abuse}

Any addictive property is an important aspect of a new or existing psychoactive prescription drug's safety profile and an important basis for clinical and regulatory decision making $(58,59$, 97). Nonetheless, evaluating the abuse potential of a medicine is complex and should be based on pre-clinical, clinical as well as observational data (59). Based on the pre-marketing evaluation and post-marketing experience regulatory measures may be taken to prevent misuse and abuse of psychoactive prescription drugs, such as a decision to place the drug in an international or national act of controlled substances $(2-4,60,98,99)$. 
The standard clinical trials that are part of each drug's development program assess the safety and efficacy of drugs in small populations in controlled studies with low or moderate doses and relatively short treatment durations, normally excluding subjects with a history of substance use problems. Thus, they have limited value for the assessment of addictive properties. When a new drug under development is known to affect the central nervous system, to be chemically or pharmacologically similar to other drugs with a known abuse potential, or to produce psychoactive effects, a program to specifically evaluate the abuse potential is therefore conducted $(60,97,100)$ This includes preclinical studies (pharmacological receptor binding studies and various animal behavioural studies) (101), a clinical program (dependence pharmacokinetic and pharmacodynamic studies and clinical laboratory studies in persons with a history of substance abuse or substance use disorder) and relevant safety data from standard clinical trials, such as adverse reported events.

Yet, the pre-clinical programs may fail in identifying addictive properties a new drug. Throughout history, the abuse of drugs has commonly been identified after a time of use in the general population, in relation to the occurrence of serious abuse-related events such as drugrelated deaths (102). Thus, post-marketing surveillance for empirical evidence from clinical use in the general population is important.

\section{Pharmacoepidemiological methods in studies of psychoactive prescription drug use disorders, misuse and abuse}

The post-marketing study of psychoactive prescription drug use disorder, misuse and abuse has involved various research methodologies. Pharmacoepidemiological studies rely completely upon the available registers and the contents (i.e. the set of included variables) and quality (the accuracy, specificity, sensitivity and reliability of variables) of each register. In the USA, an extensive prescription drug abuse monitoring system is present $(70,103)$, including a variety of tools, annual surveys, prescription drug monitoring programs, registers that collect reported adverse events related to drug abuse, analysis tools to identify "doctor shopping" in prescription databases, as well as multi-source approaches combining information from several data sources $(70,103)$. Equivalent data sources are missing in most other countries, including the European countries (with the exception of France) $(72,104,105)$. In the Scandinavian countries, monitoring for prescription drug abuse has generally been restricted to pharmacovigilance, forensic, and cause-of-death data (72). 
Due to limited clinical information held in routine data collections, prescription drug use disorder, misuse and abuse are not measured directly, but are commonly inferred based on information on drug use patterns and adverse outcomes potentially related to addiction, misuse or abuse $(70,106)$ (referred to as abuse-related events, or indicators of abuse). As suggested by Secora et al. (70), these may be sub-categorized as self-reported events, events involving health care utilisation, events involving the reporting of an adverse event, events resulting in an interaction with law enforcement, and events identified in proprietary surveillance systems (Appendix Table 2). Indicators of abuse are typically measured either in the general population (such as in household surveys (107)), in a population of patients (e.g. using dispensing data (11) or data on spontaneously reported suspected ADRs (102)), or in cohorts of individuals with drug abuse problems (such as subjects undergoing opioid substitution treatment or individuals undergoing forensic investigation (69)).

No one of the currently available indicators fully accounts for all aspects of prescription opioid use disorder, misuse or abuse, but each has unique strengths and limitations. Measures used so far commonly focus on one point in the medical system (such as emergency department), or the legal system (such as drug-impaired drivers) $(70,72)$. Thus, the results from different data sources are likely to generate different conclusions and the use of complementary data sources is crucial in the monitoring for prescription drug misuse and abuse $(58-60,108)$. The appropriate measure(s) to be used in each study, depends on the specific research question of interest. As an example, to describe the prevalence of abuse of prescribed drugs in the general population, a study population of drug abusers is not sufficient. On the other hand, for the identification of any previously unknown addictive property of a drug, studying a cohort of drug abusers may be more likely to detect any emerging abuse.

These indicator measures are ultimately put in context of the populations to which they are relevant and adjusted for an appropriate measure of population exposure or product availability (13), to provide a prevalence (or rate) of abuse-related events. Without this context, any crude counts or indicators of abuse provide only a limited understanding, give an incomplete picture and may even distort the characterisation of a drug's real-life profile of addictive properties. Nonetheless, unlike most other drug-related problems abuse of prescription drugs and its consequences can occur in other individuals than those prescribed the drug and the true "at risk"-population is therefore not known. Secora et al. (70) suggested the following exposure measures: estimates of population size, volume or weight of drug sold, total number of 
prescriptions dispensed, total number of unique recipients of dispensed drug, total patient-days of therapy, or the total number of tablets dispensed.

In recent decades, the growing availability of routinely collected data on prescribed and dispensed prescription drugs in many countries has substantially increased the opportunities to undertake research aimed at investigating patterns of drug use in the population $(69,109-111)$. Compared to studies on potentially abuse-related events, the evidence generated from such data can enhance our understanding of how psychoactive prescription drugs are used (as an example what drug doses are used), to identify sub-groups of drug users and describe the patient and other characteristics associated with identified drug use patterns (112). In particular, such data have the potential to detect any misuse and abuse in the population before the occurrence of serious adverse abuse-related events. While data on drug prescriptions (also referred to as prescription fills) may be useful for the evaluation of any irrational use originating at the prescriber level, data on drug dispenses are advantageous when the administered drug use pattern is expected to substantially deviate from the prescribed regimen, as in drug addiction and abuse (113). Population-level measures based on drug dispenses, such as skewness in the consumption of a prescription drug in a population (79) and the total sales of a certain drug (78) may indicate the extent of misuse and abuse in a population, but individual-level data are crucial for the further assessment and characterisation of such use.

Measurements based on individual-level prescription or dispensing data typically aim at identifying behaviours typical of drug addiction and drug abuse, such as substance seeking behaviour (including doctor shopping) and the use of large volumes of drug (9-11, 69). Research on prescription drug misuse and abuse needs to accurately distinguish appropriate use, which should not raise any concerns, from inappropriate use of a drug. Based on a comprehensive review, Blanch et al. (69) recently recommended four types of proxy measures of misuse in future studies based on drug dispensing data: number of prescribers, number of dispensing pharmacies, volume of dispensed drug, and/or overlapping prescriptions/early refills for future research of prescription drug misuse and abuse. Any definitions or validations of these measurements were however not provided and, subsequently, additional measures have been suggested (114-116). Thus, this research area is still in its infancy $(69,70)$. In particular, there is a lack of validated and standardised measurements that identify and separate prescription drug misuse and abuse (69). One important limitation of drug prescription and dispensing databases is that only personally prescribed drugs are covered, while the sources of abused drugs are diverse $(84,117)$. 
In summary, despite the range of observational studies conducted in the past decade to identify and characterise prescription drug use disorders, misuse and abuse, there are no internationally accepted, validated methods or measurements of misuse or abuse, substantially complicating the interpretation and comparison of study results $(69,70,72,103,118)$.

\section{Occurrence and prevalence of psychoactive prescription drug use disorder, misuse and abuse}

In parallel to the growing global clinical utilisation of psychoactive prescription drugs during the past decades, a dramatic increase in the prevalence of drug use disorders, misuse and abuse of such drugs has been observed (119). As predicted in 2006 by the United Nations International Narcotic Control Board (INCB), the worldwide prevalence of prescription drug misuse and abuse (especially of opioids, sedatives and hypnotics) now exceeds the use of illicit drugs, such as heroine and cocaine (120). In many countries, prescription drugs have become among the most prevalent type of abused substance $(106,121,122)$. In the USA, which accounts for a large proportion of the global literature, non-medical use of psychoactive medications is reported by $6.4 \%$ of the population aged $>12$ years (123) and the number of deaths and other complications related to such use exceed that of those related to illicit drug use $(103,124)$. In the USA, by far the class of prescription drugs most commonly implicated in misuse and abuse are the opioid analgesics (such as oxycodone) $(106,124)$. The increasing prevalence of abuse of prescription opioids has been directly correlated to the clinical use of these drugs $(120,125)$ and to a generally decreasing trend in illicit drug use (126) (except for cannabis use). The great majority, $70 \%$, of abused psychoactive prescription drugs in the USA are reported to be obtained from a friend or relative, the second most common source being a personal prescription for the drug $(83,123$, 127-129). In only 4\% the drug is obtained illegally. Thus, abused prescription drugs in the US general population appear to derive mainly from the health care system (9-11) and the diversion of prescribed drugs is substantial. Nonetheless, due to selection and reporting bias in these survey studies, the reported estimates may be skewed as regards the involvement of nonprescribed drugs.

While the alarming prevalence and the characteristics of prescription drug misuse and abuse in the USA are now widely described, the literature from other parts of the world is limited (104, 130). The United Nations Office on Drugs and Crime (UNODC) estimates substantial differences between countries with regards to the prevalence both of prescription drug abuse and related deaths $(120,125)$, but the lack of comparable statistics and cultural, health care and 
legislation related factors complicates such comparisons $(124,125,128)$. According to the European Monitoring Centre for Drugs and Drug Addiction (EMCDDA) the prevalence of abuse of prescription drugs is increasing also in Europe (105), although at lower levels than in the USA (125), but the understanding of the extent and characteristics of prescription drug misuse and abuse in the region is limited $(78,104)$. In a systematic review of studies of prescription drug misuse and abuse in Europe, Casati et al found widely ranging European prevalence estimates between $0.4-86 \%$. Compared to the US, a wider range of classes of prescription drugs were reported, including benzodiazepines, opioid substitution drugs (methadone and buprenorphine), opioid analgesics (such as fentanyl, codeine and tramadol) and the z-hypnotics (zopiclone and zolpidem) $(72,131)$. Subsequent research has reported yet other prevalence estimates and the misuse and abuse of additional drug classes $(116,132)$. The Internet is reported to have a growing role in the supply and marketing of psychoactive prescription drugs in Europe, supported by statistics on dramatically increasing illegal trafficking of original and counterfeit drugs (105). Misuse in patients on prescribed treatment $(78,79)$ and substanceseeking in health care is an increasingly but insufficiently described phenomenon $(133,134)$. In summary, non-prescribed drugs may have a more prominent role in prescription drug abuse in Europe compared to the USA, and abuse appears to involve a wider range of drug classes, but the literature is sparse. The risk of an alarming trend in Europe is considered to be low, but continued vigilance is important $(124,135)$.

In Sweden, there is a tradition of a low tolerance to drug abuse, including strict regulations restricting access to psychoactive prescription drugs and punishments associated with drug abuse, linked to low levels of abuse in a global perspective $(125,136)$. Psychoactive medications are only available by prescription and treatment recommendations to prescribers have generally been effective as a means to control inappropriate prescribing. Nonetheless, the misuse and abuse of psychoactive prescription drugs is known since several decades. Reflecting the global development, an emerging drug abuse problem has also received attention during the past years, however, attention has primarily focused on illicit drugs, including "new psychoactive substances" and cannabis (122).

Nevertheless, a considerable share of the drugs available on today's Swedish illicit drug market are prescription drugs. Next to cannabis and stimulants, prescription drugs are the third most common type of abused drug (137). In the past ten years, the benzodiazepines (dominated by diazepam), followed by opioid analgesics (in particular tramadol, oxycodone and morphine), 
opioid maintenance drugs (primarily buprenorphine) and z-hypnotics (zopiclone and zolpidem) have been steadily and increasingly prevalent on the illicit market $(121,137)$. The use of these drugs, obtained illicitly, by personal prescriptions or through diversion, is a well-known and increasing phenomenon in the population of established substance abusers $(121,137,138)$. This has paralleled the decreasing use of some illicit drugs, partly replaced by prescription drugs (such as heroine by buprenorphine). Notably, despite comparatively low levels of life-time ever abuse, today Sweden is reported to be among the European countries with the highest rates of problematic drug use and of drug-related deaths (105).

While misuse and abuse of psychoactive prescription drugs among established substance abusers in Sweden is well-recognised, the extent of this health problem in the general population is largely unknown. In 2011, the Swedish government estimated that prescription drug, next to alcohol addiction, was the most common form of substance use disorder, affecting 65.000 people, or $0.7 \%$ of the Swedish population (139), however, due to the stigma, low rates of diagnosis and treatment and other factors, this was judged likely to be an underestimation and the real figure to be far higher. Indeed, a household survey in 2008-2009 in Swedish inhabitants aged 15 years or above reported a prevalence of prescription drug misuse at any point in time of life (defined as "use without a doctor's prescription or use exceeding the prescribed doses") of $7.7 \%$ in women and $4.4 \%$ in men and a 12 month prevalence of $1.6 \%$ and $1.3 \%$, respectively (140). However, the survey covered only analgesic and sedative drugs controlled as narcotics in Sweden. In an academic household survey in 2010, comprehensively covering all prescription drugs, $2.2 \%$ of the adult general public in Sweden reported 1-month prevalence of drug dependence according to DSM-5 criteria (53). In another general population survey conducted in 2013, 7\% reported past use of an opioid analgesic drug and 3\% use of a sedative or hypnotic drug without a doctor's prescription at any time during the past 12 months, of which, $0.1 \%$ and $0.5 \%$ fulfilled DSM-IV criteria for abuse or dependence, respectively (141). In the 2015 annual school survey in youths, $3 \%$ and $4 \%$ of students aged 16 and 18 years, respectively, admitted lifetime ever use of a sedative or hypnotic drug without a doctor's prescription, and 4 and $6 \%$ admitted such use of an analgesic prescription drug. In total, $6 \%$ and $8 \%$ of school youth aged 16 and 18 years, reported life-time ever non-prescribed use of any such drug (142) (69, 72). Notably, use non-prescribed prescription drugs was not covered. Still knowledge of the extent and characteristics of misuse and abuse of different prescribed and non-prescribed psychoactive prescription drugs in Sweden is poorly understood. The Swedish Council for Information on Alcohol and Other Drugs (CAN) reports the Internet as a new important source of these drugs. 
This is supported by data showing a dramatically increasing trafficking of prescription drugs (original drugs diverted from early stages of the distribution process, or counterfeit drugs) from other countries (138). A proportion of illegal prescription drugs are also reported to be diverted from the health care system $(137,143,144)$, but there is a lack of reliable data.

Thus, global prevalence estimates for prescription drug use disorder, misuse and abuse range widely from 0.01 to $93.5 \%$ (70), depending on the $\operatorname{drug}(\mathrm{s})$, country and study population under study, as well as on the study period and the definition of the measure of misuse. In general, estimates are higher in populations of substance abusers compared to estimates in the general population $(127,144,145)$; for misuse compared to abuse, and abuse compared to prescription drug use disorder $(123,140)$; for non-fatal compared to fatal abuse-related outcomes (110); for composite endpoints compared to single measures (69); and for strong opioid analgesics and benzodiazepines compared to other prescription drugs $(131,146)$. However, conflicting data exist and the true prevalence of misuse and abuse is largely unknown.

\section{Factors associated with psychoactive prescription drug use disorder, misuse and abuse}

Drug addiction is associated with multiple biological, psychological and social factors which interact in a complex pattern, unique of each individual $(5,147,148)$. On the population level, a range of factors have been suggested to drive the current trend of increasing levels of prescription drug misuse and abuse. These include the increased availability to prescribed and illegal prescription drugs, the increased demands for safe and more "controllable" drugs of abuse, as well as decreasing mental health, and culture changes involving a higher acceptance of substance use and higher demands of well-being and functionality $(72,137,149)$.

On an individual level, the risk of misuse, abuse and developing a drug use disorder shows large variations (5). A wide range of risk (and protective) factors have been investigated and suggested. In part, the risk factors appear to partly correspond to the more well-established risk factors of other substance use disorders, however, some risk factors traditionally associated with addiction are not consistently implicated in prescription drug misuse and abuse.

Young age, linked to risk-taking behaviour and other factors, is a well-known risk factor of substance abuse and substance use disorders $(5,150,151)$. Todays increase in the global misuse and abuse of psychoactive prescription drugs is reported to be particularly pronounced in teenagers and young adults (106) and many studies have reported associations of young age with 
both prescription drug misuse and abuse $(127,145,152)$, but conflicting data exist (140).

Notably, in contrast to illicit drugs and alcohol, the exposure to psychoactive prescription drugs increases successively with age as a consequence of increased morbidity, health care consumption and access to prescription drugs. In addition, perceptions of prescription drugs as safer compared to illicit drugs may attract older people (153). Thus, prescription drug misuse and abuse in the adult population and in the elderly should not be neglected (154-155).

While men are substantially more often engaged in illicit drug use and alcohol abuse, this pattern is not consistently reported for prescription drug use disorders, misuse and abuse (125). In fact, prescription drug misuse and abuse have been suggested to be more prevalent in women (125), due to higher prescription rates compared to men, and perceptions of prescription drugs as safe $(72,156)$. As an example, self-reported use of opioid analgesics or sedatives without or outside a doctor's prescription was almost twice as common in Swedish women as in men $(140,148)$. Nonetheless, in many studies have failed in reporting gender associations $(10,116,127,145)$ or have reported associations with male sex $(112,157)$, possible due to gender differences in diversion.

Mental disease is common in both in persons affected by prescription drug use disorder, and in those who misuse and abuse these drugs. This includes disorders such as posttraumatic stress, anxiety, depression, bipolar disorder, and antisocial and other personality disorders (158). Nonmedical use leads to the development of a drug use disorder more often in individuals with preexisting psychiatric diagnoses, and a more problematic drug use pattern and worse outcomes are commonly seen, compared to when such health problems are not present (51,159-163). Prescription drug abuse may, in turn, increase the risk for new onset and recurrence of psychopathology (164). Linked to this, previous medical use of psychoactive prescription drugs is an important predictor of subsequent misuse, and misuse, in turn, is an important predictor of subsequent abuse (165). A history of using medications with addictive properties (such as opioid analgesics), or of disorders requiring such medications (including chronic pain), as well as previous substance abuse, substance use disorder or drug-related crime are all associated with prescription drug abuse in many studies $(116,144,166)$.

Socioeconomic disadvantage (such as unemployment, low educational level, living alone and homelessness) are well known risk factors of substance use disorders (167-169), however, research has failed in establishing a similar pattern for prescription drug misuse. While some studies have reported associations with low socioeconomic status (170), associations with higher 
socioeconomic status is reported to increase the risk in others $(157,170)$. Most studies suggest that prescription drug misuse and abuse occurs across socioeconomic groups $(145,171)$.

Traditionally, drug abuse has been more common in and around urban areas, which is reported also for psychoactive prescription drug abuse (172) in some studies. However, most studies suggest a higher occurrence of prescription drug misuse and abuse in rural areas or in small cities compared to large cities (173-175), while other studies report no difference (176). The wider range of potential sources of prescription drugs (including health care, drugs diverted from health care and the illicit market including the Internet) compared to those of illicit drugs, and worse control of prescribed medications for patients who use cross-regional care, might explain this (83).

Additional factors, such as psychological and psychosocial factors, including personality features (such as impulsivity and coping strategies) $(173)(177,178)$, childhood trauma, perceived quality of life (179), beliefs and social network (144)), as well as family and genetic factors are also likely to affect the risk of prescription drug use disorders and abuse (180), however, due to a lack of information these are commonly not accounted for in register-based studies.

In summary, prescription drug misuse and abuse appears to affect people across sex, age, socioeconomic, medical and other groups, making this an important public health concern. There might be subgroups of individuals affected by psychoactive prescription drug use disorder, misuse or abuse in whom the factors predicting misuse is likely not to be shared $(87,94,181)$. In fact, several reviewers have recently failed in summarising the important risk factors of prescription drug misuse and abuse $(69,72)$. Thus, there are large gaps in the knowledge on the factors associated with psychoactive prescription drug use disorders, misuse and abuse, which limits the possibilities for targeted preventive interventions. 


\section{Examples of psychoactive prescription drugs with concerns on drug use disorder, misuse and abuse}

In this thesis, two psychoactive drugs were evaluated, tramadol (study I-III) and pregabalin (study IV), for which the gradual increase in clinical utilization following marketing authorization has paralleled a growing body of evidence on drug use disorders, misuse and abuse.

\section{Tramadol}

Tramadol has been available in many countries since 1995. It is is an opioid analgesic drug which inhibits the reuptake of serotonin and noradrenaline in the CNS (182). Indicated in moderate acute and chronic pain, tramadol remains one of the most commonly used analgesics in the world. Various studies have been conducted to assess the abuse potential of tramadol, extending from pre-clinical receptor binding studies, studies in substance abusers $(74,183)$, and postmarketing surveillance (184). These have shown that tramadol may induce physical dependence and withdrawal reactions, and is implicated in misuse, abuse and diversion (143), as well as intoxications, emergency department visits (185), and drug-related deaths $(186,187)$. Yet, the addictive properties of tramadol are considered to be low (188-190). Notably, due to other drugrelated problems including some adverse reactions the benefit-risk profile of tramadol at the effective dose is a matter of debate (191).

In Sweden, tramadol has a widespread use as the third most prescribed opioid analgesic drug. While prescribing increased dramatically the first decade after registration, it has decreased since, as a result of regulations classifying tramadol in a schedule of narcotic drugs and following the listing of tramadol as an inappropriate medication in the elderly (192). In Sweden, tramadol is the prescription drug most commonly encountered on the illicit market (138) and one of the most prevalent prescription drugs used by subjects deceased from traffic accidents (193), as in some other countries (187). However, whereas the occurrence of misuse and abuse of tramadol is now recognised, the global prevalence and the relevance of the problem for the patients on prescribed treatment is not fully known. Tramadol is not a scheduled drug in most countries, and as such it is the only clinically available opioid analgesic not under international control $(3,4)$.

\section{Pregabalin}

Pregabalin is a gabapentinoid medication indicated in Europe primarily as an adjunctive and second-line drug in the treatment of epilepsy, neuropathic pain and general anxiety disorder in adults (194). Since the registration in 2004, the clinical utilisation has increased substantially, with 
neuropathic pain being the major indication (195-196) and today, pregabalin is one of the most commonly prescribed drugs in the world (197). The mode of action of pregabalin involves binding to calcium channels in the CNS, leading to properties analogous to the ones of $\gamma$ aminobutyric acid (GABA) (198). In addition, the pharmacokinetic properties including the high potency and fast onset of action have the potential to add to the addictive properties (199).

Studies in recreational drug users indicated subjective psychoactive effects. In clinical trials, 4\% (and 12\% in sub-populations) of subjects treated with pregabalin reported euphoria, and abrupt discontinuation of treatment was found to be associated with withdrawal symptoms (200). However, the pre-marketing program led to conflicting conclusions regarding the abuse potential of pregabalin (200).

Following marketing authorization, observational studies, case reports and meta-analyses of clinical trials have reported euphoria (200), dependence (102, 201), tolerance development and dose increases (202-204), use of supra-therapeutic doses (205), withdrawal symptoms (206), substance-seeking behaviour (132, 207), non-prescribed use and diversion (110, 132, 208), as well as intoxications, drug-related deaths $(110,187)$, and drug-impaired driving (209). Of patients dispensing pregabalin, a small proportion of the users account for a large part of the total drug expenditure $(200,210)$, which might indicate misuse and abuse (79). Increases in the daily dose during prescribed treatment are also reported (203). Daily doses exceeding the clinical recommendation measured by means of prescription fills, further suggest misuse in a proportion of patients $(112,114,211)$. Notably, sub-therapeutic effects of pregabalin are among the most commonly reported ADRs (212), potentially an important cause of treatment discontinuations (195).

In Sweden, pregabalin occurs increasingly among drugs confiscated by the Swedish Police and the Swedish Border Authority (138), and in forensic investigations (unpublished, internal data, National Board of Forensic Medicine). Today, the abuse potential of pregabalin is recognised, but the magnitude of the problem and the relevance to patients remains largely unknown (200). 


\section{Rationale of this thesis}

The harms of prescription drug use disorders, misuse, and abuse are substantial and the consequences extend by far the medical system $(36,103,127,145,213)$. Prescription drug misuse and abuse are associated with a range of serious medical, psychosocial and other adverse shortand long-term outcomes, including intoxications, mental and somatic co-morbidities, and premature death $(36,127,145,213)$. In addition, psychoactive prescription drug use disorders cause considerable loss of psychosocial health and quality of life $(36,127,145,213)$. The stigma, neglect and lack of knowledge further contribute to low treatment rates and high rates of treatment failure, leading to a recurrent need of medical, social and criminal care (36). The economic societal burden is significant (214).

The past two decades witnessed a global rice in this irrational use of psychoactive prescription drugs $(48,105,120)$. Between 1990 and 2010, the global burden of disease from substance use disorders increased by $42 \%$, for prescription opioids only (36). With increased life expectancy and morbidity and a growing access to treatments, the global clinical utilisation of psychoactive prescription drugs is expected to increase further (36). In parallell, the availability to nonprescribed prescription drugs on the illegal market is increasing dramatically (105). Thus, the global exposure to psychoactive medications is expected to increase.

As shown from this introduction, preventing prescription drug misuse has gained considerable attention the past two decades. Today, prescription drug misuse and abuse are globally $(103,153)$ and nationally (139) recognised public health concerns. Yet, prescription drug use disorders are a poorly understood, partly neglected and largely hidden health problem $(103,104)$. A better understanding of the occurrence and prevalence, and the factors associated with the misuse and abuse of different psychoactive prescription drugs are essential to improve the possibilities for preventive clinical and regulatory interventions $(103,139)$. 


\section{AIM AND OBJECTIVES}

The overall aim of this thesis is to estimate the prevalence of psychoactive prescription drug use disorders, misuse and abuse, and to investigate the association with some potential risk factors.

The specific objectives of each study within this thesis are:

I. To investigate fatal unintentional tramadol intoxications and possible risk factors in such intoxications.

II. To investigate the occurrence of tramadol dependence and potential risk factors, using spontaneously reported cases.

III. To determine the prevalence of non-prescribed use of diazepam, flunitrazepam, tramadol, zolpidem and zopiclone among subjects suspected of drug-impaired driving, and identify associated factors.

IV. To identify longitudinal patterns of pregabalin utilisation, with respect to use above the maximum approved daily dose, and investigate associated patient and refill characteristics. 


\section{METHODS}

\section{Study designs}

The papers included in this thesis have investigated different aspects of the occurrence, prevalence and associated factors of psychoactive prescription drug use disorders, abuse and misuse using the study designs as summarised in Table $\mathbf{3}$.

Table 3. Overview of studies in this thesis

\begin{tabular}{|c|c|c|c|c|c|c|c|}
\hline & Design & Data source & $\begin{array}{l}\text { Study } \\
\text { period }\end{array}$ & $\begin{array}{l}\text { Study } \\
\text { population }\end{array}$ & $\begin{array}{l}\text { PPD } \\
\text { studied }\end{array}$ & $\begin{array}{l}\text { Outcome } \\
\text { measure(s) }\end{array}$ & $\begin{array}{l}\text { Statistical } \\
\text { analysis }\end{array}$ \\
\hline I & $\begin{array}{l}\text { Case } \\
\text { series }\end{array}$ & $\begin{array}{l}\text { National forensic } \\
\text { pathology } \\
\text { database, } \\
\text { National forensic } \\
\text { toxicology } \\
\text { database }\end{array}$ & $\begin{array}{l}1995- \\
2005\end{array}$ & $\begin{array}{l}\text { Subjects } \\
\text { deceased in } \\
\text { unintentional } \\
\text { fatal intoxication } \\
(\mathrm{n}=17)\end{array}$ & Tramadol & $\begin{array}{l}\text { Occurrence of } \\
\text { fatal intoxications. } \\
\text { Subject } \\
\text { characteristics. }\end{array}$ & Descriptive \\
\hline II & $\begin{array}{l}\text { Case } \\
\text { series }\end{array}$ & $\begin{array}{l}\text { Swedish database } \\
\text { for spontaneously } \\
\text { reported ADRs } \\
\text { (SWEDIS) }\end{array}$ & $\begin{array}{l}1995- \\
2006\end{array}$ & $\begin{array}{l}\text { Spontaneously } \\
\text { reported cases of } \\
\text { dependence } \\
(n=104)\end{array}$ & Tramadol & $\begin{array}{l}\text { Occurrence of } \\
\text { dependence. } \\
\text { Patient } \\
\text { characteristics. }\end{array}$ & Descriptive \\
\hline III & $\begin{array}{l}\text { Cross- } \\
\text { sectional } \\
\text { case } \\
\text { study }\end{array}$ & $\begin{array}{l}\text { National forensic } \\
\text { toxicology } \\
\text { database, } \\
\text { SPDR, LISA, } \\
\text { Geography } \\
\text { database }\end{array}$ & $\begin{array}{l}2006- \\
2009\end{array}$ & $\begin{array}{l}\text { Subjects } \\
\text { suspected of } \\
\text { DUID with } \\
\text { confirmed intake } \\
\text { of a PPD } \\
(n=2225)\end{array}$ & $\begin{array}{l}\text { Dia- } \\
\text { zepam, } \\
\text { flunitra- } \\
\text { zepam, } \\
\text { tramadol, } \\
\text { zolpidem, } \\
\text { zopiclone }\end{array}$ & $\begin{array}{l}\text { Prevalence of non- } \\
\text { prescribed use. } \\
\text { Association } \\
\text { between non- } \\
\text { prescribed use and } \\
\text { patient and } \\
\text { toxicology factors }\end{array}$ & $\begin{array}{l}\text { Descriptive } \\
\text { Multiple } \\
\text { logistic } \\
\text { regression. }\end{array}$ \\
\hline IV & $\begin{array}{l}\text { Longitudi } \\
\text { nal } \\
\text { cohort } \\
\text { study }\end{array}$ & $\begin{array}{l}\text { Swedish } \\
\text { Prescribed Drug } \\
\text { Register (SPDR) }\end{array}$ & $\begin{array}{l}2007- \\
2008\end{array}$ & $\begin{array}{l}\text { Patients initiating } \\
\text { prescribed } \\
\text { treatment } \\
(\mathrm{n}=46,756)\end{array}$ & $\begin{array}{l}\text { Pregabali } \\
\mathrm{n}\end{array}$ & $\begin{array}{l}\text { Prevalence of use } \\
\text { above the MAD. } \\
\text { Long. utilisation } \\
\text { patterns and } \\
\text { associated factors. }\end{array}$ & $\begin{array}{l}\text { Descriptive } \\
\text { Group- } \\
\text { based } \\
\text { trajectory } \\
\text { modeling }\end{array}$ \\
\hline
\end{tabular}

ADR: Adverse drug reactions; DUID: driving under the influence of drugs; LISA: Longitudinal integration database for health insurance and labour market studies; MAD: maximum approved daily dose; PPD: psychoactive prescription drug; SPDR: Swedish prescribed drug register; SWEDIS: Swedish drug information system. 


\section{Data sources and study populations}

Sweden has a long tradition of collecting national, population-based information on demography and health $(109,215)$. The National Board of Health and Welfare has the overall responsibility for the collection of epidemiological data and keeps several national health data registers (216), such as the Cause of Death Register, the Hospital Discharge Register and the Swedish Prescribed Drug Register (SPDR) (111). Many authorities also maintain similar registers and, as most of these registers include the ten-digit personal identification (or social security) number, which is unique to every Swedish citizen, individual-level data may be collected and more information may be acquired through individual-level linkage of data from several registers (record linkage).

This thesis utilized information on forensic cause of death investigations, forensic toxicology investigations, dispensed prescription drugs, socioeconomic factors and registered residency, from five national registers. In Paper I the National forensic pathology and toxicology databases were used to identify and describe fatal intoxications with tramadol. The National forensic toxicology database was also used in Paper III to identify suspected drug-impaired drivers using five predefined psychoactive prescription drugs, and to investigate the importance of toxicology data for non-prescribed use of those drugs. In Paper III, the SPDR was used to determine whether use of the drugs was prescribed or not. This register was also used in Paper IV to identify patients who initiated prescribed treatment with pregabalin, and to assess drug utilisation.

In Studies I and II, the study results were related to population-level information on total sales of tramadol during the study periods (217). In Studies III and IV, individual-level information on socioeconomic variables (Study III) and on registered residency (Studies III and IV) were linked, to allow the assessment of potentially important associated factors and the adjustment of some potential confounders. This information was retrieved in Study III from the Longitudinal integration database for health insurance and labour market studies (LISA) and the Geography database, Statistics Sweden, and in Study IV from the SPDR.

\section{The national forensic pathology and toxicology databases (Paper I and III)}

The National Board of Forensic Medicine is responsible for all forensic toxicology and forensic pathology investigations in Sweden, including forensic cause of death and investigations for drug-impaired driving. When certifying a death, physicians are obliged to report all suspected unnatural fatalities to the police. In most of these cases, the police will request a forensic 
autopsy. Approximately 5000 autopsies (about 5\% of all fatalities) are conducted at six regional departments in Sweden each year. During autopsy, femoral blood, urine and vitreous humour are collected when available, and analysed as regards the presence of prescription drugs, illicit drugs and ethanol. The diagnosis of a fatal intoxication is based on the toxicology results, autopsy results and information in the police reports and other available relevant documentation. The manner of death is assessed by the forensic pathologist as unintentional (i.e. accidental), intentional (suicide or homicide) or undetermined. Suicide is considered whenever any expression of intent of the decedent is found, e.g. expressions of farewell, hopelessness or great stress, desire to die, efforts to prepare for death or to avoid being rescued, previous suicide attempt or suicide threat and recent history of significant losses, severe depression or mental disorder (218). Unintentional manner of death is considered when the forensic pathologist does not find any sign of suicidal intent. The manner of death remains undetermined if neither intentional nor unintentional manner of death can be established. The cause of death is finally registered using the International Classification of Diseases codes, ninth revision (ICD-9) (219).

Since 1999, Sweden has had a zero tolerance law for driving under the influence of psychoactive prescription drugs that are controlled in a schedule for narcotic drugs according to the Medical Products Agency (MPA) (2). The classification of psychoactive prescription drugs in Sweden, is in accordance with international classifications $(3,4,220)$ and, as in some other countries the Swedish classification comprises an additional class (class V) and additional drugs (including zopiclone and tramadol $(98,99))$. Driving under the influence of such drugs used without a prescription or used outside the prescribed instructions or product recommendations, is a crime (221). When an individual is suspected of driving under the influence of drugs (DUID), on account of a traffic accident, inappropriate driving behaviour, and at random stop-checks, the Swedish police is authorized to perform a field breathe test and collect a blood sample from the driver. A positive blood sample is required to prosecute a driver.

Samples for forensic toxicology analysis are sent to a national accredited laboratory, the Department of Forensic Genetics and Forensic Toxicology at the National Board of Forensic Medicine, where toxicological analyses are performed according to standardised screening and verification procedures to determine the presence and concentrations of alcohol and illicit as well as prescription drugs that may explain a death or affect driving ability (193, 221-222). In death investigations, illicit drugs are screened for only upon request by the responsible pathologist, based on circumstantial information and autopsy findings. In DUID investigations, the toxicology analysis includes illicit drugs as well as controlled psychoactive prescription drugs, 
although the verification depends on the results of the initial analysis (i.e., if alcohol is identified at the breath test or an illicit drug is identified at screening, prescription drugs may not be further determined).

Since 1992, the results from all forensic cause of death and forensic toxicology investigations are registered in two national databases, the Forensic pathology database (RättsBase) and the Forensic toxicology database (ToxBase), including personal identifier, age and sex of the subject under investigation, date of the death or the DUID arrest, information on cause and manner of death (in cause of death investigations), the presence and concentrations of alcohol, illicit drugs and prescription drugs, and any other non-mandatory information provided in narrative text by the responsible pathologist or the police (223). Examples of non-mandatory data include information on medical history, history of substance use disorder or substance abuse, and on prescribed treatments.

In Study I of this thesis, the study population of fatally intoxicated individuals were identified in the forensic pathology database based on the ICD-9 diagnose coding of the primary cause of death as assessed by the forensic pathologist (219). Specific ICD-9 diagnose codes exist that describe i.e. accidental poisoning by non-narcotic analgesics (E850.7). However, as the application of ICD coding is not standardised, a broader search was conducted including all accidental intoxications (codes 965-980, excluding suicides, homicides and uncertain deaths (E950, E962 and E980)). The role of the drug was ascertained as only cases with wit toxic concentration of tramadol were included (224).

In Study III, suspected drug-impaired drivers were identified in the forensic toxicology database, based on the prescription drugs identified upon toxicology analysis. Drivers with a confirmed intake of diazepam, flunitrazepam, tramadol, zolpidem and zopiclone were included, as these prescription drugs had different degrees of previously documented abuse potential $(3,4,220$, 225) and were relevant to the Swedish drug abuse and DUID scene at the time of the study (24, 193, 221, 226, 227).

\section{The Swedish database for spontaneously reported adverse drug reactions (Paper II)}

Spontaneous reporting of suspected adverse drug reactions (ADRs) is a crucial source for detection of previously unrecognised ADRs of marketed drugs (228). In Sweden, the ADR reporting system was established in 1965 (215) and since 1975 it is compulsory for health professionals to report suspected ADRs. During the study period of paper II physicians, dentists 
and nurses were obliged to report serious ADRs, ADRs not mentioned in the summary of product characteristics (SPC), ADRs related to the use of new drugs ( $<2$ years on the market) except those labelled as common in the SPC, and ADRs that seem to increase in frequency or in seriousness. Until June 2012, six regional pharmacovigilance centers in Sweden handled and assessed the spontaneously reported suspected ADRs within their region, followed by an evaluation at the national level at the Medical Products Agency (MPA).

The causal relation between the medication and the suspected ADR was assessed. Numerous causality assessments algorithms have been proposed throughout the years $(229,230)$. In Sweden, causality of reported ADRs is assessed on the basis of available information, according to WHO definitions as follows (24): Certain: plausible time relationship to drug exposure, positive dechallenge and rechallenge; Probable: reasonable time sequence to drug exposure, positive dechallenge, other explanations are unlikely; Possible: reasonable time sequence to drug exposure, possible lack of dechallenge, other possible explanations may exist; Unlikely: unreasonable time sequence to drug exposure and other plausible explanations exist; Unclassified: more data is needed for a proper assessment or additional data is being examined; or Unclassifiable: insufficient or contradictory information that cannot be supplemented or verified.

Drugs are listed as being suspected of having caused the reaction, as interacting with other prescribed drugs or as concomitant medication not related to the ADR. ADRs in Sweden are further classified and diagnosed according to the World Health Organization Adverse Reaction Terminology (WHO-ART (231)). This is a hierarchical categorization of ADR diagnoses and includes medical terms clustered into organ classes. A suspected ADR is considered serious if fulfilling any of the criteria for seriousness as follows (66): the ADR resulted in death, was lifethreatening, required inpatient hospitalisation or resulted in prolonged existing hospitaliation, resulted in persistent or significant disability or incapacity, was a congenital anomaly or birth defects, or of any other reason is to be considered a medically important reaction (such as a reaction that that might not be immediately life-threatening or result in death or hospitalisation but might jeopardize the patient or might require intervention to prevent one of the other outcomes listed in the definition above). Drugs are coded according to the Anatomic Therapeutic Chemical (ATC) classification system (232).

Information from each ADR report, including mandatory information on the patient, the suspected ADR, the suspected drug, the reporter and results from causality assessment and 
administrative data, as well as any non-mandatory information on co-morbidities, comedications, outcome or other information provided in narrative text, is registered in the national database, Swedish Drug Information System (SweDIS).

In Paper II, information from SweDIS was used to identify and describe spontaneously reported cases of tramadol dependence. As several WHO-ART terms exist that are related to drug use disorder and drug dependence reports diagnosed with either of the following terms were reviewed: Dependence, Addiction, Tolerance increased and Withdrawal syndrome (231). Moreover, reactions coded as Paraesthesia, Hyperhidrosis, Tremor, Anxiety, Irritation, Sleep disorder, Palpitation and Hallucination were considered to be possible withdrawal symptoms and were also reviewed. Only ADRs judged to be at least a possibly related with tramadol and that fulfilled the criteria of substance dependence of DSM-IV (67) were included.

\section{The Swedish Prescribed Drug Register (Papers III and IV)}

The Swedish Prescribed Drug Register (SPDR) is a national register established in 2005, which includes information on all drug prescriptions filled in ambulatory care (i.e. drugs dispensed in outpatient pharmacies) in Sweden, irrespective of reimbursement status (111). In Sweden, the health care system is tax-supported and provides access for all citizens, irrespective of factors such as age and socioeconomic status, including employment (109). Prescribed drugs are partly or fully reimbursed, and the reimbursement system restricts the maximum cost of prescribed drugs to 1800 SEK (approx. 180 Euros) per patient and year.

In Sweden, prescription fills are allowed to cover a maximum of three months expenditure, and there is a minimum of 2 month intervals between dispenses (drugs prescribed for intermittent or sporadic use excluded). Prescriptions are valid up to 1 year after the issue date and normally cover 4 dispenses. Of all prescriptions, 98\% are issued electronically (233) (130). Prescription drugs that are controlled by the MPA in any of the schedules for narcotic prescription drugs (classes II-V) are associated with several restrictions in prescribing (involving prescriber authorizations, specific prescriptions forms, electronic prescribing, phoned prescriptions, foreign prescriptions, prescription validity time and iterations), in dispensing (requirements of personal ID document), and in transport across country borders (which is only allowed in the presence of a valid prescription and in amounts needed for, for example the duration of a vacation (class $\mathrm{V}$ excluded)). Multi-dose dispensed drugs (ApoDos) are provided for individuals who cannot themselves manage their medication in a safe and satisfactory manner (234), such as persons with multiple medications, most residents in nursing homes and some persons with substance 
use problems. Patients with multi-dose dispensed medication receive medications automatically at predetermined time intervals (often every other week). Multi-dose dispensed drugs are included in the SPDR, with the exception of the information on the individual prescribed dosing regimen.

Information for each drug dispense (or prescription fill) includes in the SPDR: the date of prescribing and of dispensing; a unique person identifier, age, sex and place of residence of the patient; dispensed drug product and volume; profession, specialty and unique code of the practice of the prescriber, and drug costs (111). Over-the-counter medications and drugs used in hospital clinics are not covered by the register, and the register is not complete for drugs used in nursing homes and in hospital day care. Information on indication and individual prescriber identifiers are not available, and prescribed dosing regimens are available in narrative format only. Drugs are classified according to the ATC system (35).

In study IV, the SPDR was used to identify patients who initiated treatment with pregabalin, defined by the ATC code N03AX16 (35) and based on a 12-month waiting period to identify incident users (235). The SPDR was also used in this study to calculate the outcome variable and to describe characteristics of pregabalin dispensing (referred to as refill characteristics). In Study III, data on drug dispenses in the SPDR for the 12-month period preceding the DUID were linked to toxicology data on confirmed drug intake to assess non-prescribed use of these drugs.

\section{Case assessment}

\section{Assessing drug utilisation}

In Study I and III, as opposed to classical drug utilisation studies (13, 79, 236) (13), drug use at death or DUID arrest was determined using toxicology analysis results, where the presence of a certain drug upon toxicology analysis of blood confirmed its use (i.e., a binary variable measuring an intake of the drug or nor). Whether this drug use was prescribed or not was then further determined in Study III using drug dispensing data.

In Study II, the drug use suspected to have caused the ADR was provided as mandatory information by the reporter. Also non-mandatory information on drug use was provided in a proportion of the reports, including information on duration of use, and drug doses or volumes used. Drug utilisation in this study was presented descriptively and was not further assessed, due to the limited validity of such data and the small sample size. 
In Study IV, drug utilisation was based on data on drug dispensing of pregabalin during a fiveyear period, used to estimate the daily dose of the drug for each day of the observation period. Drug utilisation in this study was assessed longitudinally to assess individual-level variation over time in drug use.

\section{Defining psychoactive prescription drug use disorder, misuse and abuse}

In all studies within this thesis, different and complementing indicators of psychoactive prescription drug use disorder, misuse or abuse were assessed. In Study I, the indicator was fatalities undergoing forensic investigation where the diagnosed primary cause of death was an accidental fatal intoxication with tramadol defined by ICD-9 codes(219). Drug use was ascertained by accredited toxicological laboratory analyses confirming the post-mortem presence of drug in blood. The role of the drug was ascertained as only cases with toxic blood concentrations (245) of the drug and in which the drug was assessed to have at least a contributory role in the death were included. Historically, data on trends in drug-related deaths involving a certain drug have been crucial indicators of substance abuse (46-47, 60). However, the relation between the fatal intoxication cases and any misuse or abuse of the drug was not possible to establish given the available data.

In Study II, spontaneously reported cases of ADR terms possibly related to drug dependence were used as indicator of substance use disorder. The relation of the reported ADR to substance us disorder was strengthened by re-assessing the reports against DSM-IV criteria of drug dependence (67), which was conducted by a pharmacist and discussed with a clinical pharmacologist in case of ambiguities. The role of the drug was further strengthened by selecting only cases in which the causal relationship between the drug and reported ADR was assessed as at least possible. The relation to any prescribed treatment or misuse or abuse of the drug could not be systematically established due to the nature of the data, but was presented descriptively when available.

In Study III, non-prescribed use of psychoactive prescription drugs identified in blood at forensic toxicology analysis was used to indicate abuse (referred to as diversion in the manuscript). Non-prescribed use was defined as a confirmed intake of the psychoactive prescription drug in a subject by whom the drug (by ATC code level 5 (232)) was not dispensed in the 12 months preceding the DUID arrest and toxicology sampling (or index date). The 12 
month cut-off was chosen taking various aspects into account, including the 1-year prescription validity time in Sweden, the Swedish drug reimbursement system allowing dispenses for a maximum of three months expenditure as well as the incidence rates (79), prolonged waiting time periods (235) and stock-piling of drugs used intermittently, but was also limited by the available data, particularly the lack of historical dispensing data before July 2005 (111). The cutoff was also compared to a 6-month cut-off.

In Study IV, drug dispenses of pregabalin corresponding to a daily dose above the maximum approved level of $600 \mathrm{mg}$ (194) was used to indicate misuse, in turn an indicator of potential abuse (79). Of the various methods to assess drug utilisation based on dispensing data described to date, the proportion of days covered (PDC) method is among the most established (237-240). This and similar calculations reduce a complex pattern of observations down to a single number. As a result, there are limitations in their ability to distinguish different observational patterns. For example, identical PDC values may be calculated for patients with intense high intermittent use interrupted with gaps in use, continuous normal use, and gradually increasing use (241), differences which are of high relevance in drug abuse research (5). Moreover, the PDC relates the pattern of drug dispenses to the personally prescribed daily dose or the defined daily dose of the drug (the average daily dose of the drug used in its main indication (DDD)(232)).

As psychoactive drugs are often prescribed for intermittent use, calculations based on prescribed dosing regimens may be less useful. Moreover, although the DDD is the most widely used and accepted unit for measurement of drug utilisation (242-244), it may be less relevant in studies of misuse and abuse. The maximum approved dose (MAD) may be more useful, is explicitly defined and is also more stable across approved indications $(35,194)$. In the case of pregabalin, the MAD of $600 \mathrm{mg}$ is liberal considering the DDD of $300 \mathrm{mg}$ and the average dose of $150 \mathrm{mg}$ (194-195, 211). In two recent studies Bodén et al. (114) and Scherning et al. (112) used two different measures of use, both related to the MAD of pregabalin of $600 \mathrm{mg}$. The measure of Bodén et al. have the advantage of having a simple application and not to require data for a long period of time, whereas the definition by Schjerning et al. have the advantage of being less sensitive to occasional periods of early refills or occasional large dispensings. However, neither the PDC nor these measures allow to estimate the dose for each day of a long observation period and reflect variations over time in drug use. 
Blanch et al. (69) recently suggested four proxy variables of misuse: number of prescribers, number of dispensing pharmacies, early refills and volume of drugs dispensed. The definition of these measures was, however, not further provided.

In Study IV, the daily dose definition relates the dispensed volume of drug to the time period running between two dispenses, and as such is a reflection both of early refilling and of volume of dispensed drugs. The average daily dose of each treatment period was calculated based on the amount of drug supplied divided by number of days in the period. For each patient, all pregabalin fills during the 5 -year period were registered and described in terms of treatment periods, under the assumption that each period started on the day of a fill and continued without interruption until the day before the next fill. When more than one fill for pregabalin was registered in one day, fills were merged in this calculation. If there was a gap of $>180$ days between two consecutive fills, the treatment period was truncated at 180 days after which the daily dose was set to 0 . In instances of re-dispensings the daily dose was re-populated.

Hence, a dose for each day of the patient's total 1825 day observation period was estimated. A binary outcome variable measuring use above the maximum recommended dose of pregabalin or not, was created. Finally, as pregabalin is primarily used as a second-line treatment some patients may require regular prescriptions of higher-than-approved doses $(6,195)$. To reduce the sensitivity of our measure for occasional early refills or dispensing of large volumes, we therefore allowed one treatment period of use above the MAD. In summary, this definition allowed us to capture persistent as well as intermittent use of doses above the MAD and to describe variations in drug use, and also allowed fairly good comparison to the previous studies $(112,114)$.

\section{Assessing associated factors}

In Study I, information on sex, age and the confirmed concomitant use of other prescription drugs, illicit drug and alcohol (as included in screening and verification) were available. Due to the small study population, these were presented descriptively. Information on other potentially important patient and background factors, such as socioeconomics and place of residence, were not available. Unvalidated information on medical history and on concomitant medication is provided by the reporting police in some reports but did not enable systematic presentation or advanced statistical analysis. Thus, any independent associations could not be established.

In Study II, which was based on spontaneous reports, age and sex were the only patient factors provided in all reports, as these are among the few mandatory variables. Narrative information 
on indication, dosages, medical history, any history of abuse, and on past or current prescribed co-medications were occasionally provided by the reporter, but did not enable systematic presentation or advanced analysis. Thus, any independent associations could not be established.

In Study III, information on factors potentially associated with non-prescribed use included: age and sex at the arrest; highest attained educational level, marital status, individual income category, country of birth and place of residence (living in a large city region or not) for the half-year of the arrest; toxicology analysis results (including blood concentrations of the drug, and the presence in blood of other identified prescription drugs, illicit drugs and alcohol), and DUID history. Low, middle and high income levels were defined as the 25, 25-75 and 75 percentiles for the Swedish general population >15 years in the year 2008 as follows: 25\%: 107.436 SEK, 2575\%: 107.437-303.958 SEK, 75\%: 303.959 SEK, where 1 SEK = USD 0.107 (Personal communication. Statistics Sweden, 2015). Controlled drugs were defined as prescription drugs scheduled in classes II-V and illicit drugs as drugs scheduled in class I in Sweden (2). Prescription drugs were sub-categorized according to the ATC system (232). Drug concentrations were assessed in relation to their therapeutic intervals according to TIAFT (245).

In Study IV, the association of some background factors (referred to as predictors of) with each trajectory (i.e. each utilisation pattern) included age, sex, and place of residence for the index date, and dispensed prescribed co-medications for the 12 months before the first fill for pregabalin. The selection of factors was based on previously reported factors associated with use of pregabalin above the MAD (such as recent treatment with an antiepileptic drug $(112,114$, 200)) and some well-established risk factors of substance use disorders in general $(150,172,246)$, and was limited by the available data in the SPDR. Prescribed co-medications were defined and categorized according to the ATC system (232). Controlled drugs were defined as prescription drugs listed in any schedule of the Swedish classification of narcotic drugs (2) which corresponds to international classifications $(3,4)$.

In Study IV the pregabalin fills for the 5-year study period were described by trajectory, on the basis of variables previously shown to characterise misuse and abuse of prescribed drugs and substance-seeking behaviour. These variables included filled drug volumes, time intervals between fills, and the number of issued prescriptions and prescriber regions for a drug $(69,70)$. Due to limitations in the SPDR (111), which does not include unique prescriber identifiers, the number of prescribers (69), an indicator of "doctor-shopping", could not be assessed. Likewise, 
the relation between the individually prescribed daily dose and the dispensed daily dose, which may indicate misuse or abuse (5), was not assessed.

\section{Statistical analysis}

In Study I and II, all cases fulfilling the predefined study criteria were included without sampling. The registered variables, as available, were presented descriptively using proportion of all cases $(\%)$, and median values and ranges as summary measures. The use of medians and ranges was considered appropriate as most variables showed asymmetric distributions (which was expected due to the diverse nature of fatal intoxications, spontaneous reports and the small sample sizes) and to allow presentation of heterogeneity and extremes.

In Study III, the 3-year prevalence proportion of non-prescribed use was calculated for each drug. A sensitivity analysis was conducted in which the 12 month cut-off of the outcome variable was compared to a 6-month cut-off. Descriptive statistics were used to characterise the population. The use of medians was considered appropriate as the response (and other) variable showed asymmetric distribution. The use of ranges was considered appropriate to reflect the heterogeneity of the population and extremes. The adjusted association between the exposure variables and non-prescribed use was assessed using separate logistic regression models, one for each drug. In a first step, all covariates yielding a p-value of $<0.25$ in the global likelihood ratio test were included. In the subsequent final regression model covariates with $\mathrm{p}$-values $\geq 0.05$ were excluded and p-values $<0.05$ and 95\% confidence intervals (CIs) considered statistically significant. Forced inclusion of age and sex was applied in both steps. The regression model was restricted to individuals with complete covariate information.

In study IV, all patients who initiated medication with pregabalin and who fulfilled the study inclusion criteria were included without sampling. Group-based trajectory modelling (GBTM) was used to classify patients by their observed risk of filling doses above the maximum approved dose. Describing changes in health measures over time and studying their causes is crucial within some scientific disciplines such as psychology and sociology, where the study of long- and shortterm addiction trajectories is widespread (247-250). Introduced in 1993 by Nagin and Land (251), the GBTM method has become the statistical method of choice for studying and explaining problem behaviours (252). In 2013, Franklin et al. proposed the use of this method as a new approach for classifying and predicting data on prescription fills (241). 
Group-based trajectory modelling was used in Study IV as it is useful for the identification of unknown or hidden (i.e. latent) homogeneous groups of individuals in a heterogeneous population based on longitudinal changes in an outcome (241). This was of relevance to the study aim and to the previous knowledge on substance use disorders where gradually increasing or supra-therapeutic doses is typical (67). Moreover, the previous literature on pregabalin reported tolerance $(202-204,253)$, use of high doses in some patients $(112,114,187,208-209$, $211,254)$, and large inter-individual variations in drug use over time $(195,205)$. In alternative longitudinal approaches such as survival analysis, the time to, and risk of, an outcome is measured, but variations over time are not captured. Repeated measures techniques, latent class growth mixture modelling (255), k-means clustering (256), and latent class analysis (257), are similar, but GBMT has been shown to perform favourably and to be technically advantageous. Moreover, GBTM allows the simultaneous adjustment for confounding factors and the investigation of factors associated with each identified sub-group, an aim of our study and important as substance use disorders are multifactorial (147).

In a trajectory model, several regression models are estimated simultaneously (241) as the model is a mixture of binary logistic regression for the trajectories and multinomial logistic regression for the group membership. In Study IV, the trajectories describe each individual's probability (referred to as risk) of exceeding the maximum approved dose of pregabalin as a function of time. The term "risk" was chosen, as the safety and tolerability of a medication has not been studied and is therefore not known when the drug is used outside the approved label (258). We modelled 61 binary indicators, where the time variable was number of months since the index date, due to limitations in data processing capacity. Models using 2-7 groups were estimated, as more than 7 groups would be difficult to interpret and less clinically meaningful. We finally choose the 5-group model (Figure 2) based on median group membership probabilities, the Bayesian Information Criterion (BIC) values, and as the additional trajectories in the 6 and 7group models added limited information. As the group of lowest risk was not considered to be the only useful or relevant reference group two separate models were run using Trajectory groups 1 and 5 as references. When comparing to a 3 -year model similar trajectories as well as associated factors were identified. Similarly, as data was not available on patients dying or emigrating during the study, a sensitivity analysis was performed which excluded all individuals with a gap in recorded prescription fills for any drug in the SPDR more than 180 days prior to the end of the study period. There was neither major change in the trajectories nor in the associated patient characteristics compared to the main analysis. All analyses in Study IV were 
restricted to patients with complete co-variate information. The final co-variates were selected to the models based on clinical judgement combined with correlation analyses using a liberal correlation coefficient limit of 0.7 . Factors were considered significantly associated if $\mathrm{p}<0.05$.

Descriptive statistics were used to characterise the population, by trajectory. The use of medians was considered appropriate as the response variable showed asymmetric distribution. The 2-year prevalence proportions of pregabalin use above the maximum approved daily dose was assessed, which was compared to sensitivity analyses using daily doses of pregabalin above $1200 \mathrm{mg}$ (double the maximum approved dose) and $300 \mathrm{mg}$ (the DDD) as cut-offs. The prevalence proportions of each trajectory were also described. The $1^{\text {st }}$ and $5^{\text {th }}$ percentiles of Lorenz curves (79) were also assessed to describe the distribution of the total pregabalin utilisation in the population, for the full 5-year observation period and the first year after index date, respectively, as these measures may reflect the distribution of the drug consumption among the patients and indicate misuse (79).

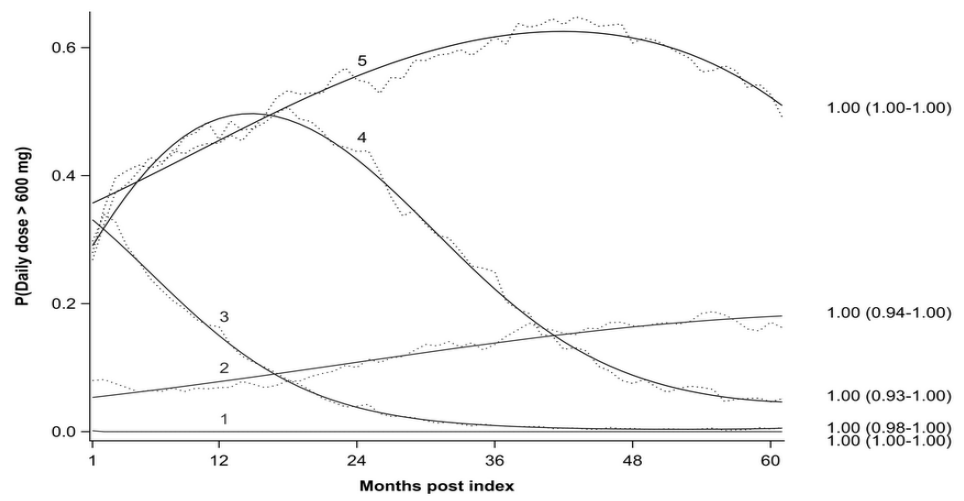

Fig 2. Distinct longitudinal patterns of pregabalin utilisation, with respect to probability (or risk) of a daily dose above the maximum approved dose (MAD) of $600 \mathrm{mg}$, among patients ( $\mathrm{n}=$ $46,756)$ initiating pregabalin treatment. The predicted probability of a daily dose above the MAD is shown with solid lines (observed proportion of individuals plotted with dotted lines). Median (and interquartile range) trajectory membership probabilities by group assignment are shown at the right. 


\section{Ethical considerations}

The studies within this thesis presented ethical challenges due to the handling of sensitive personal data without informed consent of study participants. Data were protected from being available to persons other than the researchers by confidential handling and storing, and the researchers involved were committed to professional secrecy. In Study III, data from the respective registers were linked individually using the personal ID number and replaced by a serial number at Statistics Sweden, before data were returned to the researchers. In Study IV, the study population was identified at the National Board of Health and Welfare, and the personal ID number replaced before data delivery to the researchers. In all studies, results were presented as unidentified cases (Study I-II) or at an aggregated level (Study III-IV). Thus, integrity of the study subjects was ensured. The studies were undertaken in accordance with the Declaration of Helsinki (259) and ethical principles of Good Pharmacoepidemiology Practices (GPP) (260).

In general, approval by an Institutional Review Board (IRB), Independent Ethics Committee (IEC), or similar body, should be obtained for all research involving human subjects $(259,260)$. However, in Studies I and II ethical approval was not sought, as ethical approval of these studies by a Regional Ethical Review Board was not required by Swedish law at the time of these studies. In study I, forensic data concerning deceased persons were assessed as part of the mandatory mission and regular activities the National Board of Forensic Medicine. Common practice did not involve the application of ethical approval when conducting such evaluations. In addition, as the study concerned deceased subjects, the Personal Data Act (261) and the Act on Ethical Review of Research Involving Humans (262) were not applicable. Study II used anonymized register data from the Swedish database of spontaneously reported ADRs. The study was conducted at one of the regional pharmacovigilance centers linked to the Medical Products Agency (MPA). The mission of the agency includes the continuous evaluation of routinely collected data from spontaneous reports. Common practice at the time of the study did not involve the application of ethical approval when conducting such evaluations. Nonetheless, before Studies I and II were started the projects were analyzed by the researchers from an ethical point of view. Study III in this thesis was approved by the Regional Ethical Review Board in Linköping, Sweden (M194-09). Study IV was approved by the Regional Ethical Review Board in Uppsala, Sweden (2011/036/1 and 2011/036/2). This research was considered to contribute to the knowledge on psychoactive prescription drug use disorders, misuse, and abuse and the expected benefits to outweigh the risks of integrity violations for the study subjects. 


\section{RESULTS}

\section{Fatal unintentional intoxications with tramadol (Paper I)}

During the 10-year study period tramadol was detected in $837(2 \%)$ of the 49700 forensic death investigations. Of these cases, tramadol was assessed to contribute to the death in $148(50 \%)$ of 297 cases where intoxication registered as the cause of death. In 17 (11\%) of the 148 cases the manner of death was assessed as unintentional.

Of the 17 cases, $11(65 \%)$ involved men and $6(35 \%)$ involved women. The median age was 44 years (range 18-78 years). The median femoral blood concentrations of tramadol and $\mathrm{O}$ desmethyltramadol were 2.0 (range 1.1-12.0) and 0.3 (range $0.1-1.1) \mathrm{mg} / \mathrm{g}$, respectively. In all cases, other substances were detected in addition to tramadol, of which psychoactive substances in 16 cases (94\%). Most commonly, opioids, benzodiazepines, substances acting on serotonergic system and/or ethanol were detected. Illicit drugs were detected in four (24\%) cases. Tramadol was the only substance present in toxic concentrations in seven cases. In 10 cases (59\%) multiple drug intoxication was assessed as the cause of death.

A documented history of substance abuse was present in 14 subjects (82\%). The purpose of tramadol intake was generally difficult to assess. In seven (58\%) of the 12 cases where the source of tramadol was known, the drug had been prescribed to the subject, and $2(17 \%)$ subjects had obtained tramadol from a relative. Illegal obtainment was reported in two $(17 \%)$ subjects.

\section{Spontaneously reported tramadol dependence (Paper II)}

Of 550 spontaneous reports concerning tramadol during the 12-year study period a total of 104 $(18.9 \%)$ were assessed as tramadol dependence. Of the 104 patients, 60 (57.7\%) were women and the median age (and range) was 45 (15-84) years).

The reported MeSH terms were distributed as follows: withdrawal syndrome (more than one possible withdrawal symptom reported) 36 (34.6\%); addiction 28 (26.9\%); dependence 19 $(18.3 \%)$; increased tolerance $11(10.6 \%)$, and withdrawal symptom 30 (28.9\%) cases. Tramadol was the only suspected drug in $90(86.5 \%)$ cases. In $13.5 \%$ of the cases other psychoactive drugs, most commonly codeine, were also suspected to have caused the ADR. 
A history of substance abuse was reported in 31 (29.8\%) of the patients, and in $41(39.0 \%)$ patients there was a documented past use of another psychoactive drug of abuse within the last 10 years, implicating another opioid analgesic drug i $2 / 3$ of the patients. However, in $69.2 \%$ and $40.4 \%$ of the reports, respectively, no such information was available. In total, a history of either substance abuse and/or use of drug(s) of abuse was reported in $46(44.2 \%)$ patients.

Information regarding concomitant medication was available in $75(72.1 \%)$ reports. The drugs most frequently used in combination with tramadol were other psychoactive drugs $(61.3 \%)$, including a benzodiazepine (15.3\%) or other sedative (21.3\%), but also antidepressant drugs $(17.3 \%)$, another opioid analgesic $(18.7 \%)$.

Information on the prescribed dose of tramadol (as reported by the physician) was available in $70(67.3 \%)$ reports and non-mandatory information in free-text reported used doses of tramadol in $69(66.3 \%)$ reports. In these reports, prescribed doses ranged between $50-800 \mathrm{mg} /$ day $(250$ $\mathrm{mg}$ and $300 \mathrm{mg} /$ day for men and women, respectively), as compared to 50-4000 mg/day (500 and $400 \mathrm{mg} /$ day for men and women, respectively) for the reported administered doses.

A prescription of tramadol exceeding $400 \mathrm{mg} /$ day was found in $6(5.8 \%)$ patients. Information on the duration of treatment before onset of the ADR was available in $89(85.6 \%)$ cases, where the time of onset ranged from a few weeks up to 4 years. Of the 104 patients, $34(32.7 \%)$ were treated less than 3 months and $32(30.8 \%)$ for more than 12 months, before onset of the reported ADR.

The reported ADR was classified as serious in $72(69.2 \%)$ of the cases, most commonly due to admission to a specialized clinic for detoxification or discontinuation of tramadol.

\section{Non-prescribed use of psychoactive prescription drugs among drug- impaired drivers (Paper III)}

A total of 2225 suspected drug-impaired drivers had a confirmed drug intake of diazepam (1482 $(65.6 \%))$, tramadol (476 (21.1\%)), zolpidem (283 (12.5\%)), zopiclone $(202(9.8 \%))$ and/or flunitrazepam (135 (6.0\%)). The median age (and range) was 34 (15-80) years and $1864(83.8 \%)$ were male. Most subjects were male and young, lived alone in a large city region, were born in Sweden and had a low income level. The median age was higher, more were female, fewer had been taking an illicit drug and fewer had a history of DUID, of subjects identified with zolpidem 
or zopiclone compared to the other groups. The majority had a recently prescribed treatment with other prescription drugs, including those acting on the central nervous system (ATC N).

In the total population of drivers, $1513(58.7 \%)$ subjects were classified as non-prescribed users of the identified psychoactive prescription drug. The corresponding figures for each individual drug are shown in Figure 3. These prevalence proportions did not differ significantly when using the 6 month cut-off ( $\mathrm{p}>0.1$ ). The logistic regression models showed that, for all drugs but zopiclone, being aged 15-24 years compared to all other age groups was significantly associated with non-prescribed psychoactive prescription drug use, with the decreasing association with each successive age group. Sex did not significantly affect the likelihood of non-prescribed use. Education, income, marital status, country of birth and living in the region of a large city did not affect the likelihood of non-prescribed use. Other factors differed between the investigated drugs.

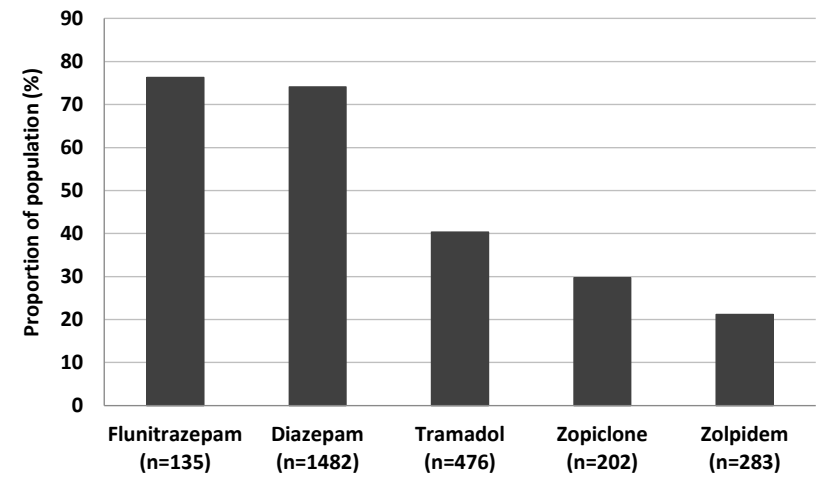

Figure 3. Prevalence of non-prescribed use of the psychoactive drugs flunitrazepam, diazepam, tramadol, zopiclone and/or zolpidem among subjects suspected of drug-impaired driving. The exact figures were as follows: flunitrazepam $76.3 \%$, diazepam $74.1 \%$, tramadol $40.3 \%$, zopiclone $29.7 \%$ and zolpidem $21.2 \%$.

\section{Longitudinal pregabalin utilisation patterns above the maximum approved daily dose (Paper IV)}

A total of 46756 eligible incident users of pregabalin were identified, with a median age of 53 years and of which $61 \%$ were women. The median treatment duration was 289 days, the median daily pregabalin dose was $47 \mathrm{mg}$, and the median number of fills for pregabalin was 4 . Out of all patients, $8353(17.8 \%)$ filled pregabalin prescriptions corresponding to $>600 \mathrm{mg}$ at least twice 
during the 5-year study period. The corresponding figures for the $1200 \mathrm{mg}$ and $300 \mathrm{mg}$ cut-offs were 4495 (9.6\%) and 13893 (29.6\%), respectively.

Using the 5-trajectory model, the following trajectories were identified with respect to the probability (referred to as the risk) of a daily dose above the maximum approved dose of pregabalin

- Trajectory 1: low, stable risk ( $\mathrm{n}=38489(82.3 \%))$;

- Trajectory 2: intermediate, slowly increasing risk ( $\mathrm{n}=2431(5.2 \%)$;

- Trajectory 3: intermediate, rapidly declining risk ( $\mathrm{n}=3688(7.9 \%))$;

- Trajectory 4: high, rapidly increasing and early culminating risk ( $\mathrm{n}=1088$ (2.3\%), and

- Trajectory 5: high, slowly increasing and late culminating risk ( $\mathrm{n}=1060(2.3 \%))$

Patient characteristics are described by trajectory in Table 4. Compared to all other groups, patients in Trajectory 1 had higher odds of being older at treatment initiation, were less likely to be male, and, compared to trajectories 3-5, had higher odds of being urban residents. Compared to trajectory groups 4 and 5, their history of recently prescribed co-medications was more likely to include a higher number of medications but, compared to all other groups, less likely to include a prescription for a controlled drug. Compared to groups 1-3 but not 4, individuals in Trajectory 5 were more likely to be younger and male. Compared to all other groups individuals in Trajectory 5 were less likely to be urban residents. Individuals in trajectory 5 were more likely to have a recent prescription for an opioid analgesic or antiepileptic medication, compared to Trajectories 1-3, but not Trajectory 4. Fewer controlled drugs were prescribed in trajectory 1 and 2 , but not 3 and 4, compared to trajectory 5.The number of fills for pregabalin, treatment durations, filled drug volumes (per fill and for the study period), median daily doses, peak daily doses, peak consecutive 6 month doses, and the number of issued prescriptions generally increased for each successive trajectory from 1 through 5. 
Table 4. Characteristics of patients initiating pregabalin medication $(n=46756)$

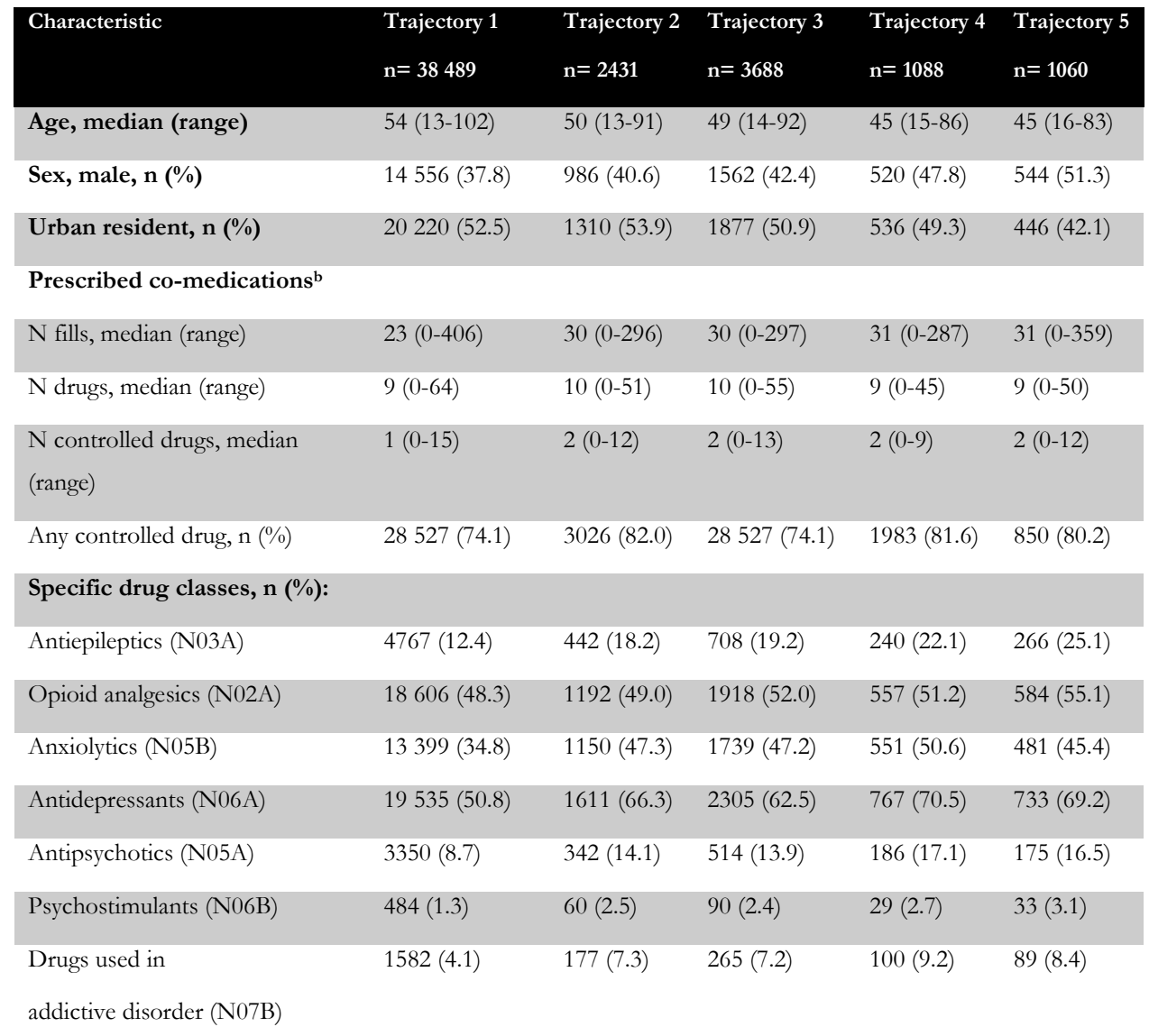

\begin{tabular}{llllll} 
Type of issuing clinic, $\mathbf{n}(\mathbf{\%})$ & & & & & \\
\hline Primary care & $11101(28.8)$ & $530(21.8)$ & $818(22.2)$ & $232(21.3)$ & $230(21.7)$ \\
\hline Psychiatric clinic & $9163(23.8)$ & $920(37.8)$ & $1180(32)$ & $417(38.3)$ & $404(38.1)$ \\
Neurological clinic & $1544(4.0)$ & $135(5.6)$ & $146(4.0)$ & $51(4.7)$ & $48(4.5)$ \\
Orthopedic clinic & $2734(7.1)$ & $113(4.7)$ & $192(5.2)$ & $34(3.1)$ & $39(3.7)$ \\
\hline Internal medicine clinic & $2393(6.2)$ & $138(5.7)$ & $242(6.6)$ & $67(6.2)$ & $55(5.2)$ \\
Pain clinic & $616(1.6)$ & $38(1.6)$ & $64(1.7)$ & $26(2.4)$ & $18(1.7)$ \\
\hline Other & $10938(28.4)$ & $557(22.9)$ & $1046(28.4)$ & $261(24.0)$ & $266(25.1)$ \\
\hline
\end{tabular}

Patient characteristics presented by the risk of a daily dose above the approved dose maximum dose of $600 \mathrm{mg} /$ day (194). Trajectory $1=$ low, stable risk, Trajectory $2=$ intermediate, slowly increasing risk, Trajectory $3=$ intermediate, rapidly declining risk, Trajectory $4=$ high, rapidly increasing and early culminating risk; and Trajectory $5=$ high, slowly increasing and late culminating risk. bPrescribed co-medications filled within 12 months before first fill for pregabalin, defined by their ATC codes (232). Controlled drugs were defined as prescription drugs listed in the Swedish classification as of narcotic drugs (2). 


\section{DISCUSSION}

\section{Occurrence and prevalence of psychoactive prescription drug use disorders, misuse and abuse}

In Study I, 17 fatal tramadol intoxications were identified, which corresponds to one fatal tramadol intoxication per 7 million sold DDDs or 19.000 patient years. This finding is in agreement with other reports (186). Recognising the young median age of the affected individuals of 44 years, even a few deaths account for many years of lost life (YLL) (36). Moreover, there are an estimated 20-25 non-fatal overdose cases to each drug-induced death (263). Although non-fatal overdoses can significantly contribute to long-term morbidity (264), non-fatal drug intoxications are largely under-reported (153). Notably, interpretation of the causal relation of a drug-related fatality to abuse is complex (213). In the case of tramadol, factors such as analytical considerations (190), post-mortal re-distribution (265), interindividual variability in metabolism, drug-drug interactions and a risk of the serotonin syndrome, or suicidal overdose (110) may also explain the death. One third of deaths caused by tramadol intoxication have been suggested to be related to abuse (110). In our study, documentation indicated abuse of tramadol in half of the cases, and the great majority of deceased individuals had a history of substance use disorder, but the validity of this information was low. Thus, the major role of these findings was to generate the hypothesis of a possible causal association of tramadol-related fatalities to abuse of the drug in Sweden.

The findings of 104 reports of tramadol dependence in Study II corresponds to 0.5 spontaneously reported cases per million sold defined daily doses (DDDs) (217), which is higher compared to a German study (266), but lower to US studies $(184,267,268)$. ADRs possibly related to substance use disorders constitute one of the most frequently reported ADRs of tramadol (269). Discrepancies in study results between studies may be explained by differences between countries in the features of the pharmacovigilance system, legislation, prescription rates, treatment recommendations, definitions of dependence, and the investigated study period. As an example, in Germany, tramadol was available several decades before it was registered in Sweden and the USA. Moreover, we assessed the fulfillment of DSM-IV criteria for substance dependence (67), and only included cases assessed as at least possibly (24) related. Furthermore, we based our selection on the reported ADR term and did not include all specific sub-terms of possible relevance, which may further explain the low estimate in our study. Nonetheless, due to 
underreporting and selective reporting of suspected adverse drug reactions (270) such comparisons between studies are less useful. It has been estimated that only $15 \%$ of all serious and $2-4 \%$ of all non-serious adverse drug reactions are reported $(228,271,272)$. Given these reporting rates and the fact that 72 reports $(69 \%)$ of cases were classified as serious and 32 as non-serious, an estimated prevalence of 500 serious and 800-1600 non-serious cases of tramadol dependence were suggested to have occurred during the study period in Sweden. However, due to reporting bias, the low validity of the reported information and questionable representativeness, such figures should be interpreted cautiously. As an example, of our spontaneous reports, $40 \%$ were reported by one single physician. Nonetheless, as described by the WHO DALY (disability adjusted life years) indicator (36), due to the young incidence age, chronicity, high co-morbidity and psychosocial disability, each case of substance use disorder potentially causes many years of disability. In summary, Study II primarily had a role of describing the occurrence of tramadol dependence also in patients on prescribed treatment without a history of abuse, and the potential seriousness such disease.

In Study III, non-prescribed use of tramadol, diazepam, flunitrazepam, zolpidem and zopiclone, was found to occur with an overall prevalence of 59\% among drug-impaired drivers tested positive for these drugs, similar to the few other studies reporting corresponding figures of $63 \%$ (127) and 76\% among fatal intoxications (145). The somewhat lower prevalence in our study is likely explained by our study population characteristics, since fatally intoxicated subjects with a history of abuse may constitute a more extreme group of substance users. Nonetheless, a history of substance abuse is a common rationale for suspicions on drug-impaired driving (221). Notably, Rönkä et al. (145) used a wider definition of personally prescribed use, including dispensing from three years and also drugs with a similar mode of action (such as other opioid analgesics if codeine was identified). Differences between studies may also be related to various efforts by the police to convict drug-impaired drivers, and to differences between countries in clinical utilisation, legislation, and the availability to various drugs on the illegal drug market.

Discrepancies between studies with regards to non-prescribed use may also be explained by the drugs studied. Hall et al. (127) included mostly opioids, of high relevance to the US prescription drug misuse and abuse scene (273), whereas Rönkä et al. comprehensively included all classes of psychoactive prescription drugs, reflecting the European and Scandinavian drug abuse scene (72, 105). Our data on non-prescribed use supports established knowledge that different psychoactive prescription drugs carry various degrees of addictive properties. As an example, benzodiazepines are considered to have a higher abuse potential, and thus, are also controlled in 
higher schedules than tramadol, zolpidem and zopiclone (3). Furthermore, since the availability to prescribed benzodiazepines has greatly decreased as a result of recommendations promoting alternative treatments and due to high availability to non-prescribed drugs $(24,137,226)$, the illegal market may be perceived as a more convenient source. Likewise, the clinical utilisation of tramadol has varied in Sweden as a result of changes in treatment recommendations, but compared to the benzodiazepines tramadol is still more widely prescribed (192). Despite efforts to reduce the illegal trade of tramadol, including placing the drug in a schedule for controlled drugs, tramadol remains one of the most commonly encountered drugs on the Swedish illegal drug market $(24,121,122,137,226)$. In contrast, over-prescribing and misuse of zolpidem and zopiclone remains a significant clinical problem (274-276) and, thus, these hypnotics may be more easily accessible in the health care compared to on the illegal market. Therefore, our measure of non-prescribed use may reflect the availability to the different drugs in the health care vs the illegal market rather than their addictive properties alone. Availability has been shown an important aspect of drug abuse (83). Importantly, since our outcome measure indicated only non-prescribed abuse among drug-impaired drivers, and did not capture misuse or abuse of prescribed drugs, the total rates of misuse among drug-impaired drivers remains unknown.

In Study IV , 18\% of patients initiating pregabalin treatment filled daily doses of the drug above the maximum approved level, a higher estimate than $8.5-9.6 \%$ previously reported $(114,112)$. In one other study, considerably lower estimates of $1.0 \%$ were reported, as individual-level patterns of drug dispenses were not taken into account (211). Considering our longer observation period, a higher estimate was expected, but differences in the definition of the outcome variables may further explain discrepancies. Bodén et al. (114) used the time between the second and third dispensings for the assessment of daily doses, which may underestimate the prevalence due to the short observation period. Schjerning et al. (112) used any consecutive 6 month period of excessive use, which is not as sensitive to occasional early refills or occasional dispensings of larger drug volumes, but may be less useful to capture occasional use in multiple-drug users who switch between drugs, which is common in substance abuse $(81,82)$. Our measure allowed us to estimate a daily dose for each day of the study period, a requirement for our longitudinal design, but despite efforts to reduce the sensitivity of the measure, we probably over-estimated the use of daily doses above the MAD in patients with prescribed doses at the maximum approved level. Across studies $(112,200)$, levels of abuse of pregabalin are considered low, but recognising the wide use of pregabalin, misuse estimates of $9-18 \%$ constitute a clinically significant number. Notably, although it has been shown that dispensing data can be used to identify substance- 
seeking behaviour and prescription drug abuse (69), it is unknown to what extent our measurement captured misuse vs abuse of pregabalin.

Specifically, we found different patterns of pregabalin utilisation with respect to the risk of refilling daily doses of the drug above the approved level. Over the course of up to 5 years treatment, $5 \%$ of the patients may be at higher risk compared to the others of reaching such doses. The absolute figure may be an overestimation, however, the primary aim was to assess variations over time. Comparable studies have not been conducted, but the findings are consistent with previous findings of high treatment discontinuation rates (195) and low average doses $(195,211)$, corresponding to our low risk trajectory. The development of tolerance and subsequently, gradually increasing doses in some subjects, is further supported by our identified trajectories. The use of high daily doses in a small proportion of patients was found, likely linked both to misuse due to sub-therapeutic effect, and to the occurrence of abuse of the drug. Nonetheless, the results from this analysis requires careful interpretation and comparable literature is lacking.

Altogether, the findings of this thesis emphasize that misuse and abuse of newly marketed and established psychoactive prescription drugs occur across groups in the Swedish population, in persons with a history of substance use problems as well as in those without, and that it involves prescribed as well as illegally obtained drugs. The prevalence estimations in this thesis differed considerably between studies, in support of the existing literature $(69,70,72)$. Prevalence estimates of drug abuse were high in drug-impaired drivers, but also in cases of fatal intoxications and spontaneously reported drug use disorder a relation to abuse was commonly reported. Lowest prevalence estimates of misuse were found in the general population of patients on prescribed treatment, nevertheless, considering the large population size, even a low prevalence estimate accounts for many affected persons.

Differences between the studies within the thesis were mainly explained by differences in the population characteristics, in the definitions of the outcome measures, in the drugs studied, and in the study period investigated. The large variation in results also from previous studies may, indeed, partly be explained by the use of numerous different indicators of misuse that are not comparable $(69,70,103)$. Thus, while there appears to be a lower prevalence of misuse in the general population of patients on prescribed therapy with psychoactive drugs, the prevalence of misuse and abuse is suggested to be high in sub-populations of substance abusers. Many subjects may need to be exposed in order for a fatal intoxication to occur, or for a signal of substance use 
disorder to be caught by the pharmacovigilance system. Usually, a series of case reports are required in order for a signal to be identified (278). Thus, pharmacoepidemiological research based on data on sub-populations of substance abusers is important as it may enable the earlier identification of prescription drug misuse before the occurrence of more serious abuse-related events, as recently suggested by others $(70,110,277)$. Non-prescribed use assessed in the selected population of drug-impaired drivers was common, and may enable individual-level monitoring directly following registration of a drug $(70,103)$. Notably, this thesis did not investigate whether prescribed drugs were misused among drug-impaired drivers, but data from study III indicated the occurrence also of such use.

Measuring use above approved maximum doses for a drug among all patients to indicate misuse resulted in considerably lower prevalence estimates in our study, consistent with previous data $(69,116)$. Prevalence estimations based on dispensing data are important to reflect the extent to which prescribed drugs are misused, which is relevant to the population of treated patients. Using a daily dose above the approved level as an indicator of abuse has been suggested by others (69), but this research area is in its infancy and more research is needed.

\section{Factors associated with psychoactive prescription drug use disorders, misuse and abuse}

Although tramadol is more commonly prescribed in women and with increasing age, fatal unintentional tramadol intoxications in Study I affected more men and the median age was 44 years. Similar findings were reported by others (186). In Study II, 58\% of spontaneous reports on tramadol dependence concerned women and the median age was 45 years, partly a better reflection of the population of treated patients (50). In Study III, non-prescribed was found more commonly with decreasing age, as did some others $(127,145)$. In Study IV, the patients at highest risk of using pregabalin above the approved daily dose over the course of the five years after treatment initiation, were also more likely to be younger, in support of previous studies $(112,114)$. Thus, this thesis points to the teenagers or young adults as an important risk group of psychoactive prescription drug use disorder, abuse as well as misuse, consistent with the more extensive literature on substance use disorders in general (12). Substance use disorders, risk taking behaviour and drug-impaired driving are all more common in the young $(151,221,246)$. In fact, prescription drug abuse may be a major means by which young people initiate their drug abuse career (248). Nonetheless, others have reported the importance of intermediate or older age groups as well $(153,279)$. In particular, rates of exposure to drugs with addictive properties 
increase over the course of life, reflecting incident and prevalent morbidity in pain disorders and mental health problems (153). Thus, as opposed to illicit drug use, incidence rates of which peak in teenage and young adulthood, there is a risk of prescription drug abuse throughout the life. In Sweden, the high prevalence of prescription drug abuse in the adult population has been shown in household surveys (140), but the present thesis was unable to confirm this.

The association of sex and prescription drug use disorders, misuse and abuse appears complex. Substance use disorders, in general, are more common in men (151, 172, 221, 246). Fatal tramadol intoxications were more frequent in men, as subsequently reported by others (186), but spontaneously reported tramadol dependence in this thesis was more common in women. No differences were found between men and women in non-prescribed use of psychoactive prescription drugs among drug-impaired drivers, like some others $(127,145,280)$, but in contrast to a Swedish household survey (140). Notably, results in Study III may be biased by the large proportion of men and by the misuse also of prescribed drugs in the DUID population (221). In Study IV, the utilisation of highest risk of using pregabalin above approved doses was found more often in men, in line with existing data $(112,114)$. This discrepancy might be explained by various factors. In addition to differences in the study designs, gender differences in the risk for abuse vs substance use disorder, in spontaneous reporting $(270,271)$ and in prescription rates are probable explanations. Higher prescription rates may put women at certain the risk of substance use disorder $(152,153)$. Moreover, gender differences in the preferred methods of diversion have also been suggested (152). As psychoactive medications are perceived as safer, less criminal, more convenient, and less stigmatising compared to illicit drugs (83), they might attract women more, especially if prescribed. In summary, while women may be at higher risk of drug use disorder, men may be at higher risk of abuse due to their higher risk-taking behaviour (151). However, the data within this thesis and others report conflicting findings, and more research is needed.

A history of substance use disorder or substance abuse was explored as a potentially important risk factor in this thesis. In study I, a history of substance abuse was reported in the majority of decedents, but there was a lack of data, low validity, and a risk of reporting bias in information on potential confounders this study. In study II, in about a third of cases a documented history of abuse was reported, and reported tramadol doses exceeded by far the prescribed or approved doses in some cases, but due to lack of information and reporting bias figures may be underestimated. Notably, also patients without a history of abuse were affected by tramadol dependence (184). In study III, various indicators of abuse were explored, including past DUID 
history, drug concentrations and presence of illicit drugs, none of which significantly separated prescribed from non-prescribed users, probably linked to the abuse also of prescribed drugs in this population. However, non-prescribed use of diazepam and tramadol was associated with the use of multiple psychoactive substances. Furthermore, while supratherapeutic concentrations may indicate misuse and abuse, concentrations of the investigated drugs in study I and III ranged widely, due to a lack of standardisation in the time between drug intake, death/DUID, and blood sampling, and inter-individual variation in dosages, metabolism, tolerance, and post-mortal redistribution (213). In Study IV, the likelihood of recent drug treatment of addictive disorder did not significantly differ between the identified trajectories, in contrast to previous data (114), probably linked to the inability of the outcome measure to separate abuse from other misuse.

Across the studies in this thesis, mental co-morbidity and past use of psychoactive medications is suggested to be a factor strongly associated with prescription drug use disorders, misuse and abuse. In study I, all decedents but one used another psychoactive medication, however intentions of this drug use was unknown. In study II, a medical history of pain or a history of mental disorder was reported in a majority of the cases, but there was a lack of information in others. In study III, non-prescribed use of diazepam, zolpidem and zopiclone was associated with the confirmed intake of another controlled prescription drug, however, the recent dispensing of other prescribed psychoactive or controlled drugs predicted a prescribed drug use across drug-impaired drivers in our study. In Study IV, the patients at highest risk of high dose use of pregabalin were more likely to have a recent prescription for an opioid analgesic and an antiepileptic drug, and, to some extent, more controlled drugs compared to the trajectory groups of low and intermediate risk, in support of previous studies $(112,114)$.

There is a high mental co-morbidity both in chronic pain, neurological disorders and in substance use disorders $(40,150)$, thus, mental disorders in individuals who abuse psychoactive prescription drugs may further explain their use of multiple psychoactive medications (150). Moreover, there has been a trend among drug addicts in recent years, where multiple psychoactive substances (alcohol, illicit drugs and prescription drugs) are used simultaneously to modify their individual effects $(81,82)$. Conflicting findings have, however, been reported $(9,10$, $114,152)$. Due to restrictive prescribing, persons with a history or substance use problems should find it more difficult to obtain a prescription for psychoactive medications with an abuse potential. However, the recent dispensing of other prescribed psychoactive drugs or a history including mental co-morbidity may be a marker not only of medical history, but also of established health care contacts and a higher probability of being prescribed psychoactive drugs, 
also when intentions of drug use are not medical (150). In study IV, recent antiepileptic medication was the strongest predictor of pregabalin use above the maximum approved dose, similar to other reports $(112,114)$. This effect was largely accounted for by gabapentin. Switching from gabapentin to pregabalin may reflect treatment-resistant disease and, thus, subtherapeutic effect may be related to the use of high prescribed doses of pregabalin (281), but more research is needed.

While we considered living in the region of a large city as a factor possibly affecting illegal drug market and health care availability as well as traffic police density, our results suggest that nonprescribed use of drugs is as common in rural as in urban areas, in support of some studies (129) but not of others (172). In study IV, not being an urban resident was more common in the patients at the highest risk of pregabalin use above the approved dose, and was in fact the only factor which significantly separated the two high risk trajectory groups. In non-urban areas, prescription drug misuse may be more prevalent due to worse control of prescribed medications (174) and the lower availability to illicit drugs (83).

Low socioeconomic status is traditionally considered to be associated with substance abuse (169), but this thesis did not find differences in non-prescribed use of psychoactive prescription drugs between socioeconomic groups. Differences in mental morbidity and health care and medication utilisation between socioeconomic groups might influence this (169), and factors such as perceived safety or availability of prescription drugs, may explain the occurrence of abuse across socioeconomic groups and the source of drug.

Thus, while the results of this thesis indicate that psychoactive prescription drug use disorders, misuse and abuse are related to some factors typically associated with drug addiction, such as young age and mental illness, the data also suggest that the prescription drug use disorders, misuse and abuse occur also in groups of the population not typically considered to be at high risk of substance use problems (such as women, non-urban residents and socioeconomically advantaged persons). As such, the factors predicting prescription drug misuse and abuse may differ from the factors predicting illicit drug user. Moreover, the discrepancy in our and other studies might be linked to the existence of sub-groups of prescription drug misusers and abusers who differ for example with respect to their motives for drug misuse, patterns of drug use and preferred source of drug $(92-93,172,282)$. Further research is needed $(69,70)$. 


\section{Methodological considerations}

\section{Combination of data sources and study designs}

One strength of this thesis is the use of multiple and complementing, national, individual-level data to study different aspects of psychoactive prescription drug use disorders, abuse and misuse, especially as the current literature is limited to a few countries, a few classes of prescription drugs and few types of data sources $(70,103)$.

Study I was the first study to describe a national sample of unintentional fatal drug intoxications with tramadol and the possible association to abuse. Study II was the first study to summarise spontaneously reported adverse drug reactions possibly related to tramadol dependence in Europe. Study III was the first study to link forensic and prescription data to assess the use of non-prescribed drugs, a novel indicator of abuse, in living subjects. Study IV was the first study to describe longitudinal patterns of pregabalin utilisation, and the first study to use group-based modeling to identify sub-groups of drug misusers. However, some important weaknesses of this research should be acknowledged.

Other aspects of psychoactive prescription drug use disorder, misuse and abuse would have been relevant to consider, such as hospitalisations for treatment of substance use disorders, but was not considered due to the low coverage of diagnoses for mental disorders in the Swedish Hospital Discharge Register and due to the limitations in diagnose codes. Moreover, regular household surveys and surveys among school students, that have shown important for the monitoring of prescription drug abuse in other countries, are not regularly conducted in Sweden, or do not comprehensively cover all psychoactive prescription drugs (104). Prescribing patterns, were not used as the relevance of dispensing patterns provide more relevant data and as national data on drug prescriptions are not available in Sweden. Due to the pharmacoepidemiological approach and a lack of register data, qualitative data, crucial for the understanding of patient and drug user perspectives, were not considered.

Moreover, the results of this thesis are not directly comparable, as different drugs, study periods and outcome measures were included, which would have given a better picture of prescription drug misuse and abuse as a whole. Also, although prescription drugs of abuse derive from a variety of sources, only one aspect was considered in each study. 


\section{Study populations, selection bias and representativeness}

In this thesis, sampling error was not a problem since all subjects or cases fulfilling the predefined study criteria were comprehensively included in the studies, without sampling. However, reporting and selection bias, and representativeness, are important limitations.

In Study I and III, the study populations consisted of subjects subjected to a forensic autopsy or suspected of drug-impaired driving. Because psychoactive prescription drugs are commonly detected and substance use disorders are prevalent, these populations are relevant in studies of psychoactive prescription drug abuse (110). Nonetheless, classifying deaths into appropriate cause of death categories is not a straightforward task, and drug impaired drivers are a highly selected and heterogeneous population neither characteristic nor representative of patients with chronic pain, sleep disorders, or anxiety (36). The studies should be interpreted considering these limitations. There are also several sources of selection bias. Not all fatalities undergo forensic investigation, and our inclusion of cases was based on the assessment of primary cause of death the forensic pathologist and blood concentrations of tramadol, thus, cases of tramadol-related deaths may have been excluded, i.e. when intoxication was the secondary cause of death or when such a secondary cause was not registered. Moreover, even though the postmortem routine analysis covers more than 200 substances and the forensic analysis in DUID investigations covers most drugs of abuse, substances are only analysed when an intake is suspected. Likewise, the likelihood of being suspected of drug-impaired driving depends on various factors, including the efforts and density of the traffic police but also documented history of abuse. Furthermore, analyses in suspected impaired driving cover only established or emerging drugs of abuse and analyses for prescription drugs are not always undertaken if alcohol or illicit drugs are detected. Thus, some cases of tramadol-impaired driving were probably not included.

In Study II spontaneous reporting data were used to identify tramadol dependence. Spontaneous reporting of suspected ADRs are considered to be an important method for surveillance of drug safety as a means to detect signals on unknown or rare adverse drug reactions after marketing authorisation (228), however, underreporting and selective reporting of suspected adverse drug reactions is a well-known disadvantage of spontaneous reporting systems $(270,271)$. The reporting rate is related to various factors such as the time since registration of a drug product, features of the drug product or similar products, seriousness of the reaction, media attention, to what degree the reaction is perceived as recognised, and lack of knowledge, misunderstanding or insecurity regarding the reporting system. We assessed the fulfillment of DSM-IV criteria for 
substance dependence (67), and only cases judged as at least possibly (24) related were included, however the selection was based on terms as reported by the physician and not all sub-terms possibly related to dependence were included. Moreover, the information given in reports may also be biased. As an example, in a patient with a history of substance use disorder other possible causes of the reported reactions, such as sub-therapeutic effects, may be underreported. Thus, the limited number of reported cases of tramadol dependence and the described population characteristics in our study may not be representative to all cases of tramadol dependence. Moreover the low number of cases caused imprecise estimates in both Studies I and II.

In Study IV, all patients initiating prescribed treatment with pregabalin were identified using the SPDR, which has national coverage for most psychoactive outpatient medication, as psychoactive drugs are not available over-the-counter in Sweden. The main strength is that the entire patient population was covered and fills for five years were followed, thus, results have high clinical relevance for short- as well as long-term treatments. However, we excluded patients with multi-dose dispensed medication during the study period, as they receive medication automatically at predetermined time intervals, and subjects with no registered residency for the study period, which may both be more pronounced in individuals with substance use disorders.

This thesis included a selection of prescription drugs of relevance to the Swedish clinical setting and drug abuse scene at the time for the studies $(24,137,226)$, and their use during a limited period of time in Sweden. However, as the clinical utilisation and illegal use of a certain drug change over time and vary between countries, the results may not be representative to other drugs, time periods and countries. For example, tramadol is among the most commonly encountered prescription drugs on the illegal market $(24,137,226)$ in Sweden, while the drug may be less prevalent in other countries (72). Furthermore, tramadol prescription rates in Sweden have decreased and legislation for tramadol has changed during the work with this project (192). Moreover, while prescription drug abuse in some countries is reported to often concern personally prescribed drugs and drugs diverted from the health care system, in Europe and Scandinavia the illegal market may have a more crucial role $(24,105,137,226)$.

\section{Defining and classifying drug use, misuse and abuse}

To classify drug use, and to separate abuse and misuse from other use of psychoactive medications, this thesis used various definitions. In Study I and III information on drug utilisation was based on forensic toxicology data, with the main strength that drug intake and 
concentrations are confirmed by accredited laboratory analysis of blood, and that entered data are likely to be correct since the information is validated at several steps in the routine case management system. However, information on time of the drug intake, duration of drug use, source of the drug, and the rationale of drug use (including any abuse) is generally missing, or rely upon information in the police reports, which holds low validity and may be biased. Historically, data on trends in drug-related deaths involving a certain drug have been crucial indicators of substance abuse issues (60). Nonetheless, fatal intoxications with PPDs may have several explanations. Although the relation between the fatal intoxication cases and any misuse or abuse of the drug should preferably have been established, this was not possible given the available data. It is reasonable that in subjects, in whom a history of abuse of the suspected drug was not reported, a majority used the drug appropriately, however, this data holds low validity.

In Study II information on drug use was based on non-mandatory information given by the reporting physician, and thus, information on prescribed drug treatments, duration of treatment and daily doses used was questionable. In both studies I and II, assessment of the role of misuse or abuse, in particular whether the cases fulfilled definitions, for example, for possible misuse and abuse related events (MAREs) as described in the Analgesic, Anestethic, and Addiction Clinical Trials, Translations, Innovations, Opportunities, and Networks (ACTTION) classification system, could not be systematically reviewed (73). Nonetheless, strengths of both Study I and Study II were that all available data in each case was assessed. Linkage to medical record data or other valid data on drug prescriptions or dispenses would have increased the validity of information on drug utilisation, but this was not conducted as it was not part of the study aims. Moreover, the expedited information on this emerging safety signal was important, and thus any additional steps required in a record linkage study were avoided not to delay study results.

In Study III, toxicology data was linked to information on dispensed prescription drugs in Study III to indicate whether there was an ongoing prescribed treatment with the drug identified in blood. A cut-off of 12 months was used taking into account the prescription validity time in Sweden, the Swedish drug reimbursement system, and the high intermittent use and prolonged waiting time period for the studied drugs $(79,235)$. Although this introduced a risk of misclassification in individuals with older prescriptions, and in those with drugs prescribed abroad or during hospitalisation, the false assignment of non-prescribed users was judged to be exceptional. Moreover, as this study defined non-prescribed use only, and since results indicated the occurrence of misuse also among individuals in whom the identified drug was prescribed, 
this study underestimated the total prevalence of abuse in drug-impaired drivers, likely affecting also the investigation of associated factors.

In Study IV, classification of drug use was based on filled prescriptions for pregabalin, i.e. dispensed daily doses. Studies of dispenses compared to prescriptions have some advantages when studying drugs suspected of carrying a abuse potential, where patients might not dispense their drug as intended by the prescriber (i.e. primary non-adherence) and where multiple prescribers might be involved $(69,112,113)$. Nonetheless, as patients may also not use their drug as dispensed (due to stock-piling, lost drug packages or prescriptions, or variability over time in drug use intensity, and other factors) there is a risk of classification bias $(60,237,283)$. As an example, patients with changes in treatment regimens and, as a result, early refills may have falsely been classified as users of pregabalin doses above the recommended daily dose. This issue may be especially important in the beginning of treatment and in patients with prescribed doses at the maximum level. Nonetheless, our outcome measure allowed us to estimate a dose for each day of the observation period and to reflect variations in drug use over time, of relevance to substance use disorders (5), to substance-seeking behaviour (69) and to previous results on pregabalin dispensing. The cut-off level at the maximum approved dose was considered clinically relevant and explicitly defined(194), and allowed comparison to previous studies $(112,114)$. Nonetheless, our definition may have overestimated the absolute prevalence of use above the approved maximum dose. Notably, pregabalin is primarily used as adjunctive or second-line treatment and, thus, some patients may require regular prescriptions for higher-than-approved doses. As data were not available, our outcome variable did not differentiate use of higher than the approved doses following an appropriate benefit-risk assessment in the individual patient, from use of such high doses of causes including non-medical intentions. To more accurately separate prescription drug misusers and abusers from other users, a composite outcome variable taking into account not only daily doses but rather individual-level patterns of drug use based on several variables (such as the daily dose, the number of prescriptions, and the time between dispenses (69)) might have been more advantageous, but was not done for practical reasons and due to limitations in the prescription data. Finally, although pregabalin appears to be prevalent in the Swedish illegal drug market (24), this study did not include non-prescribed misuse or abuse of the drug.

Thus, the effort to categorize drug users into distinct sub-groups in Study III and IV of this thesis, added new information but is a simplification of the clinical situation, which limits the conclusions that can be drawn from the results. 


\section{Statistical considerations}

As Studies I and II evaluated series of a limited number of cases, and due to the nature of the data, advanced statistical analyses were not applied and these studies had a hypothesis-generating role.

In study III, the associations of some potentially important risk factors with non-prescribed use was assessed using logistic regression, but all potential confounders were not controlled for due to limitations in the available data. As an example, information on each individual's rationale for using prescribed drugs was missing and information on medical history was not available.

In Study IV, group-based trajectory modeling (GBTM) was identified as a useful method (see Methods). Nonetheless, since the method has not been applied in similar settings before, the application of the method and the interpretation of the results were challenging. In particular, choosing the number of trajectories requires balancing measures of model fit with an arbitrary chosen limit of a maximal number of allowed trajectory groups considering clinical meaningfulness and interpretability. Due to limitations in data processing capacity, a monthly indicator was created indicating whether a daily dose above the cut-off was present. Also, variations in risk was described rather than variations the daily dose, which complicates interpretation. Moreover, the groups were heterogeneous with regards to their trajectories but heterogeneous in other aspects, possibly related to the lack of information on important confounders and due to limitations in the outcome variable. As an example, information on socioeconomics and medical history was missing, of which the latter was replaced by proxy variables based on drug dispenses. The results of Study IV, however, were consistent with and complemented previous literature on pregabalin, which supports the usefulness of the method used. In Study IV, refill characteristics were described and a range of variables were created to indicate misuse. However, these measures could not accurately separate abuse from other forms of misuse. Thus, the "risk" of using daily doses above the MAD could be linked to abuse but could also be explained by clinical situations such as sub-therapeutic effects. Due to limitations in the SPDR, which does not include unique prescriber identifiers, the number of issuing prescribers, an important indicator of doctor shopping, could not be assessed. Likewise, the relation between the individually prescribed daily dose and the dispensed daily dose was not assessed. As all studies were non-controlled and observational and since all potential confounders were not controlled for, causality of the presented associations is unknown. 


\section{Implications}

As psychoactive prescription drug use disorders, abuse and misuse affect individuals across groups in the population, interventions are important to increase the knowledge on this public health problem. Increased awareness is needed on the prevalence and seriousness of misuse and abuse of psychoactive prescription drugs, and on the characteristics of affected individuals, which may differ from the expected picture $(92,93,172)$. Ultimately, this would reduce the stigma, and improve possibilities for proactive preventive interventions, early identification, and successful treatment (103).

As the prevalence of abuse and misuse is high in sub-populations, clinical and regulatory interventions directed to the individuals at the highest risk are required, to enable treatment in the patients where the benefits outweigh the risks. The individual need for safe and effective treatment needs to be carefully balanced to the population-level risk of misuse and abuse (36, 103).

As abuse of psychoactive medications involves a wide range of drug sources interventions aimed to reduce such use of prescribed as well as non-prescribed drugs are needed $(83,284)$. This requires comprehensive and proactive clinical and regulatory efforts. Cross-national cooperation and globally harmonised legislation would create better possibilities to reduce the trafficking of illegal drugs $(104,137)$. To reduce the misuse of prescribed drugs, enhanced possibilities and responsibilities of health care and pharmacies to identify substance-seeking patients, and prescription registers shared across health care settings and regions, would be beneficial.

As the abuse of tramadol may be associated with serious outcomes, and appears to be widespread in sub-populations of substance abusers, preventing abuse is important. The lack of harmonised international legislation, may explain the continued role of tramadol on the Swedish illegal drug market despite national regulations $(2,137)$. Restrictions in the prescribing of tramadol continue to be important. As the clinical utilisation of pregabalin is expected to increase, and since a proportion of the patients appears to be at high risk of using higher than the approved doses, clinicians and regulators should be aware of the addictive properties of the drug, but also for other potential causes of high dose use, such as sub-therapeutic effects.

Finally, as a mental health problem appears to often be present in persons with prescription drug use disorders, prevention should not merely be focused on the problematic substances, but primarily on treating the underlying causes of their misuse. 


\section{CONCLUSIONS}

Fatal intoxications with tramadol may occur unintentionally, however, fatal toxicity of tramadol seems to be rare considering the widespread use of the drug. Subjects with a history of substance abuse may be at certain risk and precaution is warranted when prescribing tramadol in such patients. Concomitant use of other psychoactive substances may increase the risk.

There is an occurrence of tramadol dependence in association with analgesic treatment within the recommended dose range of the drug. In susceptible patients, a severe and serious substance use disorder may develop. A history of abuse and past use of a psychoactive medication seem to be important risk factors. An individual benefit-risk assessment that identifies possible risk factors and evaluates the need for pharmacological analgesic treatment should be done in each patient before tramadol is introduced.

Non-prescribed use of psychoactive prescription drugs was common in subjects suspected of drug-impaired driving, and more frequent for benzodiazepines and tramadol compared to zolpidem and zopiclone. The youngest compared to older age groups, and multiple-substance users were more likely, whereas subjects with ongoing prescribed treatment with other psychoactive drugs were less likely, to use non-prescribed drugs. Monitoring non-prescribed use among drug-impaired drivers may be a valuable method to enable the early identification of misuse, abuse and diversion of psychoactive prescription drugs in the population.

There are distinct longitudinal utilisation patterns for pregabalin, which differ with respect to the risk of use above the maximum approved daily dose over the course of prescribed treatment. A small proportion of patients are at high risk of such use. The highest risk was associated with younger age, male sex, non-urban residency and having a recent prescription for an antiepileptic or opioid analgesic drug. Substance-seeking behaviour was found increasingly with increasing risk. The associated patient and refill characteristics should be recognised when planning interventions to reduce misuse and abuse of pregabalin. The future application of latent growth models to identify subgroups of psychoactive prescription drug users is encouraged.

Psychoactive prescription drugs use disorders, misuse and abuse occur across groups in the population. The high prevalence in some sub-groups and the considerable adverse outcomes demonstrate that this is a significant clinical and public health concern. 


\section{FUTURE RESEARCH}

Based on the findings in this thesis, areas of interest for future research have been identified. Pharmacoepidemiological studies are important and useful in the identification and characterisation of prescription drug use disorders, misuse and abuse. Yet, a great majority of the literature is based on data from a few countries and data sources, and concern a limited number of drugs. Studies from a wider range of settings are needed to improve the global understanding. This requires enhanced possibilities for observational research, including improved registers.

The diverse nature of psychoactive prescription drug use disorders, misuse and abuse, and the various definitions and terms complicate research. Internationally harmonised, validated and standardised terms and definitions would enhance the possibilities for earlier identification of misuse and abuse and allow for better comparison across countries and over time. This would improve the understanding of the extent of and trends in psychoactive prescription drug use misuse, and facilitate development of preventive strategies.

Better methods to identify and separate sub-groups of persons who misuse psychoactive prescription drugs, with different motives and patterns of their drug use, might enable more accurate determination of the prevalence of the different types of misuse and the factors associated with each type. This would facilitate directing treatment to the patients most likely to benefit while offering more appropriate interventions to individuals at high risk of misuse.

Although psychoactive drugs may be obtained by a variety of sources, previous studies have generally considered only one of these aspects. A more complete and accurate picture of the prevalence and important risk factors requires that future monitoring consider both prescribed and non-prescribed use of psychoactive prescription drugs. This would enhance the understanding of the diversity in sources of misused drugs and, thus, facilitate the identification of targets for tailored interventions aimed to prevent such use.

Finally, future research aimed to prevent misuse and abuse of psychoactive prescription drugs should recognise the importance of investigating the underlying causes. Understanding of the perspective of the drug user, the prescriber and others is critical to succeed in the implementation of preventive strategies, thereby improving the safe and rational use of psychoactive prescription drugs. 


\section{ACKNOWLEDGEMENTS}

The research of this thesis was financially supported by the Swedish Research Council, Linköping University, Östergötland County Council and the Forensic Science Centre, which are gratefully acknowledged.

I would like to express my sincere gratitude to everyone who has supported me, inspired me, and contributed to make this thesis possible, especially:

My supervisors, for believing in me and for your endless support, patience, optimism and calm. Your skills, your networks of collaborators and you being my tutors have been more beneficial to me than you can imagine. My main supervisor, Staffan Hägg, for always being there and taking the time, even when you were busy, and for generously sharing your broad skills in clinical pharmacology, pharmacovigilance, pharmacoepidemiology, ethics, psychiatry and much more. Co-supervisor, Johan Ahlner, for embracing me with open arms when I stepped in to your office and asked for a project, for showing interest in all aspects of my project, and for sharing your skills and experience in forensic toxicology. Co-supervisor and friend, Anna Jönsson, for being so supportive and constantly available along my whole journey toward this doctoral thesis, for all the practical support, for welcoming me in your home, and for sharing your skills in particular in pharmacoepidemiology.

My statistician colleagues, Tatiana Zverkova Sandström, Elisabet Nikolic, and Linus Schiöler for great cooperation, endless patience with all my questions and requests, and for valuable discussions on statistical methodology. My studies would not have been possible without you! Let's continue the interesting projects we started!

Co-author, Carola Bardage at the Medical Products Agency, for being positive about running a joint project, for good collaboration and for sharing knowledge and your regulatory perspective.

My colleagues at Clinical Pharmacology, University hospital in Linköping, for welcoming me in your group, for sharing your clinical experience, and for many interesting clinical and scientific discussions and seminars on drug safety. Especially Ingela Jacobsson, for all you taught me on spontaneous reporting, for all your practical support and for welcoming me in your home. Thomas Bradley, for your trust in me and for letting me embark on my clinical path. Madeleine Örlin at the Department of Drug Research, for your precious administrative help that made things easier with the distance. 
My colleagues at the National Board of Forensic Medicine, for your great interest in my project and for sharing your deep knowledge in forensic toxicology. Special thanks to Anita Holmgren, for kind assistance with data retrieval.

My current and former fellow doctoral student colleagues at the Department of Drug Research, the National Board of Forensic Medicine, the former Nordic School of Public health, and other PhD student colleagues in Sweden and around the world, for sharing the life of a PhD student, and for valuable talks and support!

Colleagues at Futurum, Academy for Health and Care at Region Jönköping County, especially Boel Andersson Gäre, for welcoming me in your facilities and giving me the opportunity to develop my academic skills in a clinical and regional setting.

Colleagues at the Department of Clinical Pharmacy, Region Jönköping County, especially Anne Hiselius and Malin Holmqvist, for giving me the possibility to discuss and keep up-dated on clinical pharmacy while focusing on research. I hope we will be able to continue the work we started!

Colleagues at the Department of Clinical Pharmacology, University of Southern Denmark, Odense, Denmark, for supporting me in the last part of my project, especially Anton Pottegard, for kindly sharing your broad skills and experiences, for advice and comments and for your endless optimism. Lotte Rasmussen, for being a valuable doctoral student colleague and a friend, and for sharing thoughts, experiences and my interest in the field of prescription drug misuse. Lotte and Anton, I hope we will have the opportunity to continue our collaboration!

My friends, for all the good times we spend together! Without your encouragements, energy, and support my time as a doctoral student would not have been as delightful. In times when we did not manage to meet as often, you were always present. I am so glad that you are a part of my life!

My great family, mother Eva, father Kent, brother Niclas, parents-in-law, Dorya and Jan-Owe, and all my precious brothers and sisters-in-law and families, for all the moments we spend together and for all the energy, love, encouragements and comfort you give me! Thanks for all the invaluable, practical help in busy times, without which this thesis would not be possible to accomplish for me as a mother of two small children. For all the interest you have shown in my work even though it is far from your world. My grandmother, farmor Britt, for your endless love, for all our talks and for all the times you spent worrying about me, even when you didn't have to. My beloved parents, Eva and Kent, special thanks for always supporting me in education as well 
as working life, for making me believe in myself and in what I can achieve, for caring about me and reminding me to take it easy from time to time, and for giving me values that motivate me to care for people that are less fortunate.

My beloved husband, Jobannes. Without your unbelievable patience, support and endless love, this journey would not have been possible. Thank you so much for being understanding, for tolerating my long working hours and me often being absent minded, and for taking so good care of our children. And, of course, for all the fantastic dinners you make! You are my rock in the world and you mean everything to me!

My beloved children, Iris and Svea. You are a bright and shining light of my life! Thanks for all the joy you bring to my life, for your never-ending love, kisses and hugs, for your curious questions, and for giving me perspective on the important things in life. I love you to the stars and back! 


\section{REFERENCES}

1. European Union (EU). DIRECTIVE 2010/84/EU OF THE EUROPEAN

PARLIAMENT AND OF THE COUNCIL of 15 December 2010 amending, as regards pharmacovigilance, Directive 2001/83/EC on the Community code relating to medicinal products for human use. The European Union. Strasbourg, 2010.

2. Medical Products Agency (MPA). Swedish law on narcotic drugs. [Föreskrift om ändring i Läkemedelsverkets föreskrifter (LVFS 1997:12) om förteckningar över narkotika (2009:22). Uppsala, Sweden; November 2009.

3. United Nations (UN). Convention on Psychotropic substances. UN. Vienna, Austria; 1971.

4. United Nations (UN), 1975. Single Convention on Narcotic Drugs of 1961, as amended by the protocol amending the Single Convention on Narcotic Drugs,1961. Vol 976. UN. New York, 1975.

5. American Psychiatric Association (APA). Diagnostic and Statistical Manual of Mental Disorders (DSM-5). Fifth ed. Washington, DC, London, England. American Psychiatric Association; 2013.

6. European Medicines Agency (EMA). Guidelines on good pharmacovigilance practices (GPV). Module VI - Management and reporting of adverse reactions to medicinal 5 products (Rev 1). EMA, 2013. Accessed on 19 July 2016.

http:/ /www.ema.europa.eu/docs/en_GB/document_library/Scientific_guideline/2013/06/WC 500144009.pdf.

7. National Institute on Drug Abuse (NIDA), National Institutes of Health, Bethesda, MD, USA. Official webpage of NIDA. Accessed on 22 June 2016:

https://www.drugabuse.gov/publications/teaching-packets/neurobiology-drug-addiction.

8. National Center for Biotechnology Information. U.S. National Library of Medicine. Medical Subject Heading (MeSH) term "prescription drug misuse”. Introduced 2013. Tree Number(s): E02.319.754; MeSH Unique ID: D063487; Retreived 8 June 2016.

http://www.ncbi.nlm.nih.gov/mesh/68063487; Rockville, Bethesda, MD, USA. 2013.

9. Peirce GL, Smith MJ, Abate MA, Halverson J. Doctor and pharmacy shopping for controlled substances. Medical care. 2012 Jun;50(6):494-500. PubMed PMID: 22410408.

10. Cepeda MS, Fife D, Chow W, Mastrogiovanni G, Henderson SC. Assessing opioid shopping behaviour: a large cohort study from a medication dispensing database in the US. Drug safety. 2012 Apr 1;35(4):325-34. PubMed PMID: 22339505. 
11. Rouby F, Pradel V, Frauger E, Pauly V, Natali F, Reggio P, et al. Assessment of abuse of tianeptine from a reimbursement database using 'doctor-shopping' as an indicator. Fundamental \& clinical pharmacology. 2012 Apr;26(2):286-94. PubMed PMID: 21210844.

12. American Psyhiatric Association. Substance use disorder Fact sheet. 2013. Accessed on 19 July 2016.

http://www.dsm5.org/documents/substance $\% 20$ use $\% 20$ disorder $\% 20$ fact $\% 20$ sheet.pdf.

13. World Health Organization. Introduction to drug utilization research. WHO International Working Group for Drug Statistics Methodology, WHO Collaborating Centre for Drug Statistics Methodology, WHO Collaborating Centre for Drug Utilization Research and Clinical Pharmacological Services. Oslo, Norway; 2003.

14. Last JM. A dictionary of epidemiology. 4th ed. New York: Oxford University Press, 2001. 15. World Health Organization. The importance of pharmacovigilance. Safety monitoring of medicinal products. Geneva, 2002.

16. World Health Organization. Lexicon of alcohol and drug terms. Chapter 1. Substance Abuse terminology. WHO. Geneva. 1994.

17. World Health Organization. The Rational Use of Drugs. Report of the Conference of Experts. WHO; Geneva: 1985.

18. World Health Organisation. Promoting rational use of medicines: Core components- WHO Policy perspectives on medicines. 2002.

19. Witoft G, Ericsson O, Fastbom J. Prescription drugs: Health in Sweden: The National Public Health Report 2012: Chapter 18. Scand J Public Health. 2012;40(9 Suppl):293-304.

20. Looking back on the millennium in medicine. The New England journal of medicine. 2000 Jan 6;342(1):42-9. PubMed PMID: 10620649.

21. Hepler CD, Strand LM. Opportunities and responsibilities in pharmaceutical care. American journal of hospital pharmacy. 1990 Mar;47(3):533-43. PubMed PMID: 2316538.

22. Nelson KM, Talbert RL. Drug-related hospital admissions. Pharmacotherapy. 1996 JulAug;16(4):701-7. PubMed PMID: 8840382.

23. Lazarou J, Pomeranz BH, Corey PN. Incidence of adverse drug reactions in hospitalized patients: a meta-analysis of prospective studies. Jama. 1998 Apr 15;279(15):1200-5. PubMed PMID: 9555760.

24. World Health Organization. International drug monitoring: The role of the hospital. Report No. 498. World Health Organization. 1972; Geneva.

25. Reason J. Human error: models and management. Bmj. 2000 Mar 18;320(7237):768-70.

PubMed PMID: 10720363. Pubmed Central PMCID: 1117770. 
26. Morimoto T, Gandhi TK, Seger AC, Hsieh TC, Bates DW. Adverse drug events and medication errors: detection and classification methods. Quality \& safety in health care. 2004 Aug;13(4):306-14. PubMed PMID: 15289635. Pubmed Central PMCID: 1743868.

27. Kanjanarat P, Winterstein AG, Johns TE, Hatton RC, Gonzalez-Rothi R, Segal R. Nature of preventable adverse drug events in hospitals: a literature review. American journal of healthsystem pharmacy : AJHP : official journal of the American Society of Health-System Pharmacists. 2003 Sep 1;60(17):1750-9. PubMed PMID: 14503111.

28. Amery WK, Ispe. Why there is a need for pharmacovigilance. Pharmacoepidemiology and drug safety. 1999 Jan;8(1):61-4. PubMed PMID: 15073950.

29. BL S. Study designs available for pharmacoepidemiology studies. In: Chichester, editor. Pharmacoepidemiology Wiley and Sons Ltd; 2005. p. 17-28.

30. Sorensen HT, Lash TL, Rothman KJ. Beyond randomized controlled trials: a critical comparison of trials with nonrandomized studies. Hepatology. 2006 Nov;44(5):1075-82. PubMed PMID: 17058242.

31. Van Spall HG, Toren A, Kiss A, Fowler RA. Eligibility criteria of randomized controlled trials published in high-impact general medical journals: a systematic sampling review. Jama. 2007 Mar 21;297(11):1233-40. PubMed PMID: 17374817.

32. Council of Europe. Practices. EGoSM. Creation of a better medication safety culture in Europe: Building up safe medication practices. Council of Europe; 2006.

33. Bates DW, Larizgoitia, Prasopa-Plaizier N, Jha AK. Research priority setting working group of the WHO World Alliance for Patient Safety. Global priorities for patient safety research. BMJ 2009;14(338):17775.

34. National Board of Health and Welfare. Report. Current status of patient safety 2013 [n Swedish: Lägesrapport inom patientsäkerhetsområdet 2013]. Västerås, 2013.

35. World Health Organization, Collaborating Centre for Drug Statistics Methodology, Guidelines for ATC classification and DDD assignment, 2015. Oslo, 2014.

36. Whiteford HA, Degenhardt L, Rehm J, Baxter AJ, Ferrari AJ, Erskine HE, et al. Global burden of disease attributable to mental and substance use disorders: findings from the Global Burden of Disease Study 2010. Lancet. 2013 Nov 9;382(9904):1575-86. PubMed PMID: 23993280.

37. Organisation of Economic and Cooperative Development (OECD). Mental Health and Work: Sweden, Mental Health and Work, OECD Publishing, Paris. DOI: http://dx.doi.org/10.1787/9789264188730-en. 
38. Försäkringskassan. Social Insurance Report 2014. [In Swedish: Socialförsäkringsrapport 2014:4. Sjukfrånvaro i psykiska diagnoser]. Stokholm, Sweden. 2014.

39. National Board of Health and Welfare. Report of the National Board of Health and Welfare. [In Swedish: Folkhälsorapport 2009]. Socialstyrelsen, Stockholm, 2014.

40. Goldberg DS, McGee SJ. Pain as a global public health priority. BMC public health. 2011;11:770. PubMed PMID: 21978149. Pubmed Central PMCID: 3201926.

41. Phillips CJ. The Cost and Burden of Chronic Pain. Reviews in pain. 2009 Jun;3(1):2-5. PubMed PMID: 26526940. Pubmed Central PMCID: 4590036.

42. Statens beredning för medicinsk utvärdering (SBU). [In Swedish: Rehabilitering vid långvarig smärta. En systematisk litteraturöversikt. Stockholm: Statens beredning för medicinsk utvärdering (SBU); 2010. SBU-rapport nr 198.] ISBN 978-91-85413-34-8.

43. Covanis A, Guekht A, Li S, Secco M, Shakir R, Perucca E. From global campaign to global commitment: The World Health Assembly's Resolution on epilepsy. Epilepsia. 2015 Nov;56(11):1651-7. PubMed PMID: 26391429.

44. de Boer HM, Mula M, Sander JW. The global burden and stigma of epilepsy. Epilepsy \& behavior : E\&B. 2008 May;12(4):540-6. PubMed PMID: 18280210.

45. Medical Products Agency (MPA). Pharmacological treatment of epilepsy. Information 2001:1. [In Swedish: Epilepsi- definitioner, klassifikationer och epidemiologi. I: Läkemedelsbehandling av epilepsi-bakgrundsdokumentation. Information från Läkemedelsverket 2011:1]. Medical Products Agency,Uppsala, Sweden, 2011. .

46. Crocq MA. Historical and cultural aspects of man's relationship with addictive drugs. Dialogues in clinical neuroscience. 2007;9(4):355-61. PubMed PMID: 18286796. Pubmed Central PMCID: 3202501.

47. Vetulani J. Drug addiction. Part I. Psychoactive substances in the past and presence. Polish journal of pharmacology. 2001 May-Jun;53(3):201-14. PubMed PMID: 11785921.

48. World Health Organization, 2006. Technical report of the WHO Expert Committee on Drug Dependence, WHO technical report series 942, 34:threport, Geneva, March 2006.

49. National Board of Health and Welfare.Statistics on drug sales for prescription drugs of ATC N, 2006-2015. Accessed on 8 June 2016.

http://www.socialstyrelsen.se/statistik/statistikdatabas/lakemedel.

50. National Board of Health and Welfare. Drug sales statistics. Accessed on 8 June 2016.. http://www.socialstyrelsen.se/statistik/statistikdatabas/lakemedel. 
51. European Monitoring Centre for Drug and Drug Addiction (EMCDDA). Insights, Report No 19. Comorbidity of substance use and mental disorders in Europe. EMCDDA, Lisbon, Portugal, 2015. .

52. Ruths S, Straand J, Nygaard HA. Multidisciplinary medication review in nursing home residents: what are the most significant drug-related problems? The Bergen District Nursing Home (BEDNURS) study. Quality \& safety in health care. 2003 Jun;12(3):176-80. PubMed PMID: 12792006. Pubmed Central PMCID: 1743717.

53. Hakkarainen KM, Andersson Sundell K, Petzold M, Hagg S. Prevalence and perceived preventability of self-reported adverse drug events--a population-based survey of 7099 adults. PloS one. 2013;8(9):e73166. PubMed PMID: 24023828. Pubmed Central PMCID: 3762841. 54. Einarson TR. Drug-related hospital admissions. The Annals of pharmacotherapy. 1993 JulAug;27(7-8):832-40. PubMed PMID: 8364259.

55. Kongkaew C, Noyce PR, Ashcroft DM. Hospital admissions associated with adverse drug reactions: a systematic review of prospective observational studies. The Annals of pharmacotherapy. 2008 Jul;42(7):1017-25. PubMed PMID: 18594048.

56. Tache SV, Sonnichsen A, Ashcroft DM. Prevalence of adverse drug events in ambulatory care: a systematic review. The Annals of pharmacotherapy. 2011 Jul;45(7-8):977-89. PubMed PMID: 21693697.

57. Howard RL, Avery AJ, Slavenburg S, Royal S, Pipe G, Lucassen P, et al. Which drugs cause preventable admissions to hospital? A systematic review. British journal of clinical pharmacology. 2007 Feb;63(2):136-47. PubMed PMID: 16803468. Pubmed Central PMCID: 2000562.

58. Balster RL, Bigelow GE. Guidelines and methodological reviews concerning drug abuse liability assessment. Drug and alcohol dependence. 2003 Jun 5;70(3 Suppl):S13-40. PubMed PMID: 12759195.

59. Expert P. Abuse liability assessment of CNS drugs: conclusions, recommendations, and research priorities. Drug and alcohol dependence. 2003 Jun 5;70(3 Suppl):S107-14. PubMed PMID: 12759201.

60. Food and Drug Administration (FDA). Guidance for Industry. Assessment of Abuse Potential of Drugs. Draft guidance. U.S Food and Drug Administration, Centre for Drug Evaluation and Research (CDER). Silver Spring, MD, 2010.

61. Bardo MT. Neuropharmacological mechanisms of drug reward: beyond dopamine in the nucleus accumbens. Critical reviews in neurobiology. 1998;12(1-2):37-67. PubMed PMID: 9444481. 
62. Scofield MD, Heinsbroek JA, Gipson CD, Kupchik YM, Spencer S, Smith AC, et al. The Nucleus Accumbens: Mechanisms of Addiction across Drug Classes Reflect the Importance of Glutamate Homeostasis. Pharmacological reviews. 2016 Jul;68(3):816-71. PubMed PMID: 27363441. Pubmed Central PMCID: 4931870.

63. Contet C, Kieffer BL, Befort K. Mu opioid receptor: a gateway to drug addiction. Current opinion in neurobiology. 2004 Jun;14(3):370-8. PubMed PMID: 15194118.

64. Volkow ND, Morales M. The Brain on Drugs: From Reward to Addiction. Cell. 2015 Aug 13;162(4):712-25. PubMed PMID: 26276628.

65. American Academy of Pain Medicine, American Pain Society, and American Society of Addiction Medicine consensus document, 2001.

66. Edwards IR, Aronson JK. Adverse drug reactions: definitions, diagnosis, and management. Lancet. 2000 Oct 7;356(9237):1255-9. PubMed PMID: 11072960.

67. American Psychiatric Association (APA). Diagnostic and Statistical Manual of Mental Disorders (DSM-IV). Fourth ed. Washington, DC: American Psychiatric Association; 2000. 68. World Health Organization (WHO). The international Classification of Diseases and Related Health Problems. Tenth revision. Version for 2016. WHO, Geneva. Accessed on: 20 July 2016. http://apps.who.int/classifications/icd10/browse/2016/en\#/V.

69. Blanch B, Buckley NA, Mellish L, Dawson AH, Haber PS, Pearson SA. Harmonizing postmarket surveillance of prescription drug misuse: a systematic review of observational studies using routinely collected data (2000-2013). Drug safety. 2015 Jun;38(6):553-64. PubMed PMID: 25968812.

70. Secora AM, Dormitzer CM, Staffa JA, Dal Pan GJ. Measures to quantify the abuse of prescription opioids: a review of data sources and metrics. Pharmacoepidemiology and drug safety. 2014 Dec;23(12):1227-37. PubMed PMID: 25257660.

71. Barrett SP, Meisner JR, Stewart SH. What constitutes prescription drug misuse? Problems and pitfalls of current conceptualizations. Current drug abuse reviews. 2008 Nov;1(3):255-62. PubMed PMID: 19630724.

72. Casati A, Sedefov R, Pfeiffer-Gerschel T. Misuse of medicines in the European Union: a systematic review of the literature. European addiction research. 2012;18(5):228-45. PubMed PMID: 22572594.

73. Smith SM, Dart RC, Katz NP, Paillard F, Adams EH, Comer SD, et al. Classification and definition of misuse, abuse, and related events in clinical trials: ACTTION systematic review and recommendations. Pain. 2013 Nov;154(11):2287-96. PubMed PMID: 23792283. 
74. Zacny J, Bigelow G, Compton P, Foley K, Iguchi M, Sannerud C. College on Problems of Drug Dependence taskforce on prescription opioid non-medical use and abuse: position statement. Drug and alcohol dependence. 2003 Apr 1;69(3):215-32. PubMed PMID: 12633908. 75. Food and Drug Administration (FDA). Working definition of misuse presented joint meeting of the Anesthetic and Life Support Drugs Advisory Committee. FDA. July 2010. 76. Food and Drug Administration (FDA). Working definition of abuse presented joint meeting of the Anesthetic and Life Support Drugs Advisory Committee. FDA. July 2010.

77. Meyboom RH, Lindquist M, Egberts AC. An ABC of drug-related problems. Drug safety. 2000 Jun;22(6):415-23. PubMed PMID: 10877036.

78. Bramness JG, Henriksen B, Person O, Mann K. A bibliometric analysis of European versus USA research in the field of addiction. Research on alcohol, narcotics, prescription drug abuse, tobacco and steroids 2001-2011. European addiction research. 2014;20(1):16-22. PubMed PMID: 23921359.

79. Hallas J. Drug utilization statistics for individual-level pharmacy dispensing data. Pharmacoepidemiology and drug safety. 2005 Jul;14(7):455-63. PubMed PMID: 15651088. 80. United States Department of Health and Human Services. Post-marketing requirements for the class-wide extended-release/long-acting opioid analgesics. 2014. Accessed 22 June 2016. http://www.fda.gov/drugs/newsevents/ucm384489.htm.

81. Darke S. Polydrug use and overdose: overthrowing old myths. Addiction. 2003 Jun;98(6):711. PubMed PMID: 12780352.

82. Jones JD, Mogali S, Comer SD. Polydrug abuse: a review of opioid and benzodiazepine combination use. Drug and alcohol dependence. 2012 Sep 1;125(1-2):8-18. PubMed PMID: 22857878. Pubmed Central PMCID: 3454351.

83. Inciardi JA, Surratt HL, Cicero TJ, Beard RA. Prescription opioid abuse and diversion in an urban community: the results of an ultrarapid assessment. Pain medicine. 2009 Apr;10(3):537-48. PubMed PMID: 19416440. Pubmed Central PMCID: 2719877.

84. Inciardi JA, Surratt HL, Kurtz SP, Cicero TJ. Mechanisms of prescription drug diversion among drug-involved club- and street-based populations. Pain medicine. 2007 Mar;8(2):171-83. PubMed PMID: 17305688. Pubmed Central PMCID: 2879025.

85. Cutler KA. Prescription stimulants are "a okay": applying neutralization theory to college students' nonmedical prescription stimulant use. Journal of American college health : J of ACH. 2014;62(7):478-86. PubMed PMID: 24901548. 
86. Drazdowski TK. A systematic review of the motivations for the non-medical use of prescription drugs in young adults. Drug and alcohol dependence. 2016 May 1;162:3-25. PubMed PMID: 26851986.

87. McCabe SE, West BT, Boyd CJ. Motives for medical misuse of prescription opioids among adolescents. The journal of pain : official journal of the American Pain Society. 2013 Oct;14(10):1208-16. PubMed PMID: 23954519. Pubmed Central PMCID: 3792708.

88. Bowen; D. D. Bowen; G. Kisuule; H. Ogasawara; Ch. J. P. Siregar; G. A. Williams; C. Hall; G. Lingam; S. Mann; J. A. Reinstein; M. Couper; J. Idänpään-Heikkilä; J. Yoshida. Guidelines for the Regulatory Assessment of Medicinal Products for use in Self-Medication. World Health Organization, Geneva, 2001.

89. Duncan DF. Letter: Drug abuse as a coping mechanism. The American journal of psychiatry. 1974 Jun;131(6):724. PubMed PMID: 4827807.

90. Michelini S, Cassano GB, Frare F, Perugi G. Long-term use of benzodiazepines: tolerance, dependence and clinical problems in anxiety and mood disorders. Pharmacopsychiatry. 1996 Jul;29(4):127-34. PubMed PMID: 8858711.

91. Ford JA, Lacerenza C. The relationship between source of diversion and prescription drug misuse, abuse, and dependence. Substance use \& misuse. 2011;46(6):819-27. PubMed PMID: 21174499 .

92. Kelly BC, Rendina HJ, Vuolo M, Wells BE, Parsons JT. A typology of prescription drug misuse: a latent class approach to differences and harms. Drug and alcohol review. 2015 Mar;34(2):211-20. PubMed PMID: 25196636. Pubmed Central PMCID: 4362965.

93. McCabe SE, Boyd CJ, Teter CJ. Subtypes of nonmedical prescription drug misuse. Drug and alcohol dependence. 2009 Jun 1;102(1-3):63-70. PubMed PMID: 19278795. Pubmed Central PMCID: 2975029.

94. McCabe SE, Cranford JA. Motivational subtypes of nonmedical use of prescription medications: results from a national study. The Journal of adolescent health : official publication of the Society for Adolescent Medicine. 2012 Nov;51(5):445-52. PubMed PMID: 23084165. Pubmed Central PMCID: 3479410.

95. McKernan LC, Nash MR, Gottdiener WH, Anderson SE, Lambert WE, Carr ER. Further evidence of self-medication: personality factors influencing drug choice in substance use disorders. Psychodynamic psychiatry. 2015 Jun;43(2):243-75. PubMed PMID: 26039231. 96. Wu LT, Woody GE, Yang C, Pan JJ, Blazer DG. Abuse and dependence on prescription opioids in adults: a mixture categorical and dimensional approach to diagnostic classification. 
Psychological medicine. 2011 Mar;41(3):653-64. PubMed PMID: 20459887. Pubmed Central PMCID: 3086580.

97. European Medicines Agency (EMA).Guideline on the non-clinical investigation of the dependence potential of medicinal products. EMEA/CHMP/SWP/94227/2004. EMA, London, 2006.

98. UK Parliament, 1971. Misuse of Drugs Act, c. 38, Parliament of the United Kingdom of Great Britain and Northern Ireland, 1971.

99. Food and Drug Administration (FDA), 1970. Controlled Substances Act, Comprehensive Drug Abuse Prevention and Control Act, Public law no 91-51384 Stat. 1242. The 91st United States Congress, 1970, USA.

100. Food and Drug Administration (FDA). Guidance for Industry. Assessment of Abuse Potential of Drugs. Draft guidance. U.S Food and Drug Administration, Centre for Drug Evaluation and Research (CDER). Silver Spring, MD, USA, 2010.

101. Ator NA, Griffiths RR. Principles of drug abuse liability assessment in laboratory animals. Drug and alcohol dependence. 2003 Jun 5;70(3 Suppl):S55-72. PubMed PMID: 12759197. 102. Caster O, Edwards IR, Noren GN, Lindquist M. Earlier discovery of pregabalin's dependence potential might have been possible. European journal of clinical pharmacology. 2011 Mar;67(3):319-20. PubMed PMID: 20972557.

103. Califf RM, Woodcock J, Ostroff S. A Proactive Response to Prescription Opioid Abuse. The New England journal of medicine. 2016 Apr 14;374(15):1480-5. PubMed PMID: 26845291. 104. Lapeyre-Mestre M, Dupui M. Drug abuse monitoring: which pharmacoepidemiological resources at the European level? Therapie. 2015 Mar-Apr;70(2):147-65. PubMed PMID: 25858571.

105. European Monitoring Centre for Drugs and Drug Addiction (EMCDDA). European Drug Report for 2015. Trends and Developments.Lisbon, Portugal, 2015.

106. Hernandez SH, Nelson LS. Prescription drug abuse: insight into the epidemic. Clinical pharmacology and therapeutics. 2010 Sep;88(3):307-17. PubMed PMID: 20686478.

107. Saha TD, Kerridge BT, Goldstein RB, Chou SP, Zhang H, Jung J, et al. Nonmedical Prescription Opioid Use and DSM-5 Nonmedical Prescription Opioid Use Disorder in the United States. The Journal of clinical psychiatry. 2016 Jun;77(6):772-80. PubMed PMID: 27337416.

108. Roussin A, Doazan-d'Ouince O, Geniaux H, Halberer C, French Network of Centre for E, Information on P. Evaluation of abuse and dependence in addiction monitoring systems: tramadol as an example. Therapie. 2015 Mar-Apr;70(2):203-21. PubMed PMID: 25858577. 
109. Furu K, Wettermark B, Andersen M, Martikainen JE, Almarsdottir AB, Sorensen HT. The Nordic countries as a cohort for pharmacoepidemiological research. Basic \& clinical pharmacology \& toxicology. 2010 Feb;106(2):86-94. PubMed PMID: 19961477.

110. Hakkinen M, Vuori E, Ojanpera I. Prescription opioid abuse based on representative postmortem toxicology. Forensic science international. 2014 Dec;245:121-5. PubMed PMID: 25447184.

111. Wettermark B, Hammar N, Fored CM, Leimanis A, Otterblad Olausson P, Bergman U, et al. The new Swedish Prescribed Drug Register--opportunities for pharmacoepidemiological research and experience from the first six months. Pharmacoepidemiology and drug safety. 2007 Jul;16(7):726-35. PubMed PMID: 16897791.

112. Schjerning O, Pottegard A, Damkier P, Rosenzweig M, Nielsen J. Use of Pregabalin - A Nationwide Pharmacoepidemiological Drug Utilization Study with Focus on Abuse Potential. Pharmacopsychiatry. 2016 Jul;49(4):155-61. PubMed PMID: 26951495.

113. Pottegård. Pottegård A, Tjäderborn M, Schjerning O, Nielsen J, Damkier P, Bodén R. Re: Pregabalin prescriptions in the United Kingdom: A drug utilisation study of The Health Improvement Network (THIN) primary care database, by Asomaning et al. Int J Clin Pract. 2016 Aug;70(8):696. doi: 10.1111/ijcp.12836.

114. Boden R, Wettermark B, Brandt L, Kieler H. Factors associated with pregabalin dispensing at higher than the approved maximum dose. European journal of clinical pharmacology. 2014 Feb;70(2):197-204. PubMed PMID: 24141597.

115. Birt J, Johnston J, Nelson D. Exploration of claims-based utilization measures for detecting potential nonmedical use of prescription drugs. Journal of managed care \& specialty pharmacy. 2014 Jun;20(6):639-46. PubMed PMID: 24856602.

116. Rasmussen L, Zoega H, Hallas J, Pottegard A. Deviant patterns of methylphenidate use in adults: a Danish nationwide registry-based drug utilization study. Pharmacoepidemiology and drug safety. 2015 Nov;24(11):1189-96. PubMed PMID: 26278467.

117. Fischer B, Bibby M, Bouchard M. The global diversion of pharmaceutical drugsnon-medical use and diversion of psychotropic prescription drugs in North America: a review of sourcing routes and control measures. Addiction. 2010 Dec;105(12):2062-70. PubMed PMID: 20840172. 118. Campbell G, Bruno R, Lintzeris N, Cohen M, Nielsen S, Hall W, et al. Defining problematic pharmaceutical opioid use among people prescribed opioids for chronic noncancer pain: do different measures identify the same patients? Pain. 2016 Jul;157(7):1489-98. PubMed PMID: 26963848. 
119. Kuehn BM. Prescription drug abuse rises globally. Jama. 2007 Mar 28;297(12):1306. PubMed PMID: 17392232.

120. United Nations (UN). Report of the International Narcotics Control Board for 2014. International Narcotic Control Board. Geneva, 2015.

121. The Swedish Council for Information on Alcohol and Other Drugs (CAN). Prescription drugs in drug abuse settings in 2012. [In Swedish: CAN. Läkemedel i missbruksmiljöer. Situationen 2012 enligt rapportörer vid länspolismyndigheterna. CAN rapport 138.] CAN, Stockholm, Sweden, 2013.

122. The Swedish Council for Information on Alcohol and Other Drugs. Drug trends in Sweden 2014. [In Swedish: Centralförbundet för alkohol- och narkotikaupplysning. Drogutvecklingen I Sverige 2014. CAN rapport 144.] CAN. Stockholm, 2014.

123. United States Department of Health and Human Services, Substance Abuse and Mental Health Services Administration. Results from the 2012 National Survey on Drug Use and Health. Rockville, Maryland, USA, 2013.

124. Weisberg DF, Becker WC, Fiellin DA, Stannard C. Prescription opioid misuse in the United States and the United Kingdom: cautionary lessons. The International journal on drug policy. 2014 Nov;25(6):1124-30. PubMed PMID: 25190034.

125. United Nations (UN). Office on Drugs and Crime (UNODC). World Drug Reports 2015. UNODC. New York, USA. 2015.

126. United States Department of Health and Human Services, Substance Abuse and Mental Health Services Administration, Center for Behavioural Health Statistics and Quality. The NSDUH Report: Trends in Adolescent Substance Use and Perception of Risk from Substance Use. NSDUH. Rocville, Maryland, USA, 2013.

127. Hall AJ, Logan JE, Toblin RL, Kaplan JA, Kraner JC, Bixler D, et al. Patterns of abuse among unintentional pharmaceutical overdose fatalities. Jama. 2008 Dec 10;300(22):2613-20. PubMed PMID: 19066381.

128. Fischer B, Keates A, Buhringer G, Reimer J, Rehm J. Non-medical use of prescription opioids and prescription opioid-related harms: why so markedly higher in North America compared to the rest of the world? Addiction. 2014 Feb;109(2):177-81. PubMed PMID: 23692335.

129. Wang KH, Becker WC, Fiellin DA. Prevalence and correlates for nonmedical use of prescription opioids among urban and rural residents. Drug and alcohol dependence. 2013 Jan 1;127(1-3):156-62. PubMed PMID: 22819293. 
130. Lapeyre-Mestre M, Gony M, Carvajal A, Macias D, Conforti A, D'Incau P, et al. A European community pharmacy-based survey to investigate patterns of prescription fraud through identification of falsified prescriptions. European addiction research. 2014;20(4):174-82. PubMed PMID: 24458222.

131. Pauly V, Pradel V, Pourcel L, Nordmann S, Frauger E, Lapeyre-Mestre M, et al. Estimated magnitude of diversion and abuse of opioids relative to benzodiazepines in France. Drug and alcohol dependence. 2012 Nov 1;126(1-2):13-20. PubMed PMID: 22475815.

132. Grosshans M, Lemenager T, Vollmert C, Kaemmerer N, Schreiner R, Mutschler J, et al. Pregabalin abuse among opiate addicted patients. European journal of clinical pharmacology. 2013 Dec;69(12):2021-5. PubMed PMID: 23989299.

133. Nordmann S, Pradel V, Lapeyre-Mestre M, Frauger E, Pauly V, Thirion X, et al. Doctor shopping reveals geographical variations in opioid abuse. Pain physician. 2013 Jan;16(1):89-100. PubMed PMID: 23340537.

134. Frauger E, Nordmann S, Orleans V, Pradel V, Pauly V, Thirion X, et al. Which psychoactive prescription drugs are illegally obtained and through which ways of acquisition? About OPPIDUM survey. Fundamental \& clinical pharmacology. 2012 Aug;26(4):549-56. PubMed PMID: 21564282.

135. van Amsterdam J, van den Brink W. The Misuse of Prescription Opioids: A Threat for Europe? Current drug abuse reviews. 2015;8(1):3-14. PubMed PMID: 26084418.

136. United Nations Office on Drugs and Crime (UNODC). Swedens' succesful drug policy: a review of the evidence. UNDOC, 2007 (Ort och land ej angiveni rapporten).

137. The Swedish Police and Swedish Border Authority. The Swedish Drug Situation 2010-2012. [In Swedish: Rikskriminalpolisen och Tullverket. Drogsituationen. Lägesbild i Sverige 20102012.]. Rikskriminalpolisen och Tullverket, Sweden. 2013.

138. Medical Products Agency (MPA). Report from operation Pangea VIII. [In Swedish: MPA. Du kan behöva fråga var din patient köpt sina läkemedel.] 2016. Accessed 6 July 2016. https://lakemedelsverket.se/upload/nyheter/2016/Pangea_bilaga.pdf. 139. Official report of the Swedish Government. [n Swedish. Statens offentliga utredningar (SOU). SOU 2011:35. Bättre insatser vid missbruk och beroende. Individen, kunskapen och ansvaret. Slutbetänkande av Missbruksutredningen.] Stockholm, Sweden, 2011. .

140. Statens folkhälsoinstitut. The use of narcotic drugs in Sweden. [In Swedish: Narkotikabruket I Sverige. Statens folkhälsoinstitut. R 2010:13.] Östersund, Sweden, 2010. Accessed on 6 July 2016. https://www.folkhalsomyndigheten.se/pagefiles/12498/R2010-13Narkotikabruket-i-Sverige.pdf. 
141. The Swedish Council for Information on Alcohol and Other Drugs (CAN). Report. [n Swedish: ANDT-bruket och dess negativa konsekvenser i den svenska befolkningen 2013 - en studie med fokus på missbruk och beroende samt problem för andra än brukaren relaterat till alkohol, narkotika, dopning och tobak. Rapport nr 55.] CAN, Stockholm, 2014.

142. The Swedish Council for Information on Alcohol and Other Drugs (CAN). [In Swedish: Skolelevers drogvanor 2015. CAN Rapport 154.] Centralförbundet för alkohol- och narkotikaupplysning (CAN), Stockholm, 2015.

143. Naslund S, Dahlqvist R. Treatment with tramadol can give rise to dependence and abuse. [In Swedish: Tramadolanvandning kan skapa beroende och missbruk]. Lakartidningen. 2003 Feb 27;100(9):712-4. PubMed PMID: 12674559.

144. Johnson B, Richert T. Diversion of methadone and buprenorphine by patients in opioid substitution treatment in Sweden: prevalence estimates and risk factors. The International journal on drug policy. 2015 Feb;26(2):183-90. PubMed PMID: 25465344.

145. Ronka S, Karjalainen K, Vuori E, Makela P. Personally prescribed psychoactive drugs in overdose deaths among drug abusers: a retrospective register study. Drug and alcohol review. 2015 Jan;34(1):82-9. PubMed PMID: 25110189.

146. Paulozzi LJ, Strickler GK, Kreiner PW, Koris CM, Centers for Disease C, Prevention. Controlled Substance Prescribing Patterns--Prescription Behavior Surveillance System, Eight States, 2013. Morbidity and mortality weekly report Surveillance summaries. 2015 Oct 16;64(9):114. PubMed PMID: 26469747.

147. McCrory EJ, Mayes L. Understanding Addiction as a Developmental Disorder: An Argument for a Developmentally Informed Multilevel Approach. Current addiction reports. 2015;2(4):326-30. PubMed PMID: 26550551. Pubmed Central PMCID: 4628052.

148. Abrahamsson T, Hakansson A. Nonmedical prescription drug use (NMPDU) in the Swedish general population--correlates of analgesic and sedative use. Substance use \& misuse. 2015 Jan;50(2):148-55. PubMed PMID: 25295596.

149. Blanco C, Alderson D, Ogburn E, Grant BF, Nunes EV, Hatzenbuehler ML, et al. Changes in the prevalence of non-medical prescription drug use and drug use disorders in the United States: 1991-1992 and 2001-2002. Drug and alcohol dependence. 2007 Oct 8;90(2-3):252-60. PubMed PMID: 17513069.

150. Compton WM, Thomas YF, Stinson FS, Grant BF. Prevalence, correlates, disability, and comorbidity of DSM-IV drug abuse and dependence in the United States: results from the national epidemiologic survey on alcohol and related conditions. Archives of general psychiatry. 2007 May;64(5):566-76. PubMed PMID: 17485608. 
151. Turner C, McClure R. Age and gender differences in risk-taking behaviour as an explanation for high incidence of motor vehicle crashes as a driver in young males. Injury control and safety promotion. 2003 Sep;10(3):123-30. PubMed PMID: 12861910.

152. Buurma H, Bouvy ML, De Smet PA, Floor-Schreudering A, Leufkens HG, Egberts AC. Prevalence and determinants of pharmacy shopping behaviour. Journal of clinical pharmacy and therapeutics. 2008 Feb;33(1):17-23. PubMed PMID: 18211612.

153. United Nations Office on Drugs and Crime (UNODC). World Drug Report 2014.

Appendix 1: Recent statistics and trend analysis of the illicit drug market. UNODC. New York, USA, 2014.

154. Simoni-Wastila L, Yang HK. Psychoactive drug abuse in older adults. The American journal of geriatric pharmacotherapy. 2006 Dec;4(4):380-94. PubMed PMID: 17296542.

155. Grey C, Hall PB. Considerations of prescription opioid abuse and misuse among older adults in West Virginia--An Under-Recognized Population at Risk. The West Virginia medical journal. 2016 May-Jun;112(3):42-7. PubMed PMID: 27301154.

156. Ford JA, Reckdenwald A, Marquardt B. Prescription drug misuse and gender. Substance use \& misuse. 2014 Jun;49(7):842-51. PubMed PMID: 24491149.

157. Ives TJ, Chelminski PR, Hammett-Stabler CA, Malone RM, Perhac JS, Potisek NM, et al. Predictors of opioid misuse in patients with chronic pain: a prospective cohort study. BMC health services research. 2006;6:46. PubMed PMID: 16595013. Pubmed Central PMCID: 1513222 .

158. Katz C, El-Gabalawy R, Keyes KM, Martins SS, Sareen J. Risk factors for incident nonmedical prescription opioid use and abuse and dependence: results from a longitudinal nationally representative sample. Drug and alcohol dependence. 2013 Sep 1;132(1-2):107-13. PubMed PMID: 23399466.

159. European Monitoring Centre for Drugs and Drug Addiction (EMCDDA). Comorbidity of substance use and mental disorders in Europe. EMCDDA, Lisbon, Portugal, 2015.

160. Toblin RL, Paulozzi LJ, Logan JE, Hall AJ, Kaplan JA. Mental illness and psychotropic drug use among prescription drug overdose deaths: a medical examiner chart review. The Journal of clinical psychiatry. 2010 Apr;71(4):491-6. PubMed PMID: 20409446.

161. Martins SS, Keyes KM, Storr CL, Zhu H, Chilcoat HD. Pathways between nonmedical opioid use/dependence and psychiatric disorders: results from the National Epidemiologic Survey on Alcohol and Related Conditions. Drug and alcohol dependence. 2009 Jul 1;103(12):16-24. PubMed PMID: 19414225. Pubmed Central PMCID: 2699563. 
162. Fischer B, Lusted A, Roerecke M, Taylor B, Rehm J. The prevalence of mental health and pain symptoms in general population samples reporting nonmedical use of prescription opioids: a systematic review and meta-analysis. The journal of pain : official journal of the American Pain Society. 2012 Nov;13(11):1029-44. PubMed PMID: 23040158.

163. Shand FL, Degenhardt L, Nelson EC, Mattick RP. Predictors of social anxiety in an opioid dependent sample and a control sample. Journal of anxiety disorders. 2010 Jan;24(1):49-54. PubMed PMID: 19775865. Pubmed Central PMCID: 3001130. 164. Schepis TS, Hakes JK. Non-medical prescription use increases the risk for the onset and recurrence of psychopathology: results from the National Epidemiological Survey on Alcohol and Related Conditions. Addiction. 2011 Dec;106(12):2146-55. PubMed PMID: 21631624. 165. McCabe SE, West BT, Boyd CJ. Medical use, medical misuse, and nonmedical use of prescription opioids: results from a longitudinal study. Pain. 2013 May;154(5):708-13. PubMed PMID: 23433943. Pubmed Central PMCID: 3622844.

166. Fredheim OM, Skurtveit S, Moroz A, Breivik H, Borchgrevink PC. Prescription pattern of codeine for non-malignant pain: a pharmacoepidemiological study from the Norwegian Prescription Database. Acta anaesthesiologica Scandinavica. 2009 May;53(5):627-33. PubMed PMID: 19419357.

167. Sutherland I, Shepherd JP. Social dimensions of adolescent substance use. Addiction. 2001 Mar;96(3):445-58. PubMed PMID: 11255584.

168. Farrell M, Howes S, Taylor C, Lewis G, Jenkins R, Bebbington P, et al. Substance misuse and psychiatric comorbidity: an overview of the OPCS National Psychiatric Morbidity Survey. International review of psychiatry. 2003 Feb-May;15(1-2):43-9. PubMed PMID: 12745309. 169. Lee JO, Herrenkohl TI, Kosterman R, Small CM, Hawkins JD. Educational inequalities in the co-occurrence of mental health and substance use problems, and its adult socio-economic consequences: a longitudinal study of young adults in a community sample. Public health. 2013 Aug;127(8):745-53. PubMed PMID: 23870846. Pubmed Central PMCID: 3810533.

170. Stewart TD, Reed MB. Lifetime nonmedical use of prescription medications and socioeconomic status among young adults in the United States. The American journal of drug and alcohol abuse. 2015;41(5):458-64. PubMed PMID: 26337203.

171. Charitonidi E, Studer J, Gaume J, Gmel G, Daeppen JB, Bertholet N. Socioeconomic status and substance use among Swiss young men: a population-based cross-sectional study. BMC public health. 2016;16:333. PubMed PMID: 27079787. Pubmed Central PMCID: 4832558. 
172. Rigg KK, Monnat SM. Comparing characteristics of prescription painkiller misusers and heroin users in the United States. Addictive behaviors. 2015 Dec;51:106-12. PubMed PMID: 26253938. Pubmed Central PMCID: 4558364.

173. Hall MT, Howard MO, McCabe SE. Prescription drug misuse among antisocial youths. Journal of studies on alcohol and drugs. 2010 Nov;71(6):917-24. PubMed PMID: 20946750. Pubmed Central PMCID: 2965490.

174. Keyes KM, Cerda M, Brady JE, Havens JR, Galea S. Understanding the rural-urban differences in nonmedical prescription opioid use and abuse in the United States. American journal of public health. 2014 Feb;104(2):e52-9. PubMed PMID: 24328642. Pubmed Central PMCID: 3935688.

175. Monnat SM, Rigg KK. Examining Rural/Urban Differences in Prescription Opioid Misuse Among US Adolescents. The Journal of rural health : official journal of the American Rural Health Association and the National Rural Health Care Association. 2016 Mar;32(2):204-18. PubMed PMID: 26344571. Pubmed Central PMCID: 4779738.

176. Wang KH, Fiellin DA, Becker WC. Source of prescription drugs used nonmedically in rural and urban populations. The American journal of drug and alcohol abuse. 2014 Jul;40(4):292-303. PubMed PMID: 24853143.

177. Martel MO, Wasan AD, Jamison RN, Edwards RR. Catastrophic thinking and increased risk for prescription opioid misuse in patients with chronic pain. Drug and alcohol dependence. 2013 Sep 1;132(1-2):335-41. PubMed PMID: 23618767. Pubmed Central PMCID: 3745790. 178. Wong CF, Silva K, Kecojevic A, Schrager SM, Bloom JJ, Iverson E, et al. Coping and emotion regulation profiles as predictors of nonmedical prescription drug and illicit drug use among high-risk young adults. Drug and alcohol dependence. 2013 Sep 1;132(1-2):165-71. PubMed PMID: 23453258. Pubmed Central PMCID: 4180492.

179. Schepis TS, Hakes JK. The association between nonmedical use of prescription medication status and change in health-related quality of life: results from a Nationally Representative Survey. Drug and alcohol dependence. 2014 Sep 1;142:161-7. PubMed PMID: 24999057. 180. Amodia DS, Cano C, Eliason MJ. An integral approach to substance abuse. Journal of psychoactive drugs. 2005 Dec;37(4):363-71. PubMed PMID: 16480163.

181. Zacny JP, Lichtor SA. Nonmedical use of prescription opioids: motive and ubiquity issues. The journal of pain : official journal of the American Pain Society. 2008 Jun;9(6):473-86. PubMed PMID: 18342577. Pubmed Central PMCID: 2409193.

182. Raffa RB, Friderichs E, Reimann W, Shank RP, Codd EE, Vaught JL. Opioid and nonopioid components independently contribute to the mechanism of action of tramadol, an 
'atypical' opioid analgesic. The Journal of pharmacology and experimental therapeutics. 1992 Jan;260(1):275-85. PubMed PMID: 1309873.

183. Babalonis S, Lofwall MR, Nuzzo PA, Siegel AJ, Walsh SL. Abuse liability and reinforcing efficacy of oral tramadol in humans. Drug and alcohol dependence. 2013 Apr 1;129(1-2):116-24. PubMed PMID: 23098678. Pubmed Central PMCID: 3594406.

184. Woody GE, Senay EC, Geller A, Adams EH, Inciardi JA, Schnoll S, et al. An independent assessment of MEDWatch reporting for abuse/dependence and withdrawal from Ultram (tramadol hydrochloride). Drug and alcohol dependence. 2003 Nov 24;72(2):163-8. PubMed PMID: 14636971.

185. Bush DM. Emergency Department Visits for Adverse Reactions Involving the Pain Medication Tramadol. The CBHSQ Report. Rockville (MD)2013.

186. Randall C, Crane J. Tramadol deaths in Northern Ireland: a review of cases from 1996 to 2012. Journal of forensic and legal medicine. 2014 Mar;23:32-6. PubMed PMID: 24661703. 187.Simonsen KW, Edvardsen HM, Thelander G, Ojanpera I, Thordardottir S, Andersen LV, et al. Fatal poisoning in drug addicts in the Nordic countries in 2012. Forensic science international. 2015 Mar;248:172-80. PubMed PMID: 25645132.

188. McDiarmid T, Mackler L, Schneider DM. Clinical inquiries. What is the addiction risk associated with tramadol? The Journal of family practice. 2005 Jan;54(1):72-3. PubMed PMID: 15623411.

189. Barkin RL. Extended-release Tramadol (ULTRAM ER): a pharmacotherapeutic, pharmacokinetic, and pharmacodynamic focus on effectiveness and safety in patients with chronic/persistent pain. American journal of therapeutics. 2008 Mar-Apr;15(2):157-66. PubMed PMID: 18356636.

190. Clarkson JE, Lacy JM, Fligner CL, Thiersch N, Howard J, Harruff RC, et al. Tramadol (Ultram) concentrations in death investigation and impaired driving cases and their significance. Journal of forensic sciences. 2004 Sep;49(5):1101-5. PubMed PMID: 15461118.

191. Prescrire Int. "Weak" opioid analgesics. Codeine, dihydrocodeine and tramadol: no less risky than morphine. Prescrire Int 2016;25(168):45-50.

192. National Board of Health and Welfare. Drug sales statistics. [In Swedish: Statistikdatabas för läkemedel. Försäljning av opioider 2006-2015.]. Accessed on: 22 April 2016.

193. Ahlner J, Holmgren A, Jones AW. Prevalence of alcohol and other drugs and the concentrations in blood of drivers killed in road traffic crashes in Sweden. Scand J Public Health. 2014 Mar;42(2):177-83. PubMed PMID: 24265165. 
194. European Medicines Agency (EMA). Official website. European Summary of Product Characteristics (SPC) for Lyrica. Accessed on 3 February 2016.

http://www.ema.europa.eu/ema/index.jsp?curl=pages/medicines/human/medicines/000546/h uman_med_000894.jsp\&mid=WC0b01ac058001d124.

195. Wettermark B, Brandt L, Kieler H, Boden R. Pregabalin is increasingly prescribed for neuropathic pain, generalised anxiety disorder and epilepsy but many patients discontinue treatment. International journal of clinical practice. 2014 Jan;68(1):104-10. PubMed PMID: 23815622.

196. Harmark L, Puijenbroek E, Grootheest K. Longitudinal monitoring of the safety of drugs by using a web-based system: the case of pregabalin. Pharmacoepidemiology and drug safety. 2011 Jun;20(6):591-7. PubMed PMID: 21538671.

197. Pharma Marketing. The Top Pharma List's top 50 pharmaceutical products by global sales. Accessed on 3 February 2016.

http://www.pmlive.com/top_pharma_list/pharmaceutical_products/lyrica.

198. Gajraj NM. Pregabalin for pain management. Pain practice : the official journal of World Institute of Pain. 2005 Jun;5(2):95-102. PubMed PMID: 17177755.

199. Bockbrader HN, Wesche D, Miller R, Chapel S, Janiczek N, Burger P. A comparison of the pharmacokinetics and pharmacodynamics of pregabalin and gabapentin. Clinical pharmacokinetics. 2010 Oct;49(10):661-9. PubMed PMID: 20818832.

200. Schjerning O, Rosenzweig M, Pottegard A, Damkier P, Nielsen J. Abuse Potential of Pregabalin: A Systematic Review. CNS drugs. 2016 Jan;30(1):9-25. PubMed PMID: 26767525. 201. Schwan S, Sundstrom A, Stjernberg E, Hallberg E, Hallberg P. A signal for an abuse liability for pregabalin--results from the Swedish spontaneous adverse drug reaction reporting system. European journal of clinical pharmacology. 2010 Sep;66(9):947-53. PubMed PMID: 20563568. 202. Grosshans M, Mutschler J, Hermann D, Klein O, Dressing H, Kiefer F, et al. Pregabalin abuse, dependence, and withdrawal: a case report. The American journal of psychiatry. 2010 Jul;167(7):869. PubMed PMID: 20595436.

203. Sun P, Zhao Y, Zhao Z, Watson P. Medication dosing patterns associated with duloxetine and pregabalin among patients with fibromyalgia. Current medical research and opinion. 2011 Sep;27(9):1793-801. PubMed PMID: 21810060.

204. Westin AA, Strom EJ. [Yes, pregabalin can be abused!]. Tidsskrift for den Norske laegeforening : tidsskrift for praktisk medicin, ny raekke. 2010 Nov 4;130(21):2108. PubMed PMID: 21052104. Ja, pregabalin kan misbrukes! 
205. Gore M, Sadosky A, Tai KS, Stacey B. A retrospective evaluation of the use of gabapentin and pregabalin in patients with postherpetic neuralgia in usual-care settings. Clinical therapeutics. 2007 Aug;29(8):1655-70. PubMed PMID: 17919547.

206. Nordgaard J, Jurgens G. Pregabalin can cause addiction and withdrawal symptoms. [In Norwegian: Pregabalin kan medfore afhaengighed og abstinenssymptomer.]. Ugeskrift for laeger. 2015 Jan 26;177(2A):38-9. PubMed PMID: 25612958.

207. Gahr M, Freudenmann RW, Hiemke C, Kolle MA, Schonfeldt-Lecuona C. Pregabalin abuse and dependence in Germany: results from a database query. European journal of clinical pharmacology. 2013 Jun;69(6):1335-42. PubMed PMID: 23292158.

208. Wilens T, Zulauf C, Ryland D, Carrellas N, Catalina-Wellington I. Prescription medication misuse among opioid dependent patients seeking inpatient detoxification. The American journal on addictions / American Academy of Psychiatrists in Alcoholism and Addictions. 2015 Mar;24(2):173-7. PubMed PMID: 25864607.

209. Kriikku P, Wilhelm L, Rintatalo J, Hurme J, Kramer J, Ojanpera I. Pregabalin serum levels in apprehended drivers. Forensic science international. 2014 Oct;243:112-6. PubMed PMID: 25072779 .

210. Landmark CJ, Fossmark H, Larsson PG, Rytter E, Johannessen SI. The prescription registry and abuse of pregabalin. [In Norwegian: Reseptregisteret og misbruk av pregabalin.] Tidsskrift for den Norske laegeforening : tidsskrift for praktisk medicin, ny raekke. 2011 Feb 4;131(3):223. PubMed PMID: 21304565.

211. Asomaning K, Abramsky S, Liu Q, Zhou X, Sobel RE, Watt S. Pregabalin prescriptions in the United Kingdom: a drug utilisation study of The Health Improvement Network (THIN) primary care database. International journal of clinical practice. 2016 May;70(5):380-8. PubMed PMID: 27028939.

212. Aagaard L, Hansen EH. Adverse drug reactions reported by consumers for nervous system medications in Europe 2007 to 2011. BMC pharmacology \& toxicology. 2013;14:30. PubMed PMID: 23763896. Pubmed Central PMCID: 3685574.

213. Hakkinen M, Launiainen T, Vuori E, Ojanpera I. Comparison of fatal poisonings by prescription opioids. Forensic science international. 2012 Oct 10;222(1-3):327-31. PubMed PMID: 22884575.

214. Strassels SA. Economic burden of prescription opioid misuse and abuse. Journal of managed care pharmacy : JMCP. 2009 Sep;15(7):556-62. PubMed PMID: 19739878. 
215. Wiholm BE, Westerholm B. Drug utilization and morbidity statistics for the evaluation of drug safety in Sweden. Acta medica Scandinavica Supplementum. 1984;683:107-17. PubMed PMID: 6430038.

216. Rosén M. A finger on the pulse- Monitoring public health and social conditions in Sweden 1992-2002. Centre for Epidemiology, National Board of Health and Welfare. Stockholm. 2003. 217. National Corporation of Pharmacies.Drug Sale statistics. Apoteket AB, Sweden. 218. Rosenberg ML, Davidson LE, Smith JC, Berman AL, Buzbee H, Gantner G, et al. Operational criteria for the determination of suicide. Journal of forensic sciences. 1988 Nov;33(6):1445-56. PubMed PMID: 3204347.

219. World Health Organization (WHO). International Classification of Disease codes. Ninth revision. World Health Organization. Geneva. 1977.

220. United Nations (UN). International Narcotics Control Board Yellow List: List of narcotic drugs under international control, Vienna, Austria, 2004.

221. Jones AW. Driving under the influence of drugs in Sweden with zero concentration limits in blood for controlled substances. Traffic injury prevention. 2005 Dec;6(4):317-22. PubMed PMID: 16266940.

222. Druid H, Holmgren P. A compilation of fatal and control concentrations of drugs in postmortem femoral blood. Journal of forensic sciences. 1997 Jan;42(1):79-87. PubMed PMID: 8988577.

223. Druid H, Holmgren P, Lowenhielm P. Computer-assisted systems for forensic pathology and forensic toxicology. Journal of forensic sciences. 1996 Sep;41(5):830-6. PubMed PMID: 15637819 .

224. Moffat. A.C. Moffat, M.D. Osselton, B.Widdop (Eds.), Clarke's analysis of drugs and poisons, fourth ed., Pharmaceutical Press, London, 2004.

225. United Nations (UN). International Narcotics Control Board Yellow List: List of narcotic drugs under international control, Vienna, Austria, 2004.

226. World Health Organization (WHO). International drug monitoring: The role of the hospital. Report No. 498. World Health Organization. 1972; Geneva.

227. Jones AW, Kugelberg FC, Holmgren A, Ahlner J. Five-year update on the occurrence of alcohol and other drugs in blood samples from drivers killed in road-traffic crashes in Sweden. Forensic science international. 2009 Apr 15;186(1-3):56-62. PubMed PMID: 19232848.

228. Goldman SA. Limitations and strengths of spontaneous reports data. Clinical therapeutics. 1998;20 Suppl C:C40-4. PubMed PMID: 9915089. 
229. Meyboom RH, Hekster YA, Egberts AC, Gribnau FW, Edwards IR. Causal or casual? The role of causality assessment in pharmacovigilance. Drug safety. 1997 Dec;17(6):374-89. PubMed PMID: 9429837.

230. Hallas J, Harvald B, Gram LF, Grodum E, Brosen K, Haghfelt T, et al. Drug related hospital admissions: the role of definitions and intensity of data collection, and the possibility of prevention. Journal of internal medicine. 1990 Aug;228(2):83-90. PubMed PMID: 2394974. 231. World Health Organisation Collaborating Centre for International Drug Monitoring. Uppsala Monitoring Centre Guide: The WHO Adverse Reaction Terminology—WHO-ART Terminology for coding clinical information in relation to drug therapy. Uppsala. 2005. 232. World Health Organization. Collaborating Centre for Drug Statistics Methodology. Guidelines for ATC classification and DDD assignment, 2009. Oslo, Norway; 2008. 233. E-hälsomyndigheten. Yearly report 2015. [In Swedish: E-hälsomyndighetens Årsredovisning 2015.] Dnr: 2015/06806. E-hälsomyndigheten. Stockholm; Sweden, 2016.

234. Åkerlund M, Vissgården A. ApoDos- The National Corporation of Swedish Pharmacies' multi-dose dispensed drugs. [In Swedish: ApoDos- Apotekets dosexpedierade läkemedel]. In Läkemedelsboken 2007/2008. National Corporation of Swedish pharmacies (Apoteket AB), Sweden, 2007.

235. Pottegard A, Hallas J. Assigning exposure duration to single prescriptions by use of the waiting time distribution. Pharmacoepidemiology and drug safety. 2013 Aug;22(8):803-9. PubMed PMID: 23703741.

236. World Health Organization. Introduction to drug utilization research. WHO Collaborating Centre for Drug Statistics Methodology. World Health Organization.Oslo. 2003.

237. Andersson K, Melander A, Svensson C, Lind O, Nilsson JL. Repeat prescriptions: refill adherence in relation to patient and prescriber characteristics, reimbursement level and type of medication. European journal of public health. 2005 Dec;15(6):621-6. PubMed PMID: 16126746.

238. Ho PM, Bryson CL, Rumsfeld JS. Medication adherence: its importance in cardiovascular outcomes. Circulation. 2009 Jun 16;119(23):3028-35. PubMed PMID: 19528344.

239. Steiner JF, Koepsell TD, Fihn SD, Inui TS. A general method of compliance assessment using centralized pharmacy records. Description and validation. Medical care. 1988 Aug;26(8):814-23. PubMed PMID: 3398608.

240. Steiner JF, Prochazka AV. The assessment of refill compliance using pharmacy records: methods, validity, and applications. Journal of clinical epidemiology. 1997 Jan;50(1):105-16. PubMed PMID: 9048695. 
241. Franklin JM, Shrank WH, Pakes J, Sanfelix-Gimeno G, Matlin OS, Brennan TA, et al. Group-based trajectory models: a new approach to classifying and predicting long-term medication adherence. Medical care. 2013 Sep;51(9):789-96. PubMed PMID: 23685406. 242. Wessling A, Boethius G. Measurement of drug use in a defined population. Evaluation of the defined daily dose (DDD) methodology. European journal of clinical pharmacology. 1990;39(3):207-10. PubMed PMID: 2257853.

243. Cosentino M, Leoni O, Banfi F, Lecchini S, Frigo G. An approach for the estimation of drug prescribing using the defined daily dose methodology and drug dispensation data. Theoretical considerations and practical applications. European journal of clinical pharmacology. 2000 Sep;56(6-7):513-7. PubMed PMID: 11049016.

244. Merlo J, Wessling A, Melander A. Comparison of dose standard units for drug utilisation studies. European journal of clinical pharmacology. 1996;50(1-2):27-30. PubMed PMID: 8739807.

245. The International Association of Forensic Toxicologists (TIAFT). Reference Blood Level List of Therapeutic and Toxic Concentrations. Bulletin of TIAFT. 2010. 26,S1-34.

246. Sunderland M, Slade T, Krueger RF. Examining the shared and unique relationships among substance use and mental disorders. Psychological medicine. 2015 Apr;45(5):1103-13. PubMed PMID: 25229417.

247. Cordova D, Heinze J, Mistry R, Hsieh HF, Stoddard S, Salas-Wright CP, et al. Family functioning and parent support trajectories and substance use and misuse among minority urban adolescents: a latent class growth analysis. Substance use \& misuse. 2014 Dec;49(14):1908-19. PubMed PMID: 25033377. Pubmed Central PMCID: 4216241.

248. Lankenau SE, Teti M, Silva K, Jackson Bloom J, Harocopos A, Treese M. Initiation into prescription opioid misuse amongst young injection drug users. The International journal on drug policy. 2012 Jan;23(1):37-44. PubMed PMID: 21689917. Pubmed Central PMCID: 3196821.

249. Marti CN, Stice E, Springer DW. Substance use and abuse trajectories across adolescence: a latent trajectory analysis of a community-recruited sample of girls. Journal of adolescence. 2010 Jun;33(3):449-61. PubMed PMID: 19640578. Pubmed Central PMCID: 3990407. 250. Nagin D, Tremblay RE. Trajectories of boys' physical aggression, opposition, and hyperactivity on the path to physically violent and nonviolent juvenile delinquency. Child development. 1999 Sep-Oct;70(5):1181-96. PubMed PMID: 10546339. 
251. Nagin DS, Tremblay RE. Analyzing developmental trajectories of distinct but related behaviors: a group-based method. Psychological methods. 2001 Mar;6(1):18-34. PubMed PMID: 11285809.

252. Nagin DS, Odgers CL. Group-based trajectory modeling in clinical research. Annual review of clinical psychology. 2010;6:109-38. PubMed PMID: 20192788.

253. Sun P, Zhao Y, Zhao Z, Bernauer M, Watson P. Dosing pattern comparison between duloxetine and pregabalin among patients with diabetic peripheral neuropathic pain. Pain practice : the official journal of World Institute of Pain. 2012 Nov;12(8):641-8. PubMed PMID: 22335435 .

254. Hakkinen M, Vuori E, Kalso E, Gergov M, Ojanpera I. Profiles of pregabalin and gabapentin abuse by postmortem toxicology. Forensic science international. 2014 Aug;241:1-6. PubMed PMID: 24835028.

255. Muthe'n B. Latent variable analysis: growth mixture modeling and related techniques for longitudinal data. In: Kaplan D, ed. The Sage Handbook of Quantitative Methodology for the Social Sciences. Thousand Oaks, CA: Sage Publications; 2004:345-368.

256. Hartigan JA, Wong MA. A k-means clustering algorithm. Appl Stat. 1979;28:100-108. 257. McCutcheon AL. Latent Class Analysis. Newbury Park, CA: Sage Publications; 1987. 258. Curtin F, Schulz P. Assessing the benefit: risk ratio of a drug--randomized and naturalistic evidence. Dialogues in clinical neuroscience. 2011;13(2):183-90. PubMed PMID: 21842615. Pubmed Central PMCID: 3181998.

259. World Medical Association. Declaration of Helsinki Ethical Principles for Medical Research Involving Human Subjects. World Medical Association; Helsinki, 2008.

260. International Society for Pharmacoepidemiology. Guidelines for Good Pharmacoepidemiology Practices. Third revision. June 2015. Accessed 12 June 2016. https://www.pharmacoepi.org/resources/guidelines_08027.cfm.

261. Swedish government. Swedish law on handling of personal data, implemented from the European Union Directorate for data protection 95/46/EG. SFS 1998:204 with revisions until SFS 2010:1969. [In Swedish: Personuppgiftslag (1998:204) t.o.m. SFS 2010:1969] . Stockholm, Sweden, 2010.

262. Swedish government. Swedish Ethical Review Act.SFS 2003:460 with revisions until 2015:320. [In Swedish: Lag (2003:460) om etikprövning av forskning som avser människor. Svensk författningssamling (SFS) 2003:460 t.o.m. 2015:320]. Stockholm, Sweden, 2015. 263. European Monitoring Centre for Drugs and Drug Addiction (EMCDDA). Annual Report of the EMCDDA for 2010. EMCDDA, Lisbon, Portugal 2010. 
264. Warner-Smith M, Darke S, Day C. Morbidity associated with non-fatal heroin overdose. Addiction. 2002 Aug;97(8):963-7. PubMed PMID: 12144598.

265. Costa I, Oliveira A, Guedes de Pinho P, Teixeira HM, Moreira R, Carvalho F, et al. Postmortem redistribution of tramadol and O-desmethyltramadol. Journal of analytical toxicology. 2013 Nov-Dec;37(9):670-5. PubMed PMID: 24084873.

266. Radbruch L, Glaeske G, Grond S, Munchberg F, Scherbaum N, Storz E, et al. Topical review on the abuse and misuse potential of tramadol and tilidine in Germany. Substance abuse. 2013;34(3):313-20. PubMed PMID: 23844964.

267. Cicero TJ, Adams EH, Geller A, Inciardi JA, Munoz A, Schnoll SH, et al. A postmarketing surveillance program to monitor Ultram (tramadol hydrochloride) abuse in the United States. Drug and alcohol dependence. 1999 Nov 1;57(1):7-22. PubMed PMID: 10617309.

268. Cicero TJ, Inciardi JA, Adams EH, Geller A, Senay EC, Woody GE, et al. Rates of abuse of tramadol remain unchanged with the introduction of new branded and generic products: results of an abuse monitoring system, 1994-2004. Pharmacoepidemiology and drug safety. 2005 Dec;14(12):851-9. PubMed PMID: 15892169.

269. Tavassoli N, Lapeyre-Mestre M, Sommet A, Montastruc JL, French Association of Regional Pharmacovigilance C. Reporting rate of adverse drug reactions to the French pharmacovigilance system with three step 2 analgesic drugs: dextropropoxyphene, tramadol and codeine (in combination with paracetamol). British journal of clinical pharmacology. 2009 Sep;68(3):422-6. PubMed PMID: 19740400. Pubmed Central PMCID: 2766482.

270. Lopez-Gonzalez E, Herdeiro MT, Figueiras A. Determinants of under-reporting of adverse drug reactions: a systematic review. Drug safety. 2009;32(1):19-31. PubMed PMID: 19132802. 271. Backstrom M, Mjorndal T, Dahlqvist R. Under-reporting of serious adverse drug reactions in Sweden. Pharmacoepidemiology and drug safety. 2004 Jul;13(7):483-7. PubMed PMID: 15269932.

272. Waller PC. Making the most of spontaneous adverse drug reaction reporting. Basic \& clinical pharmacology \& toxicology. 2006 Mar;98(3):320-3. PubMed PMID: 16611209. 273. Paulozzi LJ, Budnitz DS, Xi Y. Increasing deaths from opioid analgesics in the United States. Pharmacoepidemiology and drug safety. 2006 Sep;15(9):618-27. PubMed PMID: 16862602.

274. Neutel CI, Skurtveit S, Berg C. What is the point of guidelines? Benzodiazepine and zhypnotic use by an elderly population. Sleep medicine. 2012 Aug;13(7):893-7. PubMed PMID: 22704401. 
275. Bertisch SM, Herzig SJ, Winkelman JW, Buettner C. National use of prescription medications for insomnia: NHANES 1999-2010. Sleep. 2014 Feb;37(2):343-9. PubMed PMID: 24497662. Pubmed Central PMCID: 3900622.

276. Moloney ME, Konrad TR, Zimmer CR. The medicalization of sleeplessness: a public health concern. American journal of public health. 2011 Aug;101(8):1429-33. PubMed PMID:

21680913. Pubmed Central PMCID: 3134490.

277. Karjalainen K, Haukka J, Lillsunde P, Lintonen T, Makela P. The arrest of drivers under the influence as a predictor of subsequent social disadvantage and death. Drug and alcohol dependence. 2014 Apr 1;137:114-20. PubMed PMID: 24566278.

278. Evans SJ, Waller PC, Davis S. Use of proportional reporting ratios (PRRs) for signal generation from spontaneous adverse drug reaction reports. Pharmacoepidemiology and drug safety. 2001 Oct-Nov;10(6):483-6. PubMed PMID: 11828828.

279. West NA, Severtson SG, Green JL, Dart RC. Trends in abuse and misuse of prescription opioids among older adults. Drug and alcohol dependence. 2015 Apr 1;149:117-21. PubMed PMID: 25678441.

280. Han H, Kass PH, Wilsey BL, Li CS. Increasing trends in Schedule II opioid use and doctor shopping during 1999-2007 in California. Pharmacoepidemiology and drug safety. 2014 Jan;23(1):26-35. PubMed PMID: 23956137. Pubmed Central PMCID: 3947314.

281. Uthman BM, Bazil CW, Beydoun A, Schulze-Bonhage A, Benabou R, Whalen E, et al. Long-term add-on pregabalin treatment in patients with partial-onset epilepsy: pooled analysis of open-label clinical trials. Epilepsia. 2010 Jun;51(6):968-78. PubMed PMID: 20345940.

282. Karjalainen K, Blencowe T, Lillsunde P. Substance use and social, health and safety-related factors among fatally injured drivers. Accident; analysis and prevention. 2012 Mar;45:731-6. PubMed PMID: 22269564.

283. Pottegard A, Christensen R, Houji A, Christiansen CB, Paulsen MS, Thomsen JL, et al. Primary non-adherence in general practice: a Danish register study. European journal of clinical pharmacology. 2014 Jun;70(6):757-63. PubMed PMID: 24756147.

284. Morgan O, Griffiths C, Hickman M. Association between availability of heroin and methadone and fatal poisoning in England and Wales 1993-2004. International journal of epidemiology. 2006 Dec;35(6):1579-85. PubMed PMID: 17077102.

285. The Swedish Council for Information on Alcohol and Other Drugs (CAN). Official webpage. Retrieved on 17 June 2016. www.can.se/In-English. 
286. Prior K, Mills K, Ross J, Teesson M. Substance use disorders comorbid with mood and anxiety disorders in the Australian general population. Drug and alcohol review. 2016 Jun 21. PubMed PMID: 27324816.

287. Gjerde H, Christophersen AS, Normann PT, Assum T, Oiestad EL, Morland J. Norwegian roadside survey of alcohol and drug use by drivers (2008-2009). Traffic injury prevention. 2013;14(5):443-52. PubMed PMID: 23697895.

288. Lacey JH, Kelley-Baker T, Voas RB, Romano E, Furr-Holden CD, Torres P, et al. Alcoholand drug-involved driving in the United States: methodology for the 2007 National Roadside Survey. Evaluation review. 2011 Aug;35(4):319-53. PubMed PMID: 21997324. Pubmed Central PMCID: 3635851.

289. Young AM, Glover N, Havens JR. Nonmedical use of prescription medications among adolescents in the United States: a systematic review. The Journal of adolescent health : official publication of the Society for Adolescent Medicine. 2012 Jul;51(1):6-17. PubMed PMID: 22727071.

290. Kokkevi A, Fotiou A, Arapaki A, Richardson C. Prevalence, patterns, and correlates of tranquilizer and sedative use among European adolescents. The Journal of adolescent health : official publication of the Society for Adolescent Medicine. 2008 Dec;43(6):584-92. PubMed PMID: 19027647.

291. McCabe SE, Kloska DD, Veliz P, Jager J, JE. S. Developmental course of nonmedical use of prescription drugs from adolescence to adulthood in the united states: national longitudinal data. Addiction. Epub 2016 Jun 24.

292. Zedler B, Xie L, Wang L, Joyce A, Vick C, Kariburyo F, et al. Risk factors for serious prescription opioid-related toxicity or overdose among Veterans Health Administration patients. Pain medicine. 2014 Nov;15(11):1911-29. PubMed PMID: 24931395.

293. Paulozzi LJ, Kilbourne EM, Shah NG, Nolte KB, Desai HA, Landen MG, et al. A history of being prescribed controlled substances and risk of drug overdose death. Pain medicine. 2012 Jan;13(1):87-95. PubMed PMID: 22026451.

294. Zamparutti G, Schifano F, Corkery JM, Oyefeso A, Ghodse AH. Deaths of opiate/opioid misusers involving dihydrocodeine, UK, 1997-2007. British journal of clinical pharmacology. 2011 Aug;72(2):330-7. PubMed PMID: 21235617. Pubmed Central PMCID: 3162662. 295. Pradel V, Thirion X, Ronfle E, Masut A, Micallef J, Begaud B. Assessment of doctorshopping for high dosage buprenorphine maintenance treatment in a French region: development of a new method for prescription database. Pharmacoepidemiology and drug safety. 2004 Jul;13(7):473-81. PubMed PMID: 15269931. 
296. McDonald DC, Carlson KE. The ecology of prescription opioid abuse in the USA: geographic variation in patients' use of multiple prescribers ("doctor shopping").

Pharmacoepidemiology and drug safety. 2014 Dec;23(12):1258-67. PubMed PMID: 25111716. Pubmed Central PMCID: 4777341.

297. Olsson S. The role of the WHO programme on International Drug Monitoring in coordinating worldwide drug safety efforts. Drug safety. 1998 Jul;19(1):1-10. PubMed PMID: 9673854 .

298. Swedish Institute for Drug Informatics (Läkemedelsinformationscentraler i Sverige (LIC)). Official webpage. Retrieved on 20 June 2016. http://www.lic.nu/.

299. Davis JM, Severtson SG, Bucher-Bartelson B, Dart RC. Using poison center exposure calls to predict prescription opioid abuse and misuse-related emergency department visits. Pharmacoepidemiology and drug safety. 2014 Jan;23(1):18-25. PubMed PMID: 24130046. 300. Christophersen AS, Gjerde H. Prevalence of alcohol and drugs among car and van drivers killed in road accidents in Norway: an overview from 2001 to 2010. Traffic injury prevention. 2014;15(6):523-31. PubMed PMID: 24867563.

301. Butler SF, Budman SH, Licari A, Cassidy TA, Lioy K, Dickinson J, et al. National addictions vigilance intervention and prevention program (NAVIPPRO): a real-time, productspecific, public health surveillance system for monitoring prescription drug abuse.

Pharmacoepidemiology and drug safety. 2008 Dec;17(12):1142-54. PubMed PMID: 18932173. 302. Zosel A, Bartelson BB, Bailey E, Lowenstein S, Dart R. Characterization of adolescent prescription drug abuse and misuse using the Researched Abuse Diversion and Addiction-related Surveillance (RADARS((R))) System. Journal of the American Academy of Child and Adolescent Psychiatry. 2013 Feb;52(2):196-204 e2. PubMed PMID: 23357446. Pubmed Central PMCID: 3891924.

303. Victorri-Vigneau C, Dailly E, Veyrac G, Jolliet P. Evidence of zolpidem abuse and dependence: results of the French Centre for Evaluation and Information on Pharmacodependence (CEIP) network survey. British journal of clinical pharmacology. 2007 Aug;64(2):198-209. PubMed PMID: 17324242. Pubmed Central PMCID: 2000636. 


\section{APPENDIX}

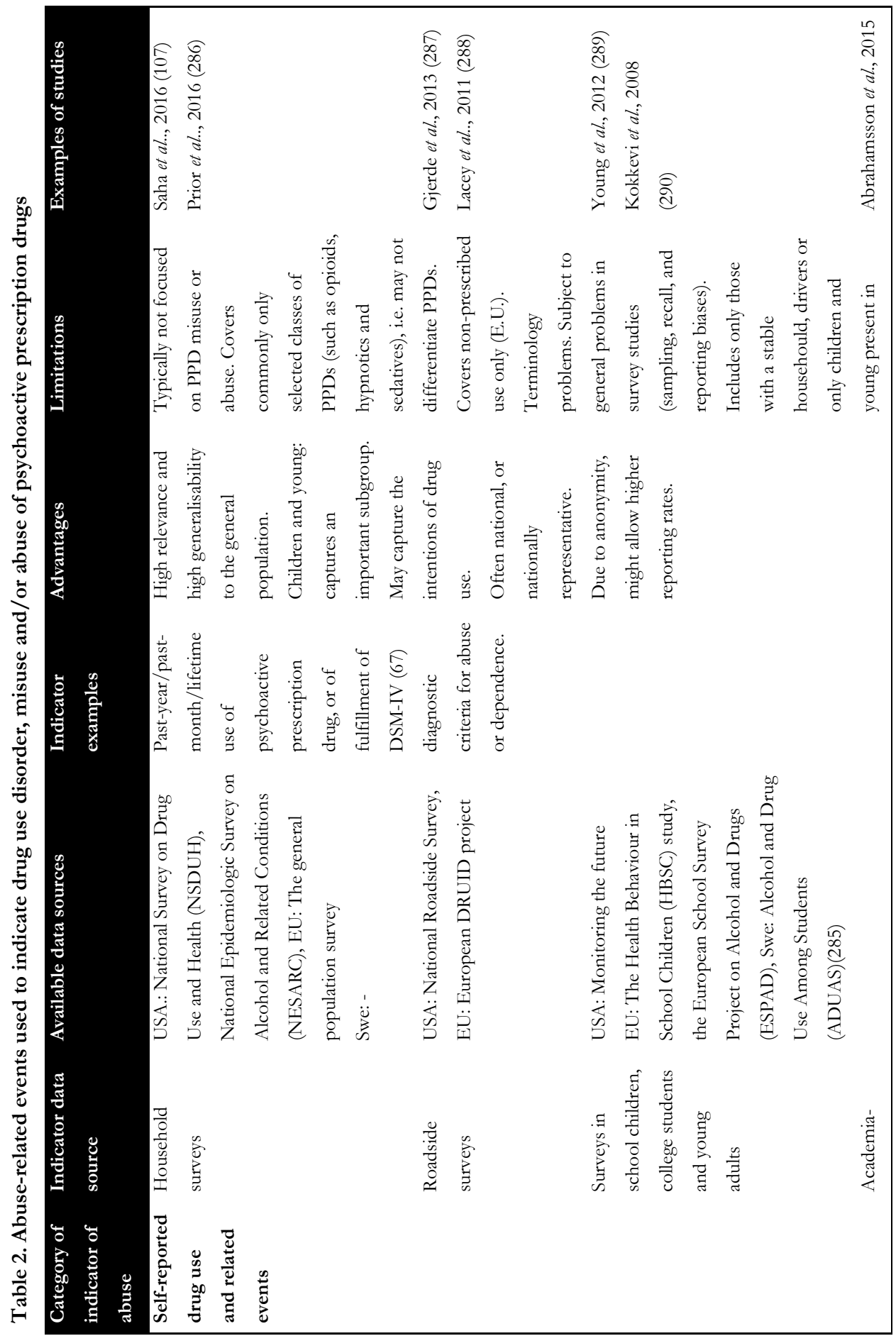




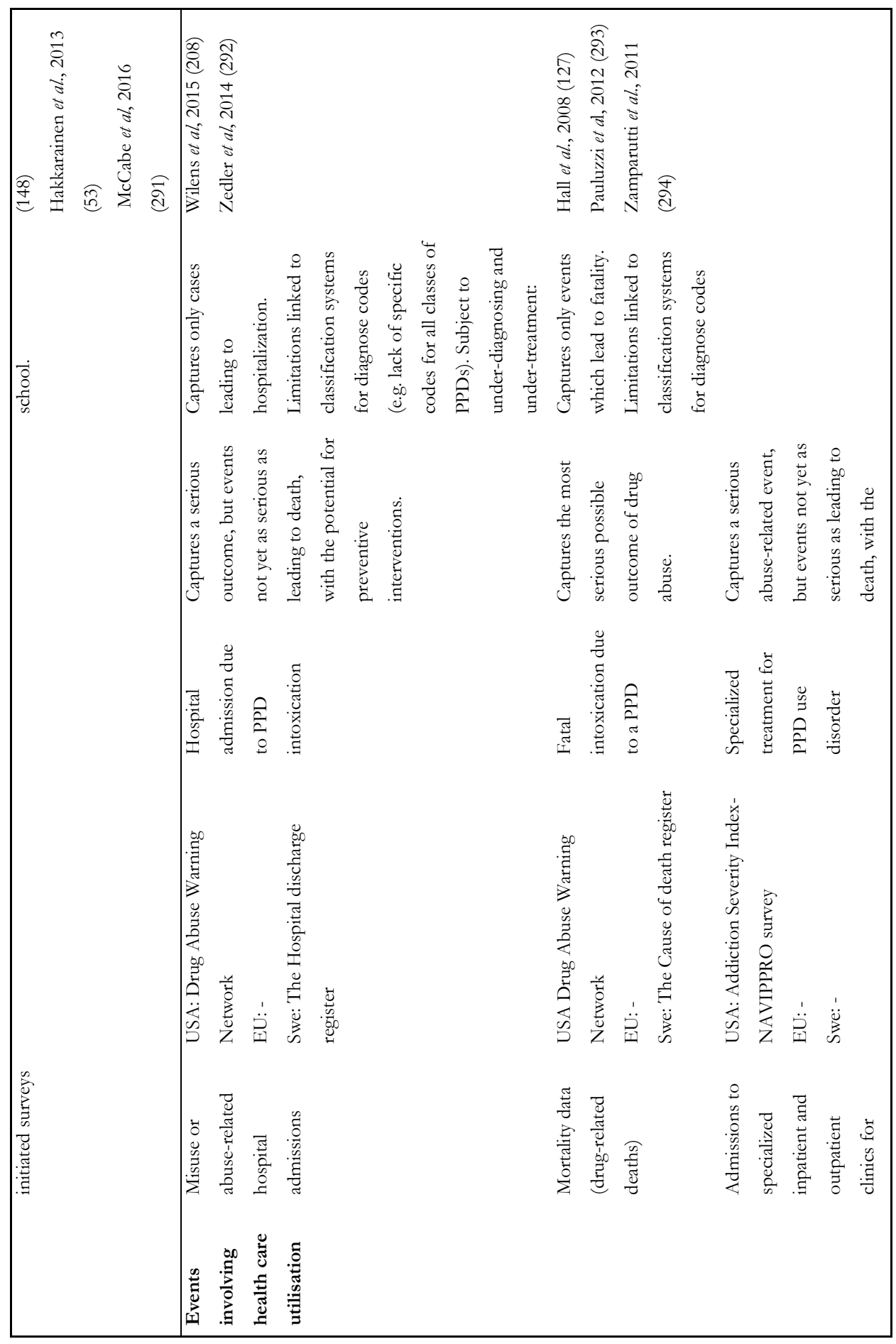




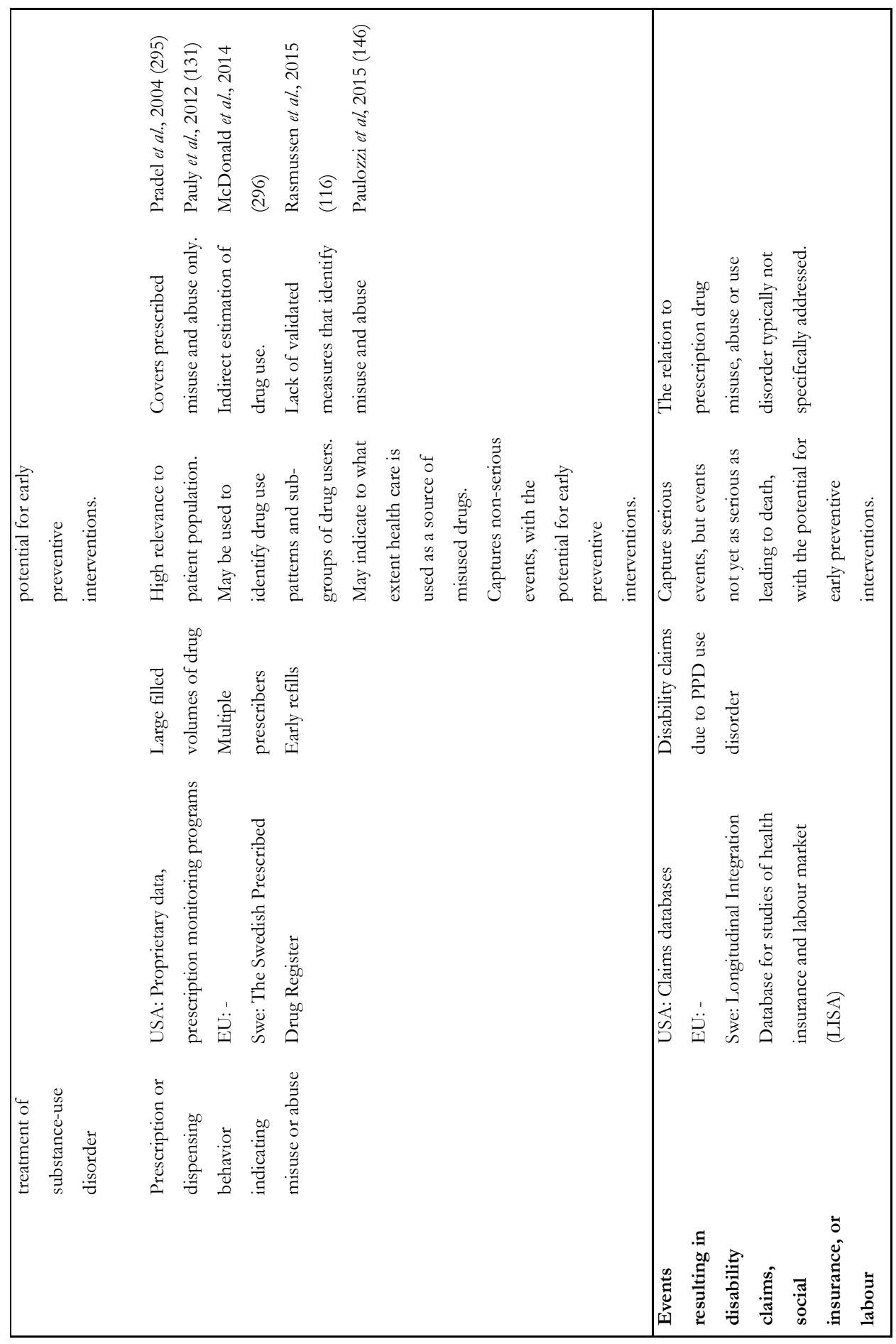




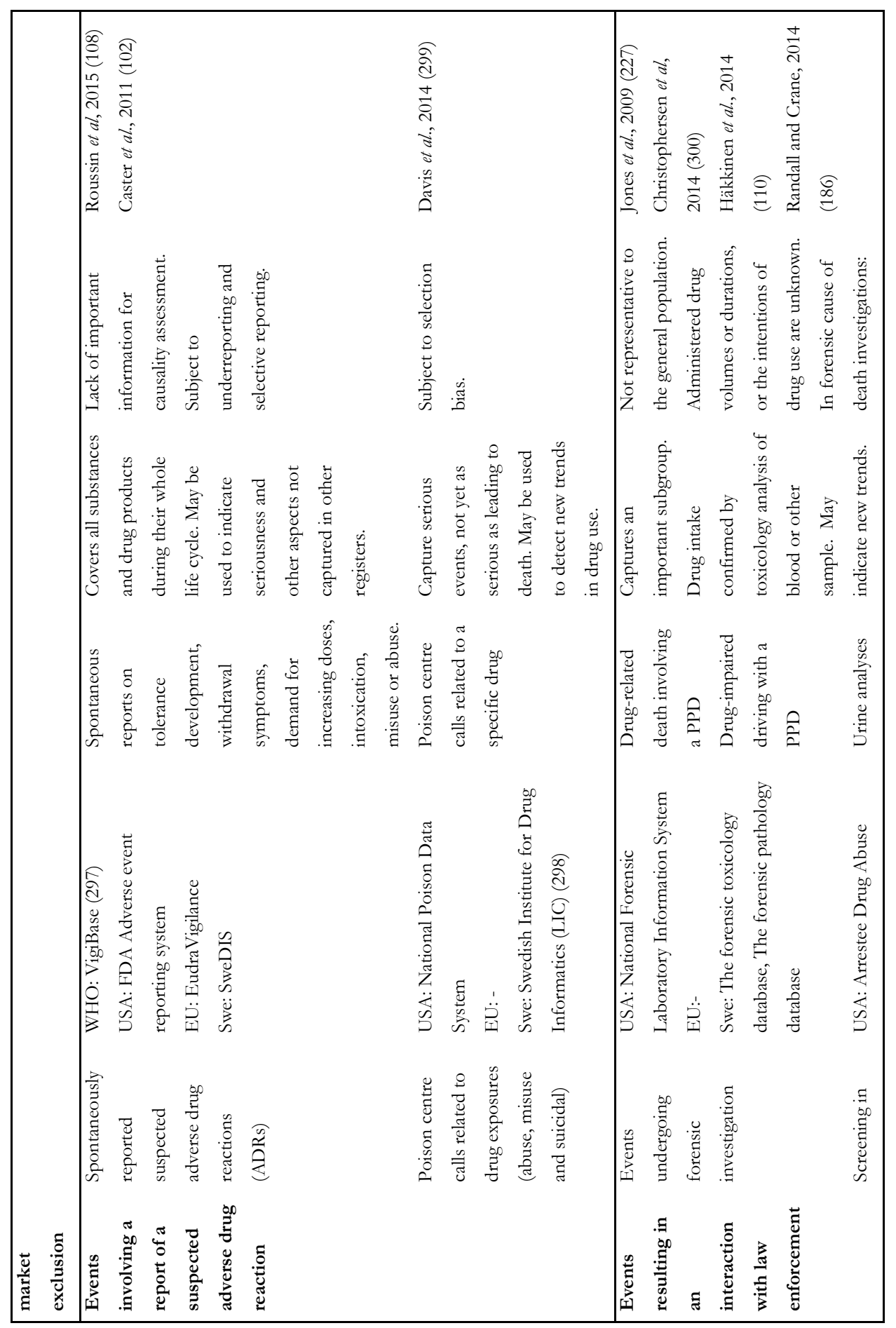




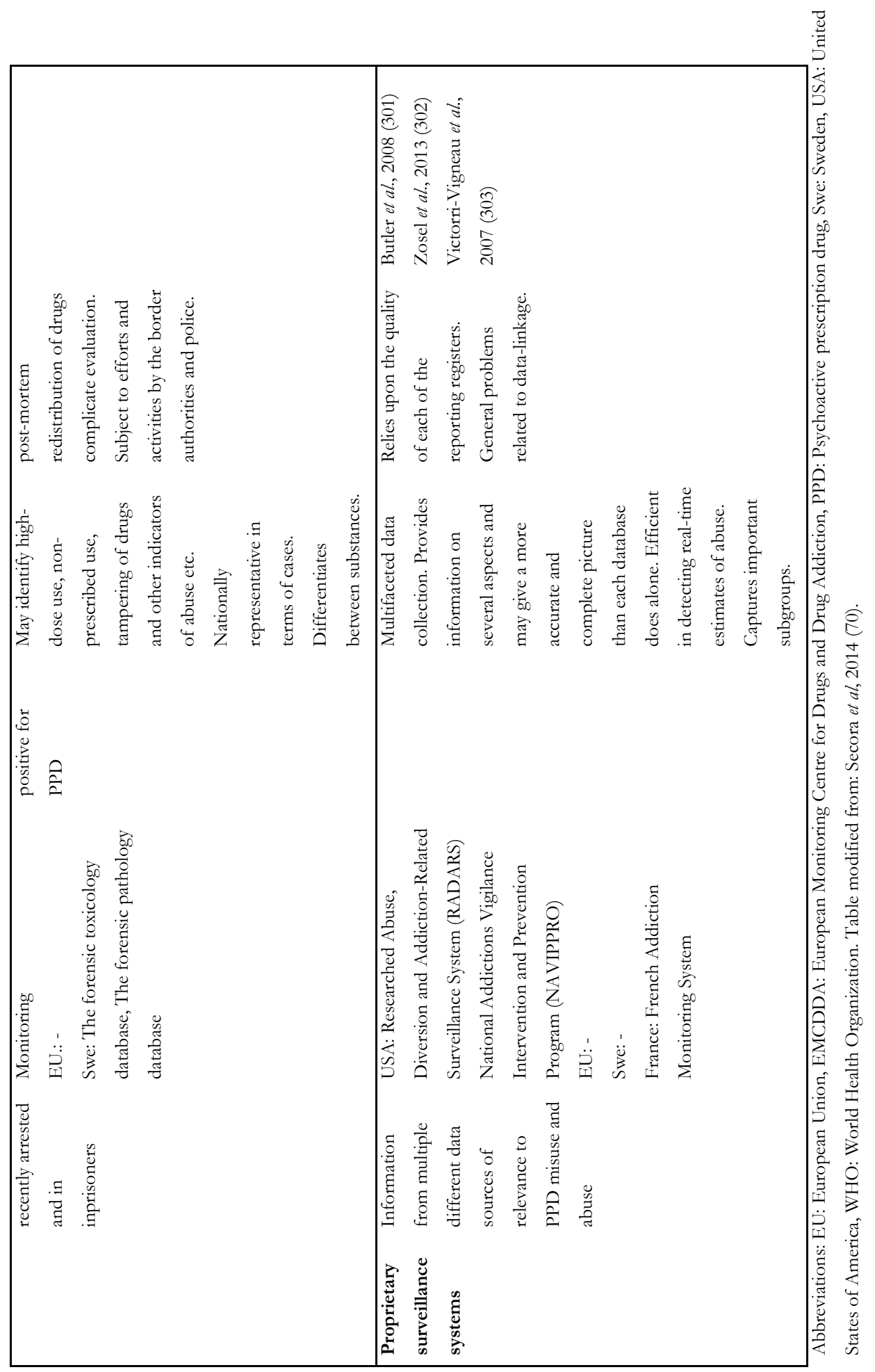





\section{Papers}

The articles associated with this thesis have been removed for copyright reasons. For more details about these see:

http://urn.kb.se/resolve?urn=urn:nbn:se:liu:diva-130768 